FHWA/IN/JTRP-2008/16

Final Report

EFFECTS OF BYPASSES

Jon D. Fricker

Joshua B. Mills

August 2009 
Final Report

FHWA/IN/JTRP-2008/16

\title{
Effects of Bypasses
}

\author{
by \\ Jon D. Fricker \\ Professor \\ and \\ Joshua B. Mills \\ Graduate Research Assistant \\ School of Civil Engineering \\ Purdue University
}

\author{
Joint Transportation Research Program \\ Project No. C-36-64Q \\ File No. 3-5-17 \\ SPR-3094 \\ Prepared in Cooperation with the \\ Indiana Department of Transportation and the \\ U.S. Department of Transportation \\ Federal Highway Administration
}

The contents of this report reflect the views of the author who is responsible for the facts and the accuracy of the data presented herein. The contents do not necessarily reflect the official views or policies of the Indiana Department of Transportation or the Federal Highway Administration at the time of publication. This report does not constitute a standard, specification, or regulation.

\author{
Purdue University \\ West Lafayette, Indiana 47907
}

August 2009 
TECHNICAL REPORT STANDARD TITLE PAGE

\begin{tabular}{|c|c|c|}
\hline $\begin{array}{l}\text { 1. Report No. } \\
\text { FHWA/IN/JTRP-2008/16 }\end{array}$ & 2. Government Accession No. & 3. Recipient's Catalog No. \\
\hline \multirow{2}{*}{\multicolumn{2}{|c|}{$\begin{array}{l}\text { 4. Title and Subtitle } \\
\text { Effects of Bypasses }\end{array}$}} & $\begin{array}{l}\text { 5. Report Date } \\
\text { August } 2009\end{array}$ \\
\hline & & 6. Performing Organization Code \\
\hline $\begin{array}{l}\text { 7. Author(s) } \\
\text { Jon D. Fricker and Joshua B. Mills }\end{array}$ & & $\begin{array}{l}\text { 8. Performing Organization Report No. } \\
\text { FHWA/IN/JTRP-2008/16 }\end{array}$ \\
\hline \multirow{2}{*}{\multicolumn{2}{|c|}{$\begin{array}{l}\text { 9. Performing Organization Name and Address } \\
\text { Joint Transportation Research Program } \\
1284 \text { Civil Engineering Building } \\
\text { Purdue University } \\
\text { West Lafayette, IN 47907-1284 }\end{array}$}} & 10. Work Unit No. \\
\hline & & $\begin{array}{l}\text { 11. Contract or Grant No. } \\
\text { SPR-3094 }\end{array}$ \\
\hline \multirow{2}{*}{\multicolumn{2}{|c|}{$\begin{array}{l}\text { 12. Sponsoring Agency Name and Address } \\
\text { Indiana Department of Transportation } \\
\text { State Office Building } \\
100 \text { North Senate Avenue } \\
\text { Indianapolis, IN } 46204\end{array}$}} & $\begin{array}{l}\text { 13. Type of Report and Period Covered } \\
\text { Final Report }\end{array}$ \\
\hline & & 14. Sponsoring Agency Code \\
\hline
\end{tabular}

\section{Supplementary Notes}

Prepared in cooperation with the Indiana Department of Transportation and Federal Highway Administration.

\section{Abstract}

This study aims to investigate the long-term impacts of bypasses on small- and medium-sized communities in Indiana. Interviews were conducted with community officials and individuals familiar with the history of each bypassed community. Statistical models were developed to analyze economic impacts across a number of key indicators including payroll and employment in various industry sectors. Lessons learned from this study vary from county to county and across industry sectors. The findings of this study will be used to develop a concise guide that will provide guidance to both Indiana Department of Transportation (INDOT) officials and community officials as to how to best adapt to the presence of the bypass.

\section{Key Words}

bypass, economic development, economic impact, case studies, statistical analysis
18. Distribution Statement

No restrictions. This document is available to the public through the National Technical Information Service, Springfield, VA 22161

\section{Security Classif. (of this report) \\ Unclassified}

\author{
20. Security Classif. (of this page)
}

Unclassified

\begin{tabular}{c|c} 
21. No. of Pages & 22. Price \\
192 & \\
\hline
\end{tabular}


TABLE OF CONTENTS

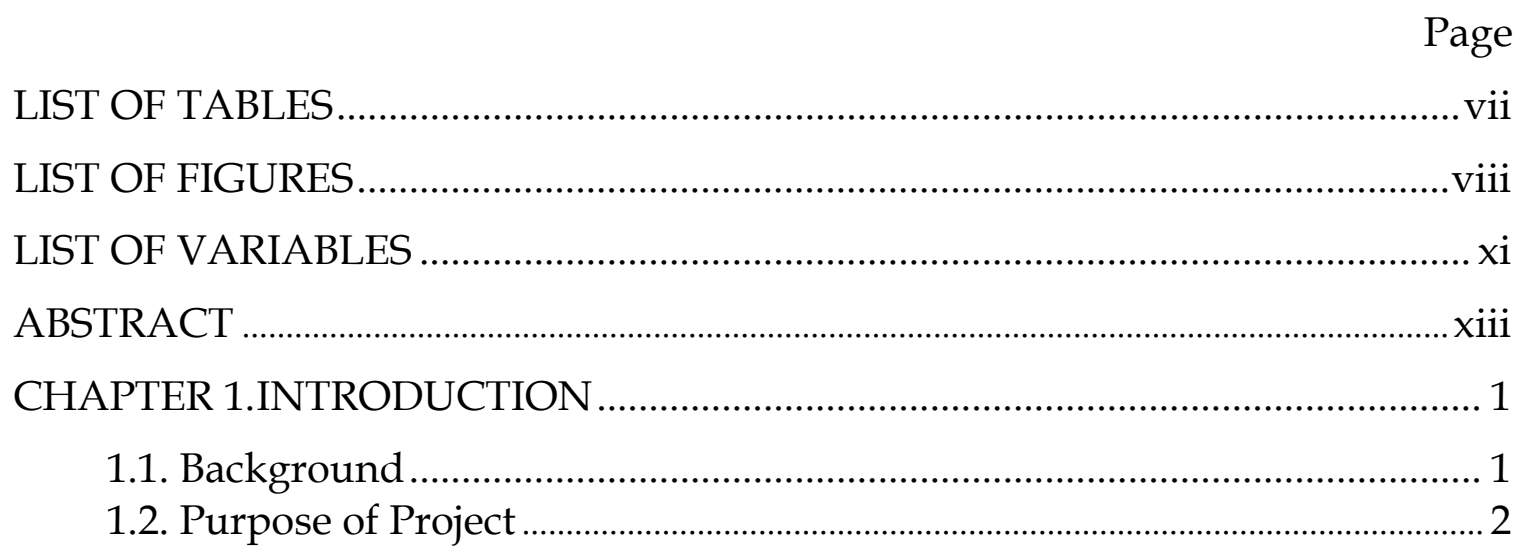

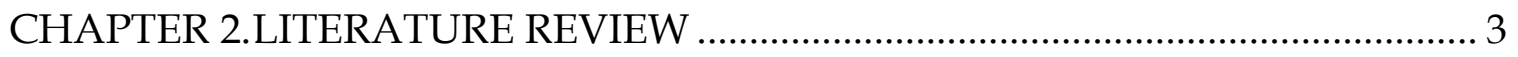

2.1. Historical Background - Older Bypasses ...................................................... 3

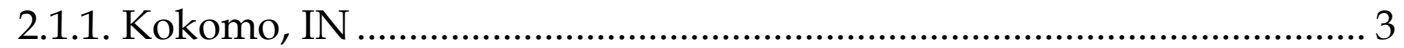

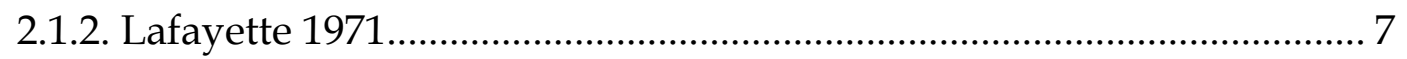

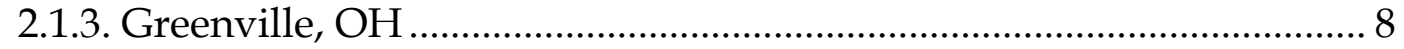

2.2. Recent Qualitative Research .................................................................. 14

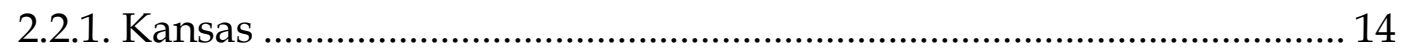

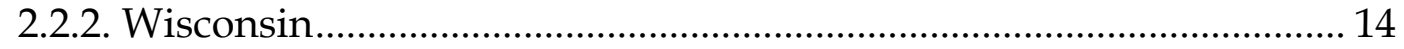

2.2.3. Texas - Planning Policies ....................................................................... 15

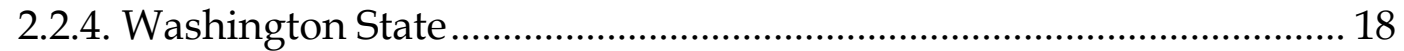

2.3. Recent Quantitative Research ................................................................. 20

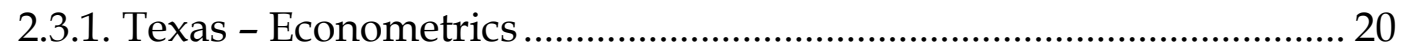

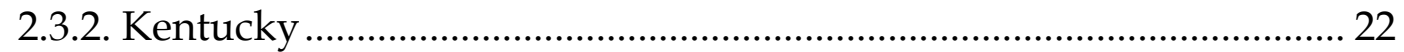

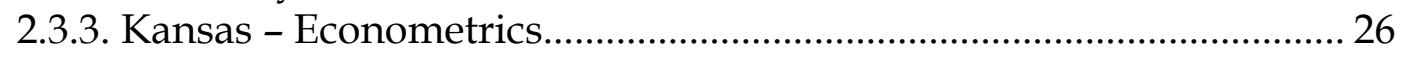

2.4. State Agency Evaluations of Proposed Bypasses ...................................... 28

2.4.1. Indiana Department of Transportation (INDOT) Policies................... 28

2.4.2. Ohio Department of Transportation (ODOT) Policies......................... 29

2.5. Identification of Issues to be Addressed ………………………………………....32

CHAPTER 3.PROFILES OF AFFECTED CITIES..................................................... 35

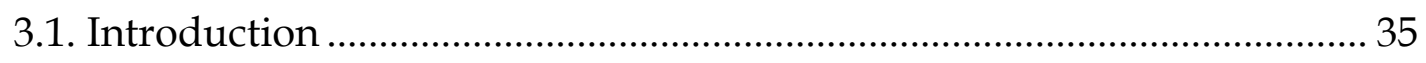

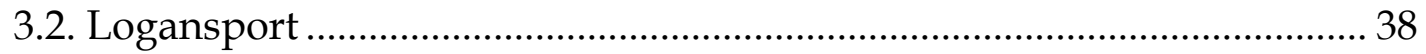

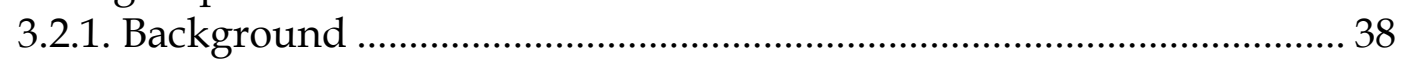




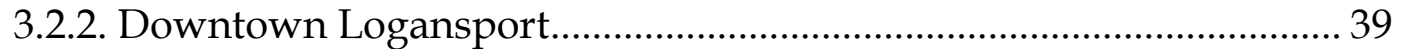


3.2.3. US-24 in Logansport: Before and After ............................................... 43

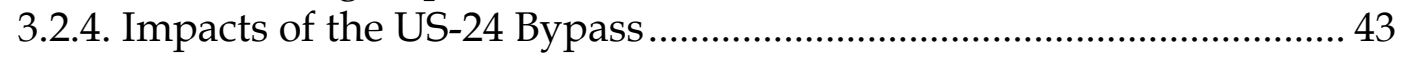

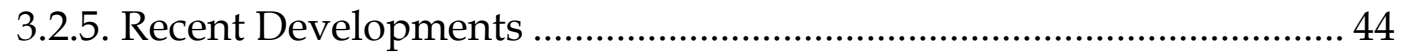

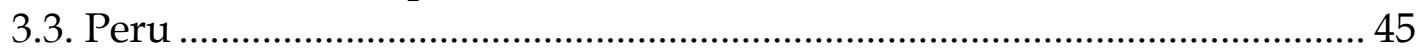

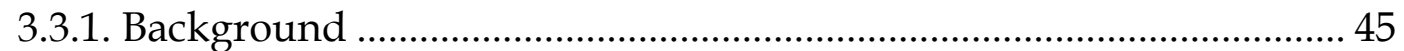

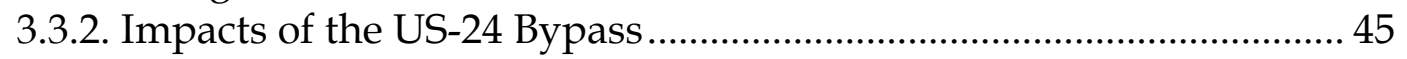

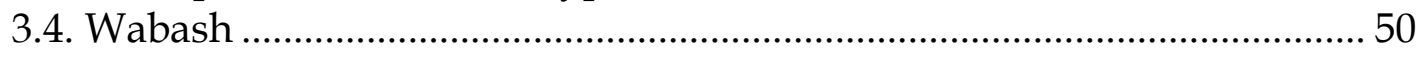

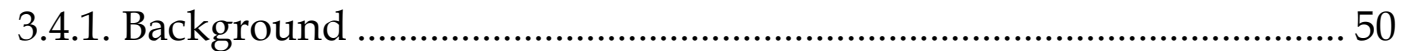

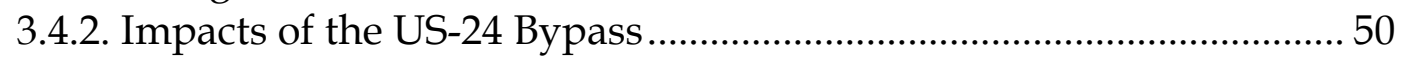

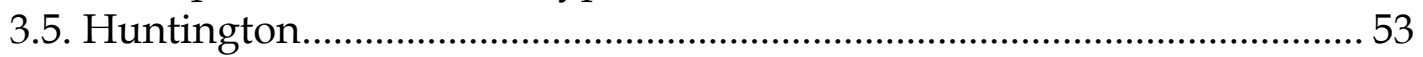

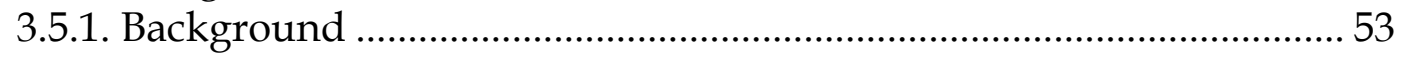

3.5.2. Bypass Construction and Zoning Changes .......................................... 53

3.5.3. Impacts on Businesses and Residents................................................... 56

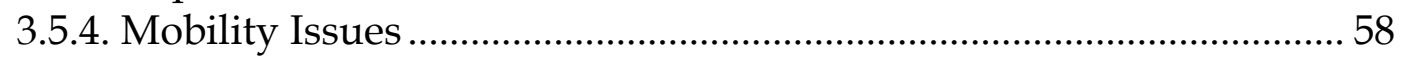

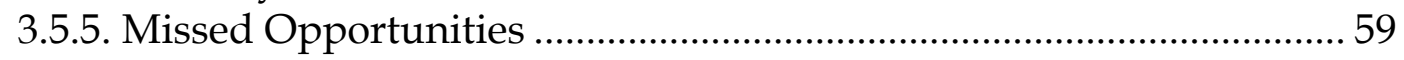

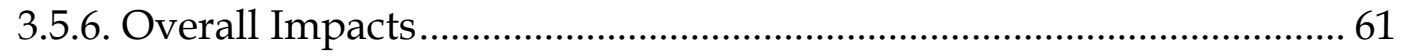

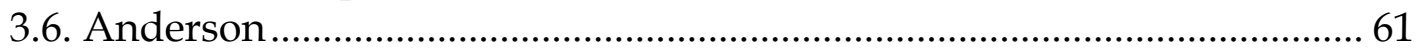

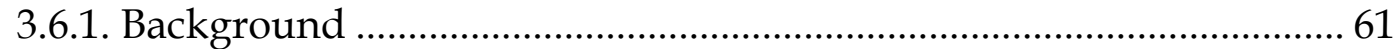

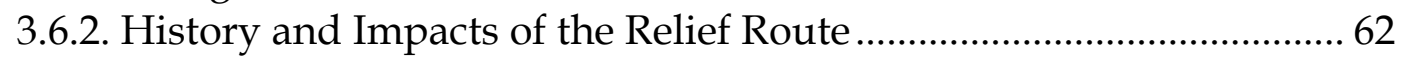

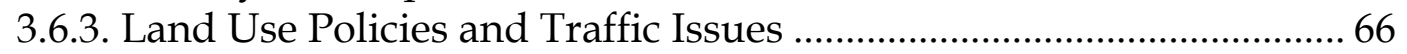

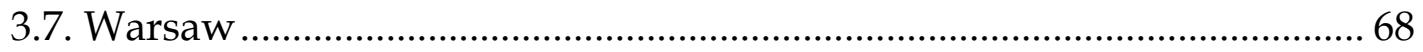

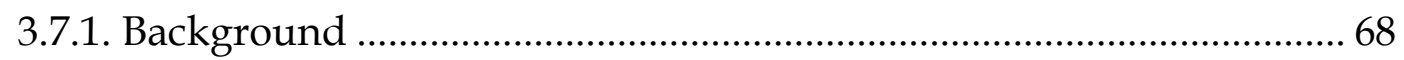

3.7.2. US-30 Bypass: Construction and Opening............................................ 68

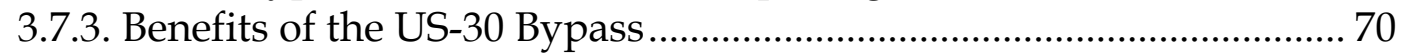

3.7.4. Current Issues with the US-30 Bypass................................................... 71

3.7.5. The "Western Corridor" - Proposed IN-15 Bypass............................... 73

3.8. Columbia City ........................................................................................... 75

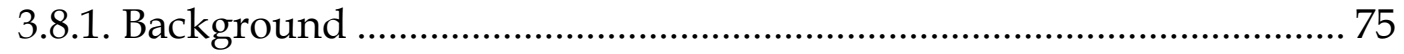

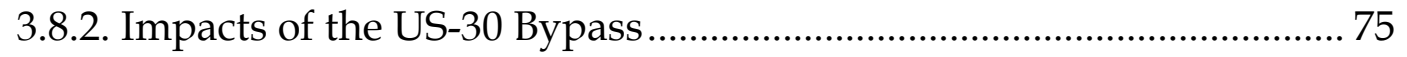

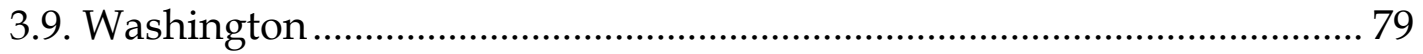

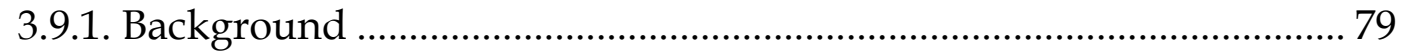

3.9.2. Construction of the Bypass and Its Impacts ......................................... 79

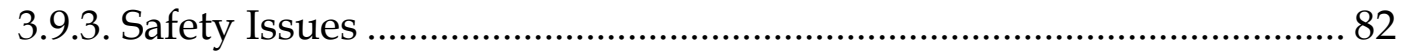

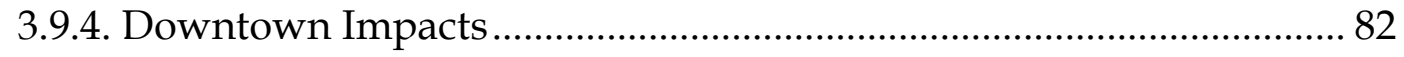

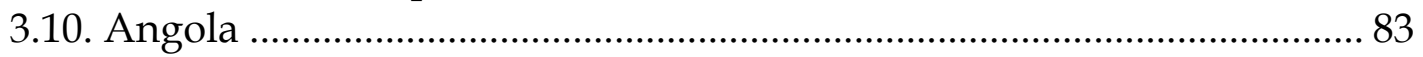

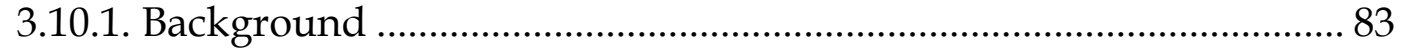

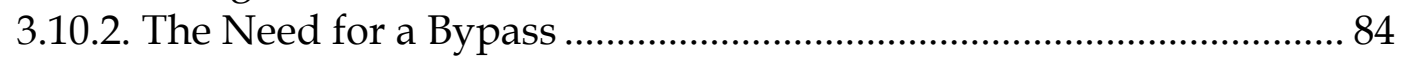

3.10.3. Recent Developments and Future Actions ........................................... 85

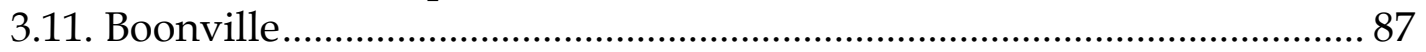

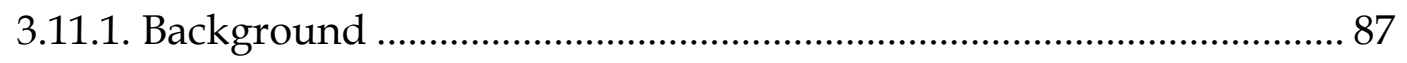


3.11.2. Impacts of Truck Traffic on Downtown Boonville ............................. 88

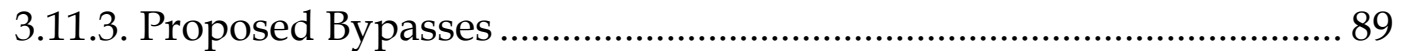


Page

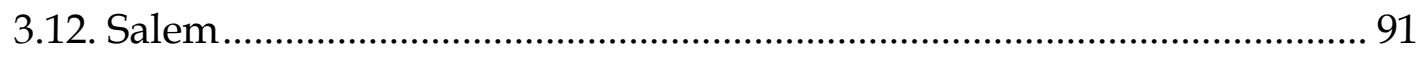

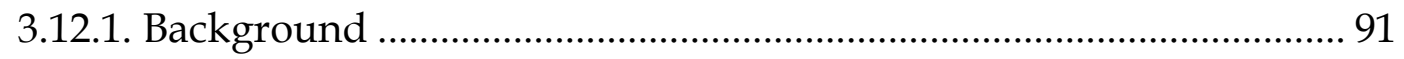

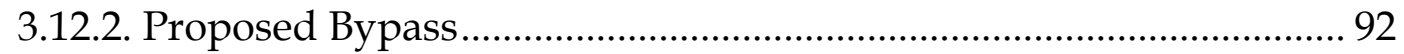

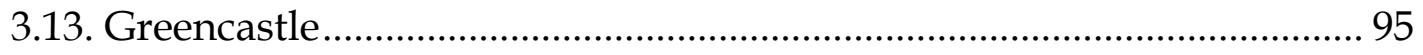

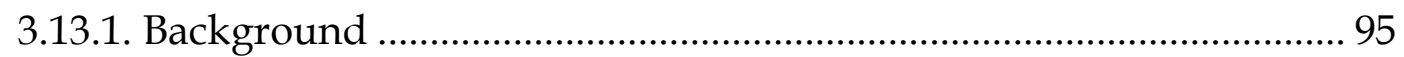

3.13.2. The Need for a Bypass ........................................................................ 96

CHAPTER 4. ECONOMETRIC ANALYSIS OF PANEL DATA............................ 100

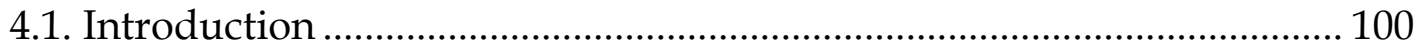

4.2. Economic Data Selected for Analysis.................................................... 100

4.3. Selection of Counties for Analysis.......................................................... 103

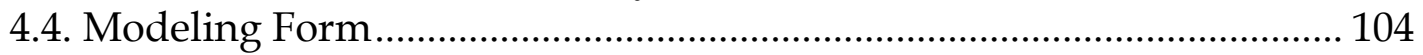

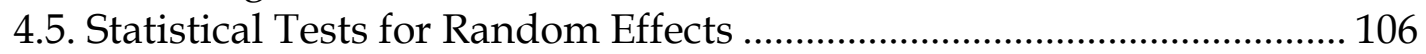

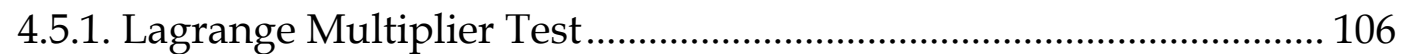

4.5.2. Hausman Test for Random Effects ........................................................ 107

4.6. Measures of Industry Economic Characteristics ..................................... 108

4.7. Industry Sectors selected for study (by SIC) .......................................... 110

4.7.1. Manufacturing (SIC 20-39) ................................................................ 110

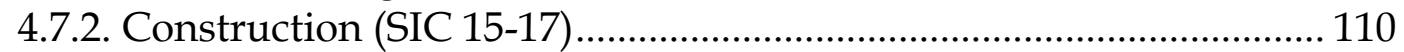

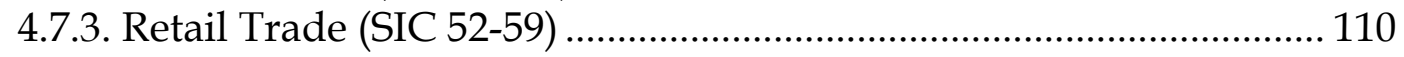

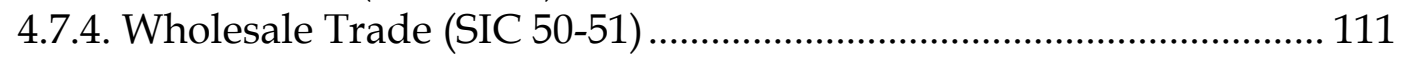

4.7.5. Transportation and Public Utilities (SIC 40-49) .................................. 111

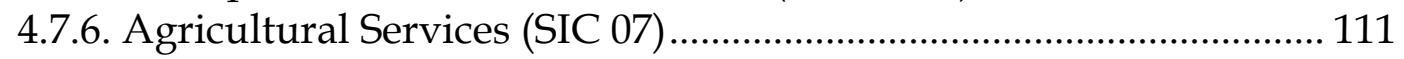

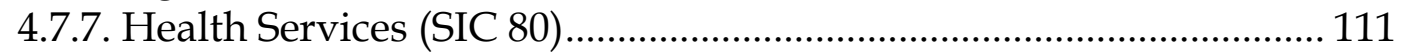

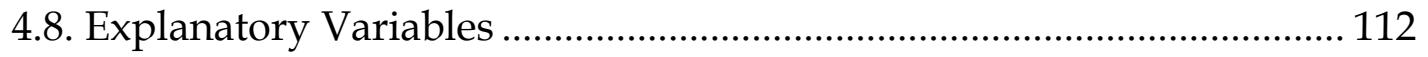

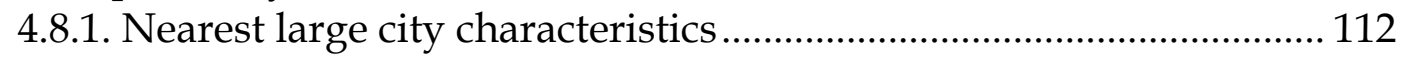

4.8.2. Bypassed county characteristics .......................................................... 113

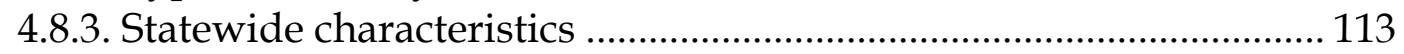

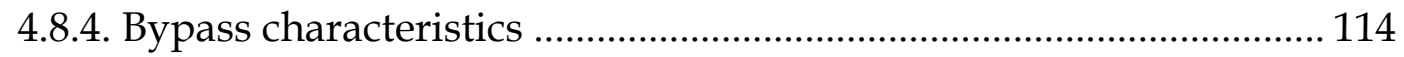

4.9. Methodology for Estimation of Impacts .................................................. 114

4.10. Sensitivity, Elasticity, and Pseudo-Elasticity Analysis.......................... 114

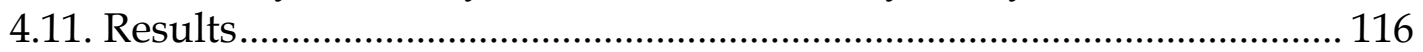

4.11.1. Total Employment: County to State Ratio (Natural Log) ................ 117

4.11.2. Proprietors' Employment, County to State Ratio (Natural Log) ............................................................................... 118

4.11.3. Manufacturing Payroll: County to State Ratio (Natural Log)........ 119

4.11.4. Manufacturing Employment: County to State Ratio......................... 120

4.11.5. Manufacturing Employment (Natural Logarithm) .......................... 121

4.11.6. Annual Earnings, Health Services, County to State Ratio............... 122

4.11.7. Retail Trade Employment: County to State Ratio............................. 123 


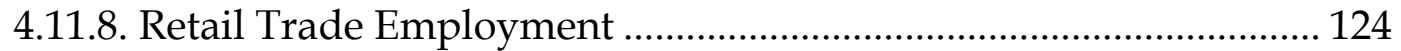

4.11.9. Retail Trade Payroll: County to State Ratio .................................. 126 
Page

4.11.10. Retail Trade Number of Establishments: County to State Ratio (Natural Logarithm). 127

4.11.11. Eating \& Drinking Places Employment: County to State Ratio ..... 128

4.11.12. Eating \& Drinking Places Payroll, County to State Ratio............. 129

4.11.13. Wholesale Trade Employment: County to State Ratio................... 130

4.11.14. Wholesale Trade Employment ............................................................. 131

4.11.15. Wholesale Trade Payroll: County to State Ratio (Natural Logarithm). 132

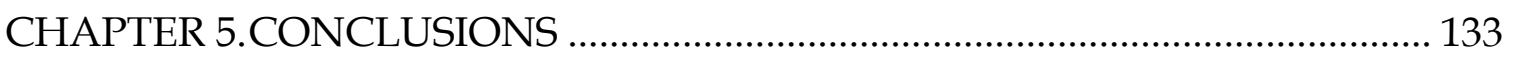

5.1. Findings of Case Studies ............................................................................. 133

5.2. Findings of Econometric Analysis........................................................... 137

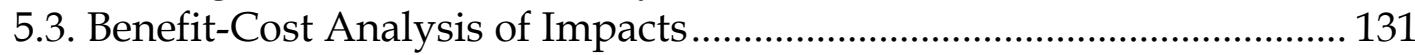

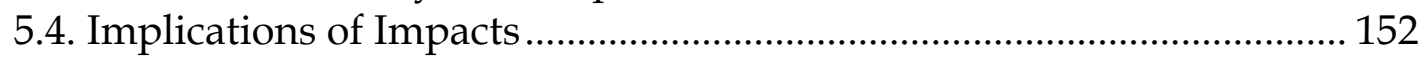

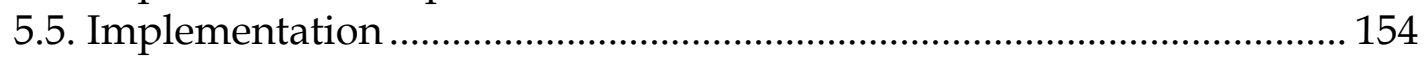

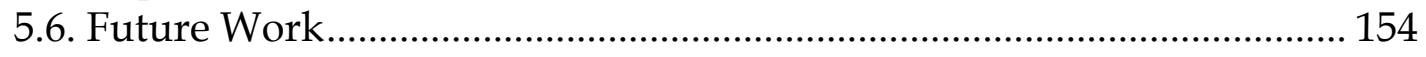

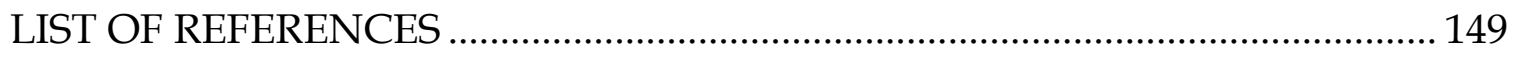

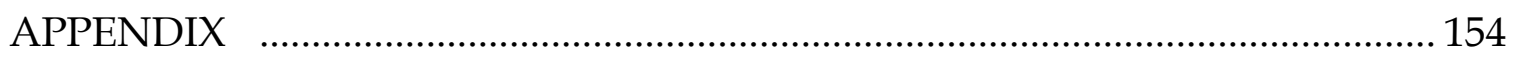




\section{LIST OF TABLES}

Table

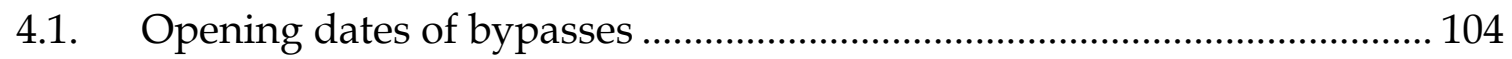

4.2. Nearest large cities of bypassed counties ............................................... 106

5.1. Sample values for benefit-cost calculations .......................................... 135

5.2. Benefit-Cost ratios for various industry sectors ..................................... 137

5.3. Nearest large cities and projection sources for Mt. Vernon and North

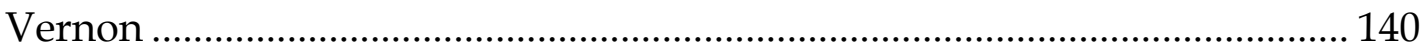

5.4. Average weekly wages, statewide projected employment, and bypass construction costs used in benefit-cost calculations

5.5. Predicted total employment for Posey County and Jennings County .... 142

5.6. Benefit-Cost calculations for Mt. Vernon ................................................ 143

5.7. Benefit-Cost calculations for North Vernon........................................... 143 


\section{LIST OF FIGURES}

Figure

2.1. Excerpt from Howard County Plan Commission Resolution

Page 2005-1 (INDOT, 2007) .................................................................................. 4

2.2. US-31 Fatal Crash Rates (INDOT, 2007)_...................................................... 5

2.3. Projected Traffic Volumes and Level of Service (INDOT, 2007)................ 6

2.4. Land use changes along US-52 corridor from 1939, 1952, and 1964 (McNeil, 1971)................................................................................... 8

2.5. (Top row, right) Vibrant CBD with angle parking. (Top row, left) Mom-and-pop pharmacy. (Middle) Traffic circle at northwestern corner of downtown. (Bottom row, left) Signage at onramp for US-127 bypass. (Bottom row, top right) Typical view along bypass at diamond interchange with $\mathrm{OH}-49$. (Bottom row, bottom right) At-grade, unsignalized intersection at northern terminus of bypass. (Photos by J. Mills).

2.6. (Left) Eaton and surrounding area. Both US-35 and US-127 provide access to Interstate 70. (Right) Greenville and surrounding area. The northern terminus of US-127's former alignment is located around Wakefield (Source: Google Maps).

3.1. Approximate locations of cities selected for study. Map outline from http://z.about.com/d/geography/1/0/k/I/in.jpg.

3.2. (Top) Aerial photo of Logansport. The US-24 bypass is located on the southern side of the city. (Middle) Inset of Downtown Logansport. Business US-24 runs along Broadway Street and Market Street. (Bottom) Inset of east side of Logansport. This area is dominated by retail businesses. Top photo from Google Maps. Middle and bottom photos from Google Earth

3.3. (Top inset) Guide sign near US-24, US-35 split, heading west on bypass. (Middle) Guide sign directing drivers to downtown Logansport. Note the awkward placement of "To Downtown" and the lack of specific service signs. (Bottom) Guide sign at US-24-35, IN-29 split. Note the Tyson plant in the background. 
3.4. Aerial photo of Peru and surrounding area. The four-lane US-24 and US-31 bypasses run to the north and west of Peru, respectively. The old alignments of the two routes are shown on the aerial. Grissom Air Reserve Base (and the Grissom Aeroplex industrial park) are located to the south along US-31 (Source: Google Earth).

3.5. Aerial photo of Wabash. The white line denotes the approximate original alignment of US-24 (Source: Google Earth).

3.6. Aerial photo of Huntington, IN. US-24 bypases the CBD to the north. US-224 terminates at US-24 (Source: Google Earth).

3.7. (Left) View of Jefferson Street in downtown Huntington. (Right) Sign promoting the shops of downtown Huntington (Photos by J. Mills)..... 56

3.8. Aerial photo of Anderson. The current alignment of IN-9 was reconstructed in 1973. Over time, new retail development sprouted up along the corridor (Source: Google Earth)

3.9. Aerial photo of Warsaw. The original alignment of US-30 ran along E. Center St and Lincoln Highway. As shown on the aerial, the city is surrounded by four lakes. The northern terminus of IN-25 is located in the CBD, at the junction with IN-15. With the exception of the folded-diamond interchange with IN-15, all intersections with the highway are at-grade.

3.10. Aerial photo of Columbia City. The original routing of US-30 ran along East Lincoln Way Road and West Business 30 and is currently signed as Business US-30 (Source: Google Earth). (Inset) Photo of downtown Columbia City (Source: http://upload.wikimedia.org/wikipedia/commons/f/f1/ Columbia-city-downtown.jpg). 75

3.11. Aerial of Washington and surrounding area. The US-50 bypass (duplexed with US-150 through the county) runs south of the CBD. Coal trucks that traveled through downtown caused endless headaches for local residents prior to the bypass's construction. 
Figure

3.12. Aerial photo of Angola and surrounding region (Source: Google Earth). (Inset) Photo of traffic circle, Monument Circle located in Angola's CBD. The geometry of this traffic circle often causes problems for thru truck traffic (Photo source: Wikipedia).

3.13. Project listing for US-20 bypass and added travel lanes on existing US-20 from Unfunded Long Range Plan Projects, INDOT, Fort Wayne district (INDOT, 2007)

3.14. Aerial photo of Boonville (Source: Google Maps).

3.15. Aerial photo of downtown Boonville. Traffic following IN-61 southbound must make a sharp turn near the Warrick Pharmacy. Thru traffic use the one-way pair and make at least one sharp turn to continue northbound on IN-61 to Interstate 64. The large amount of traffic generated by the local coal mining industry has proved detrimental to downtown Boonville. (Source: Google Earth).

3.16. (Top) Aerial of Salem and surrounding area. The proposed bypass will run from IN-56 on the west side to IN-60 on the southeast side. (Bottom) Detailed view of the downtown. The courthouse, pharmacies, attorneys' offices, and a number of banks are located in the CBD. Negotiating the square and its two traffic circles can be difficult, particularly when a railroad is passing through three blocks south of the square.

3.17. Aerial photo of Greencastle. Much of the commercial and industrial development is along IN-240, the principal east-west corridor through the city. For this reason, all proposed alignments for the proposed US-231 bypass travel to the east of the city (Source: Google Earth). 96

3.18. Proposed alignment of bypass, shown by the thick black line (Corradino Group, 2003).

5.1. Time-series Plots of Manufacturing Payroll, Whitley County 133

5.2. Estimated Project Costs for IN-25 (Hoosier Heartland Corridor), Carroll County. (Source: Indiana Department of Transportation) 
5.3. Present Values for Retail Trade, Eating \& Drinking Places sectors. Initial negative impacts on payroll, particularly Eating \& Drinking Places, negated

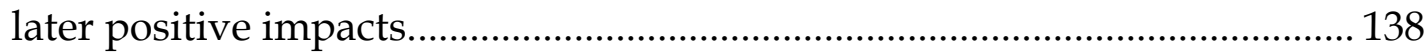




\section{LIST OF VARIABLES}

\begin{tabular}{|c|c|}
\hline Variable & Description of Variable \\
\hline LPLD & Population of nearest large city / Distance (mi) from study city to nearest large city \\
\hline LLPLD & Population of nearest large city / LN(Distance (mi) from study city to nearest large city) \\
\hline ELPLD & Population of nearest large city / (Distance (mi) from study city to nearest large city $)^{\wedge} 10$ \\
\hline LSPLD & Population of study city / LN(Distance (mi) from study city to nearest large city) \\
\hline BYPASS & Indicator: 1 if bypass has been opened, 0 otherwise \\
\hline BCBD & Bypass indicator * Distance from study city CBD to bypass along original route \\
\hline BNUM & Bypass indicator * Number of turns along original route in study city CBD \\
\hline POPSL & Population of study city / Population of nearest large city \\
\hline POP_IN & Population of Indiana \\
\hline POP_LG & Population of nearest large city \\
\hline US30 & Indicator: 1 if study city bypassed by US-30, 0 otherwise \\
\hline HHIC & Indicator: 1 if study city bypassed by US-24, 0 otherwise \\
\hline AGRIER & Annual earnings, Agricultural Services (County to State Ratio) \\
\hline CONEARR & Annual earnings, Construction (County to State Ratio) \\
\hline CONEMP & Annual employment, Construction \\
\hline CONEMPR & Annual employment, Construction (County to State Ratio) \\
\hline EATEMPR & Mid-March employment, Eating \& Drinking Places (County to State Ratio) \\
\hline EATESTR & Number of establishments, Eating \& Drinking Places (County to State Ratio) \\
\hline HEALTHR & Annual earnings, Health Services (County to State Ratio) \\
\hline MFGEMP & Mid-March employment, Manufacturing \\
\hline MFGEMPR & Mid-March employment, Manufacturing (County to State Ratio) \\
\hline MFGESTR & Number of establishments, Manufacturing (County to State Ratio) \\
\hline MFGPAYR & First-quarter payroll, Manufacturing (County to State Ratio) \\
\hline MTEMP & Mid-March employment, Manufacturing / Total Employment \\
\hline PROPEMPR & Annual Proprietors' Employment (County to State Ratio) \\
\hline RETEMP & Mid-March Employment, Retail Trade \\
\hline RETEMPR & Mid-March Employment, Retail Trade (County to State Ratio) \\
\hline RETPAYR & First-quarter payroll, Retail Trade (County to State Ratio) \\
\hline TPEMP & Annual employment, Transportation and Public Utilities \\
\hline TPEMPR & Annual employment, Transportation and Public Utilities (County to State Ratio) \\
\hline TRUCKR & Annual earnings, Trucking and Warehousing (County to State Ratio) \\
\hline WHOEMP & Mid-March Employment, Wholesale Trade \\
\hline WHOEMPR & Mid-March Employment, Wholesale Trade (County to State Ratio) \\
\hline WHOESTR & Number of establishments, Wholesale Trade (County to State Ratio) \\
\hline WHOPAYR & First-quarter payroll, Wholesale Trade (County to State Ratio) \\
\hline Z1 & Bypass Age Indicator: Years 1 to 5 \\
\hline $\mathrm{Z} 2$ & Bypass Age Indicator: Years 6 to 10 \\
\hline Z12 & Bypass Age Indicator: Years 1 to 10 \\
\hline
\end{tabular}


Z123

$\mathrm{Z} 4$

Z1234

Z5

$\mathrm{Z6}$

Z456

Z56

$\mathrm{Z7}$

$\mathrm{Z8}$

Z9

YR5
Bypass Age Indicator: Years 1 to 15

Bypass Age Indicator: Years 16 to 20

Bypass Age Indicator: Years 1 to 20

Bypass Age Indicator: Years 21 to 25

Bypass Age Indicator: Years 25 to 30

Bypass Age Indicator: Years 16 to 30

Bypass Age Indicator: Years 21 to 30

Bypass Age Indicator: Years 31 to 35

Bypass Age Indicator: Years 36 to 40

Bypass Age Indicator: Years 41 to 45

Indicator: 1 if bypass has been open more than 5 years, 0 otherwise

(Number of years bypass has been open)^2

Note: For the employment, payroll, and establishment variables, an "L" preceding the name of the variable denotes that the natural logarithm of the variable was taken. For example, the variable "LWHOEMP" is the natural logarithm of the wholesale trade employment variable. 


\section{CHAPTER 1. INTRODUCTION}

\subsection{Background}

A bypass typically redirects through traffic around the central business district (CBD) of a town. Often, these bypasses are built to accommodate increasing volumes of traffic, particularly truck traffic. Bypasses typically have geometry and cross-sections far more truck-friendly than typical city streets, many of which were constructed decades ago. Bypasses are typically rerouting of major arterials, typically US highways or state routes. Typically, when a bypass is built, the state agency relinquishes control of the original route to local agencies.

Bypasses have become prevalent in the state of Indiana and across the nation. The rerouting of principal arterials around an affected city's central business district has raised concerns among community members, public officials, and state agencies regarding the long-term effects on the community's economy. Previous studies have mainly focused on the impact of bypasses on travel-dependent businesses, such as motels, gas stations, and restaurants, with an emphasis on how sales were impacted. According to these studies, while short-term impacts on these businesses will be negative, affected communities will adapt to the presence of a bypass. However, there is no clear-cut set of guidelines for "adapting" to the presence of a bypass. 


\subsection{Purpose of Project}

This study aims to document the long-term impacts of bypasses on small- and medium-sized communities. Data were collected to document economic changes that took place in communities with bypasses. Models from previous studies were built upon and adapted to these communities to quantify changes that may have taken place. Using the before-and-after approach, mathematical relationships were developed that will form the basis of future bypass impact evaluation guidelines. Communities with proposed bypasses were studied to determine how these future guidelines could affect these communities.

The findings of this study will be used to develop guidelines on how future bypasses can be designed to benefit both the affected community and the users of the bypass. Using the study's findings, a concise guide will be prepared that will provide guidance to both Indiana Department of Transportation (INDOT) officials and community officials as to how to best "adapt" to the presence of the bypass.

Following a review of previous studies and identification of issues to be addressed, detailed profiles of each affected community are provided. The details of the statistical analysis process are then discussed. Finally, the findings of the study and details of implementation of these findings are presented. 


\section{CHAPTER 2. LITERATURE REVIEW}

\subsection{Historical Background - Older Bypasses}

\subsubsection{Kokomo, IN}

The Branham and Michael 1953 JHRP report, Economic Evaluation of Two Indiana Bypasses, analyzed the newly opened bypasses around Kokomo and Lebanon, located in central Indiana. The study analyzed traffic impacts, safety impacts, land use impacts, land value impacts, and effects on local businesses. Through a combination of origin-destination studies, roadside interviews, and aerial photo analysis, the study found that the Lebanon bypass, which is now part of Interstate 65 , greatly decreased through traffic on the original route (volumes on the original route, formerly US-52, dropped up to over 80 percent), while traffic volumes on the original route through downtown Kokomo not only did not decrease but were projected to experience congestion worse than before the bypass was opened in 1951; travel times on the original route actually increased following the bypass's opening (Branham et al., 1953).

Furthermore, it was found that most traffic on the Kokomo bypass was local traffic, likely due to "a shortage of north-south streets." The report recommended “...some method, such as limited access, should be employed to control development along the route so as to insure safer facilities and maximum economic return to the state and to the users of the facility...the relative ease of movement 
that now exists on these bypasses must be maintained for the life of the facilities," (Branham et al., 1953).

The study also noted that "...the Kokomo Planning Commission is attempting to control the development and the access points by the use of an intelligent zoning ordinance and a required platting procedure."

At present, retail and service establishments have proliferated along the Kokomo bypass, and incoming traffic is warned by signage of a "Congested Area Ahead, Next 7 Miles." The development that has occurred along the corridor is criticized by the Howard County Plan Commission (see Figure 2.1). Congestion has become so severe on the Kokomo bypass that a limited-access facility, referred to by the layman as a "bypass of a bypass," will be built to the east of the current bypass.

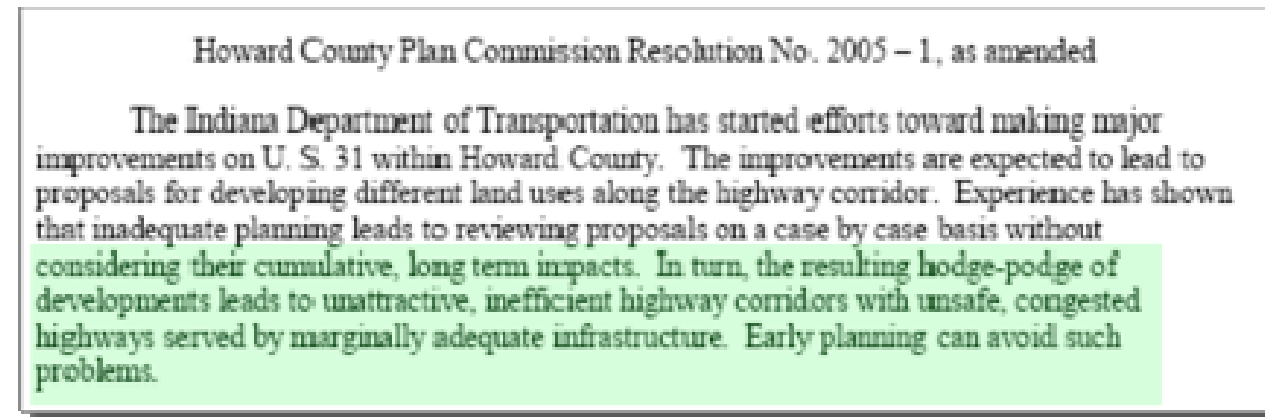

Figure 2.1 Excerpt from Howard County Plan Commission Resolution 2005-1 (INDOT, 2007).

Figure 2.2, from the Final Environmental Impact Statement (FEIS) for the US 31 Kokomo corridor project through Kokomo, released March 9, 2007, details the fatal crash rates experienced along the US 31 corridor. According to the FEIS, fatal crash rates exceed average Indiana fatal crash rates by up to a factor of 2.5. 


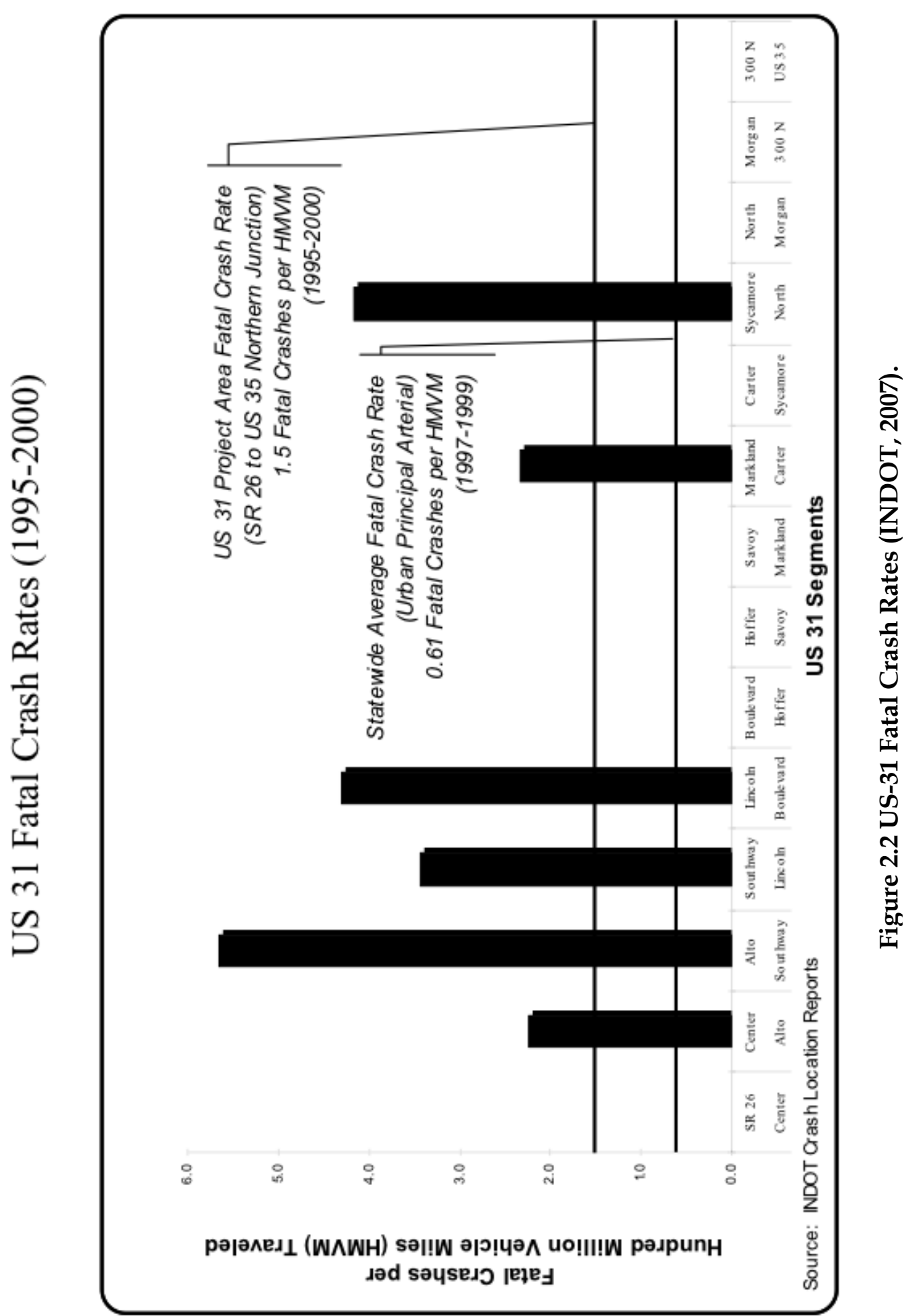


With respect to crash rates, uncontrolled land use development, which appears to be the case with the original US-31 bypass of Kokomo, can potentially pose a major safety risk to drivers, as shown in Figure 2.2. The proposed realignment of US-31 will be controlled-access, which will likely reduce crashes.

The current crash rates on US-31 illustrate what could be construed as a "cumulative and long-term" impact; as the number of uncontrolled access points (approximately 140 such points exist along US-31, according to the FEIS) has increased along current US-31, along with traffic volumes. Coupled with limited land use restrictions, these factors have contributed cumulatively to the current fatal crash rates. Such impacts should be considered in bypass proposals.

The excerpt below from the FEIS mentions the use of the Kokomo and Howard County Governmental Coordinating Council (KHCGCC) computer forecasting model for predicting future traffic volumes along US-31. This model could potentially link to a database of traffic levels along US-31 and other principal routes in Howard County.

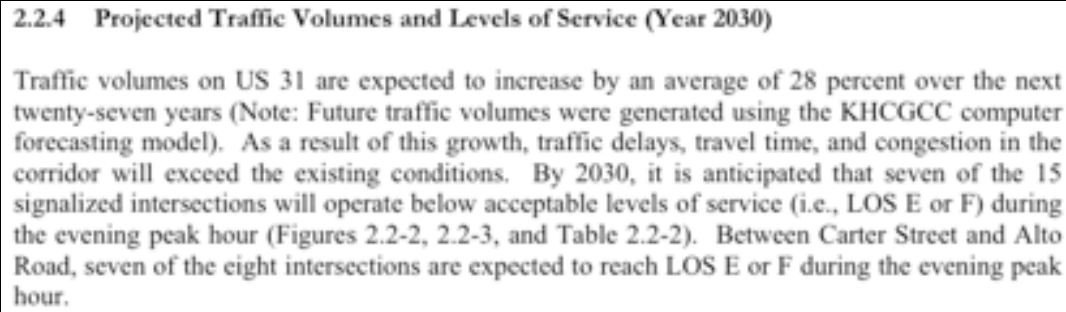

Figure 2.3 Projected Traffic Volumes and Level of Service (INDOT, 2007). 


\subsubsection{Lafayette 1971}

A 1971 JHRP study examined long-term impacts on land-use, safety, and travel time on the US-52 corridor through Lafayette, Indiana. The original bypass was opened as a two-lane facility in 1938 and was in the process of being widened to four lanes at the time of the study (McNeil, 1971). Over time, the corridor attracted a large variety of retail and manufacturing companies. The study noted how "the absence of effective community or state control on the number and location of access points to development on the Bypass resulted in considerable areas of continuous access or in frequent access drives on both sides of the facility" (McNeil, 1971).

Figure 2.4 details land-use changes over a period of 26 years. Today, the corridor carries Purdue University-bound traffic, local traffic, and truck traffic; it no longer functions as a bypass. 


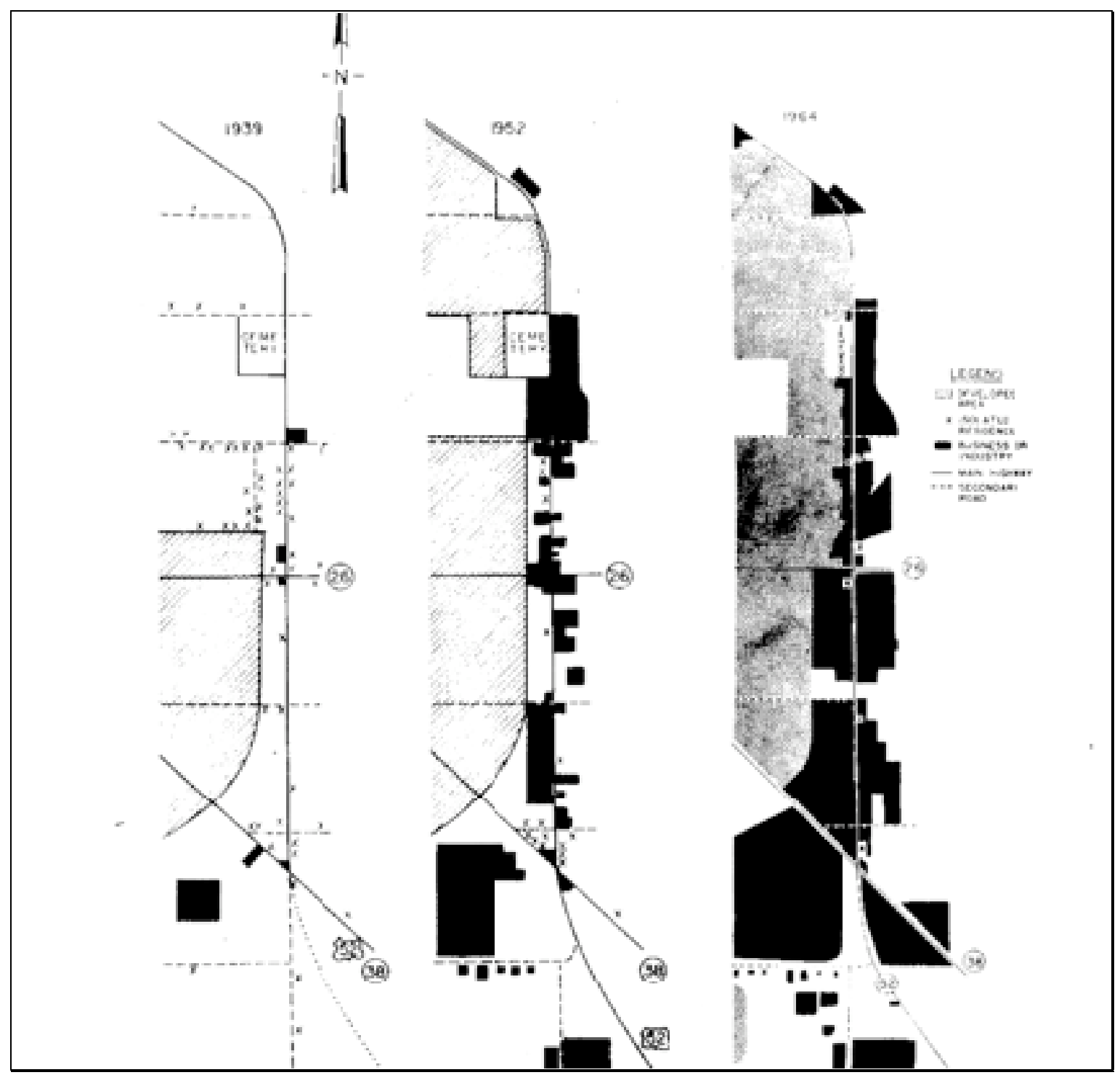

Figure 2.4 Land use changes along US-52 corridor from 1939, 1952, and 1964 (McNeil, 1971).

\subsubsection{Greenville, $\mathrm{OH}$}

The June 2001 study Impact of By-Passes to Ohio Communities Under 35,000 Population by John E. Kleymeyer found that retail sales were not significantly impacted by the presence of a by-pass, with the exception of gasoline service stations, 
which were negatively affected. Of the 11 cities studied, Kleymeyer selected six for on-site visits.

Kleymeyer selected three "city-pairs" for comparison; one city did not have a bypass, while the other city did. All cities were county seats. No statistical analyses for selecting these "city-pairs" were cited in the report.

Similar to the Kentucky study and this project, the CBD of each city was photographed and observed. Prominent city officials were also interviewed, including mayors, county officials, Chambers of Commerce directors, and area economic development officials (Kleymeyer, 2001).

Two city-pairs selected for analysis were Eaton and Greenville. US-127 runs through the CBD of Eaton and bypasses Greenville to the east (see maps, below). At the time this is written, Greenville's CBD is at full occupancy, whereas Eaton's CBD has one vacancy, according to the report. Truck traffic along US-127 is the chief complaint of merchants of downtown Eaton, and "a committee has been formed to study the possibility of requesting a by-pass highway," according to the report.

Further evidence is presented in the report that bypasses do not have major impacts on retail sales. In Greenville, according to Kleymeyer, " $t$ there appeared to be more concern about the new retailing along old US-127 than about the new by-p[ass US-127...[i]t would appear that the change in tenancy of the CBD was caused by the new suburban style strip malls in both communities."

The extent of manufacturing employment of Eaton was compared to Greenville. Preble County, of which Eaton is the county seat, had 30 major manufacturing 
plants with 3,689 employment, whereas Darke County, of which Greenville is the county seat, had 25 major manufacturing plants with 4,609 employment, per the report. The study concluded "[b]oth communities appear to be similar in development pattern, with Greenville having slightly more of everything when compared to Eaton. Therefore, it can be concluded that the by-pass highway in Greenville brought no negative effects, but only positive ones."

US-127 bypasses Greenville to the east, with its northern terminus at CR-98 and its southern terminus at the southern split with US-36, just south of the OH-49 interchange. The bypass was built in 1967-68, according to Kleymeyer. Intersections with major roads along the bypass are grade-separated, while intersections with minor roads are at-grade and unsignalized.

Similar to Logansport and Huntington, while the major US routes bypass the CBD of Greenville, state routes continue to run through downtown.

Eaton, $\mathrm{OH}$, is located approximately 12 miles east of Richmond, IN and 5 miles south of Interstate 70. In contrast, Greenville is located approximately 35 miles northwest of Dayton, 15 miles southeast of Union City, and 17 miles north of Interstate 70. US-127 and US-36, the only principal roads in Darke County, narrow to two lanes outside the city.

US-127 and US-35 both travel through the CBD of Eaton. All truck traffic must travel through downtown, whereas in Greenville, truck traffic is diverted to the bypass. A site visit to Greenville was conducted on 12 May 2007. Both the CBD and the bypass were photographed (see Figure 2.5). The bypass was driven from the at-grade intersection with Childrens Home-Bradford Road to its southern 
terminus at the split with US-36. Maps of Greenville and Eaton are shown below in Figure 2.6. 


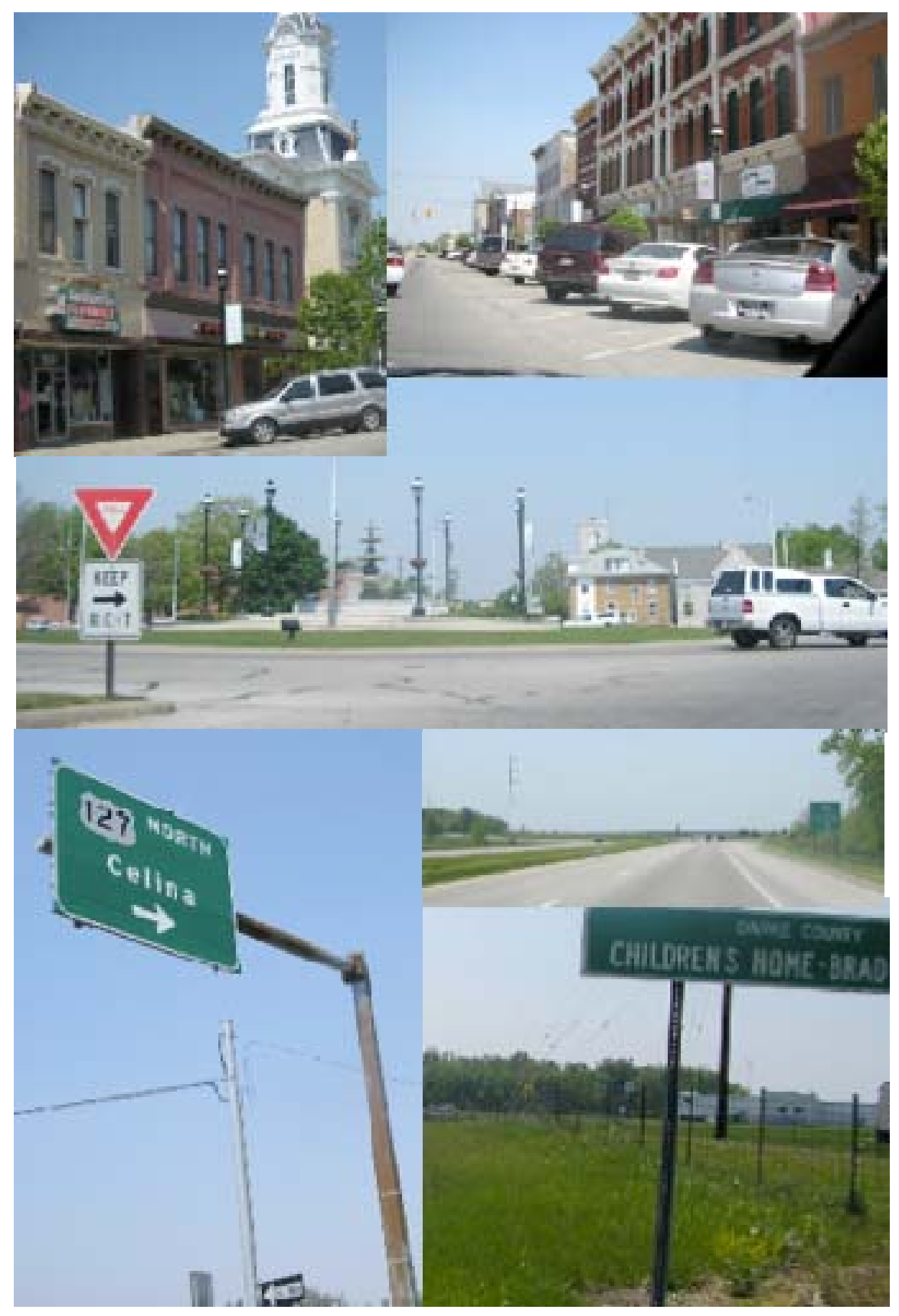

Figure 2.5 (Top row, right) Vibrant CBD with angle parking. (Top row, left) Momand-pop pharmacy. (Middle) Traffic circle at northwestern corner of downtown. (Bottom row, left) Signage at onramp for US-127 bypass. (Bottom row, top right) Typical view along US-127 bypass at diamond interchange with $\mathrm{OH}-49$. (Bottom row, bottom right) At-grade, unsignalized intersection at northern terminus of bypass. All photos by J. Mills. 


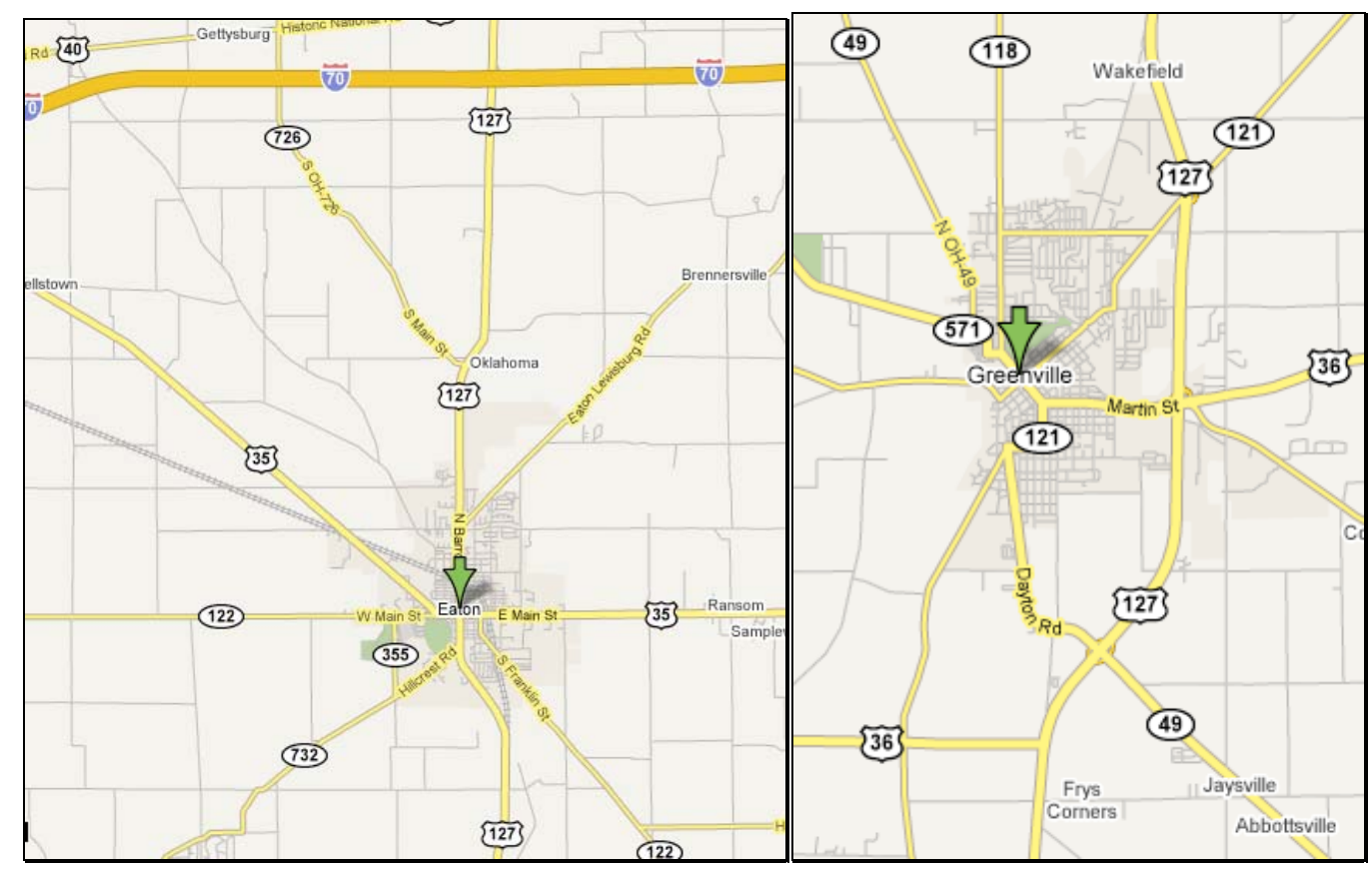

Figure 2.6: (Left) Eaton and surrounding area. Both US-35 and US-127 provide access to Interstate 70. (Right) Greenville and surrounding area. The northern terminus of US-127's former alignment is located around Wakefield (Source: Google Maps).

No retail development was present along the US-127 bypass; only manufacturing companies could be seen from the bypass. The majority of retail development is located along the old alignment of US-127; however, heading southbound, only one fast food restaurant was advertised on advance signage along the bypass. Along OH-49 northbound approaching downtown, signage for "Business Loop US-127" suddenly appeared. However, attempts to follow the routing of this business loop, presumably along old US-127, were unsuccessful, as no further signs were spotted. 


\subsection{Recent Qualitative Research}

\subsubsection{Kansas}

Studies conducted by the Institute for Public Policy and Business at the University of Kansas have found that only travel-dependent businesses, such as motels, restaurants, and gas stations were impacted negatively by the construction of a bypass (Burress, 1996). Over the long-term, cities and counties with bypasses experienced growth in basic industry, which later brought about "second-round effects" of growth in the retail and service industries. Burress also noted that external economic factors, such as the onset of big-box stores and other such national economic trends (e.g., recessions, stock market crashes), can have greater effects on a small city's economy than a bypass.

\subsubsection{Wisconsin}

Through a combination of origin-destination surveys, interviews with community officials, and statistical analysis of employment data, sales data, and traffic counts, the 1998 Wisconsin Department of Transportation Study The Economic Impacts of Highway Bypasses on Communities found that "bypasses rarely have created adverse economic impacts on communities." The study found that only towns with populations of 2,000 or fewer were more likely to be adversely impacted by the construction of bypasses (Yeh et al., 1998). Conversely, in the larger cities, long-term traffic counts on bypassed routes remained constant or actually increased after the bypass was constructed. The study found that medium and large cities were unlikely to experience negative impacts in their overall economies. 
Many of these cities had diversified economies and served as "destinations," hence the higher traffic counts on the old alignments. Construction of these bypasses helped reduce congestion on the old routes with the reduction in truck traffic, stimulating economic development along the bypassed routes. Smaller cities with less diversified economies were found more likely to have traffic levels drop precipitously (to a point at which traffic-dependent businesses are forced to close) than larger cities.

The higher traffic levels on the old routes may provide a reason as to why retail flight has not occurred on the old alignments. The WisDOT study found that less than $5 \%$ of businesses residing in bypassed communities were located within half a mile of the bypass. The lower levels of traffic on the bypass (relative to the original route) gave businesses little incentive to relocate (Yeh et al., 1998).

In its recommendation for WisDOT, the study stated that the agency "should continue to respond to communities' desires for additional information and analysis on potential impacts of bypasses, and assist in land use and development planning efforts."

\subsubsection{Texas - Planning Policies}

The report Planning for the Impacts of Highway Relief Routes on Small-and MediumSized Communities, conducted at the University of Texas at Austin, examined possible planning techniques for both local communities and transportation agencies for minimizing the potential negative impacts of a bypass. The report noted that currently, there is "little in the way of an established set of planning practices" relating to bypasses and relief routes (Jarrett et al., 2000). 
The report highlighted studies conducted by the Transportation Research Board (TRB) regarding minimizing the potential negative impacts of a bypass. Among its recommendations, the study suggested advertising local businesses on the bypass and allowing for easy access to the town from the bypass. The study also suggested restricting development to non-commercial use near any interchanges on the bypass. This restriction on development, however, could have the potential to backfire. As reported by the Texas study, a survey conducted by the TRB found that almost one-fifth of through travelers on the bypass would not travel beyond the bypass if they were unable to see their potential destination, that is, local businesses. This percentage may seem small, but from the viewpoint of a business owner on the bypassed route, a 20 percent drop in sales would adversely impact his or her establishment. Other recommended strategies included the placement of utilities along the relief route (which is characteristic of industrial and business parks) and active community involvement in all stages of planning (Jarrett et al., 2000).

The Texas study also highlighted findings of studies conducted in Washington State. Communities with a solid local customer base and a thriving downtown business district were least likely to be adversely impacted by the construction of a bypass, whereas communities with business districts highly dependent on through travelers would experience widespread business closures. Businesses with a focus on the local community were found to replace the through traffic-dependent businesses over the long-term. Furthermore, the report cautioned that "[p]lanning strategies targeted on the impacts of the relief route may not be enough to save" locally-owned retail businesses in small towns (Jarrett et al., 2000). 
Case studies conducted in Washington state found that some communities "adapted" to the presence of the new bypass by making the central business district a tourist destination. Business owners were schooled in the ways of tourism and hospitality, and information brochures and kiosks were developed.

The report also highlighted a video produced by Mountains-to-Sound Greenways in Oregon that provided community planners with case studies and suggestions for how to "adapt" to the presence of bypasses. The video emphasized presentation of the town is key to the traveler; a town bordered by lines of gas stations and run-of-the-mill fast food restaurants leave the traveler disinclined to further explore the town. The video focused on the town of Jacksonville, Oregon, a popular tourist destination. Community officials proposed restrictions of development along highways, including limitations on commercial development along bypasses and strict design guidelines requiring all development along through routes to "be compatible with the style of the town." Consistent building design helps to give towns a unique appearance, making such towns appealing to tourists.

The case of the proposed Traverse City, Michigan, bypass illustrates a situation in which the public and transportation agencies have a more contentious relationship. The 33-mile bypass, proposed by the Grand Traverse County Road Commission with an estimated cost of $\$ 42.5$ million, has met "significant public opposition" due to its high cost, potential damage to the local economy and to the Boardman River Valley, according to an article from the Great Lakes Bulletin News Service published on the Michigan Land Use Institute website (Schneider and Thayer, 2003). According to the article, it was learned following analysis of the Grand Traverse County Road Commission's own technical documents that the proposed bypass "would do nothing to relieve traffic congestion in the 
Grand Traverse region and could instead make it worse" (Schneider and Thayer, 2003).

Community members suggested a less-expensive alternative plan, calling for improvements to the existing bridge carrying much of the through traffic. As noted in the Texas report, residents of the community worked together with the MLUI and the Coalition of Sensible Growth to formulate a "Smart Roads" plan emphasizing the conservation of open space, increased usage and affordability of mass transit, and the promotion of further development in already developed areas (Jarrett et al., 2000).

The Texas report also outlined "creative alternatives" developed in Arizona for "adjusting" to the presence of a bypass, such as giving the hardest-hit businesses (in terms of lost sales) "the preferential right to relocate to the relief route" or to commission market studies to determine which particular businesses in a city will be most adversely affected by the presence of a bypass (Jarrett et al., 2000).

\subsubsection{Washington State}

Case studies were conducted for three communities with recently constructed bypasses in the February 1994 report Lessons from Eastern Washington: State Route Mainstreets, Bypass Routes, and Economic Development in Small Towns.

The findings of the report and relevance to bypassed Indiana towns are as follows (Gillis, 1994):

(1) Downtown business districts in communities with a welldeveloped local customer base are less adversely impacted by a state route bypass than communities highly dependent on drive- 
by traffic. Will the economic vitality of Delphi remain strong once the IN-25 bypass is constructed? Does this finding hold true in the case of Washington, whose downtown has not declined since the opening of the US-50 bypass in 1991, or with Huntington, whose citizens shop locally but prefer to shop at chain stores not located downtown?

(2) Bypass routes that improve access to major trading centers open up new opportunities for small towns. Community officials from Logansport, Peru, and Wabash believe that the completion of the Hoosier Heartland Industrial Corridor (HHIC) will induce higher levels of economic development.

(3) Systematic development of highway-related businesses and other retail services along bypass interchanges can help mitigate possible economic losses that occur from the diversion of traffic from the downtown business district. This has yet to occur around Logansport, though such development has been proposed for the areas surrounding the future portion of the HHIC. A number of "big-box" stores have opened around Huntington and Wabash along US-24. Was this development "systematic?"

(4) Annexing property associated with new interchange developments is an important tool that can be utilized by cities to mitigate tax base losses associated with possible business closing and land use changes in the downtown business district. Regardless of the type of interchange associated with bypasses in Indiana, several cities have taken steps to ensure areas surrounding the bypass 
contribute to the tax base. For example, the US-30 corridor through Columbia City has attracted significant retail development. Community officials believe the west side of the city may become a part of the downtown. The establishment of a Tax Increment Finance (TIF) district has solidified the employment base in the city according to local officials interviewed for this study (see Chapter 3).

(5) Land use plans should be flexible enough to accommodate new types of downtown uses in communities that are impacted by a state route bypass. Numerous economic development corporations and community officials in Indiana have taken steps to ensure their respective downtown areas will thrive, such as the development of an entertainment district in downtown Wabash, anchored by the Honeywell Center.

(6) Enticing tourists and shoppers to travel into the central business district is important to the economic and overall quality of life in bypasses communities. With improvement to the riverfront area, an aggressive PR program, and proper signage, downtown Logansport could attract considerably more visitors and tourists to the CBD. Logan's Landing is currently taking such steps to revitalize the downtown.

\subsection{Recent Quantitative Research}

2.3.1. Texas - Econometrics 
In the Texas study The Impacts of Bypasses on Small-And Medium-Sized Communities: An Econometric Analysis, Srinivasan and Kockelman used an econometric model structure to determine the economic impacts of relief routes Past studies of economic impacts of bypasses did not fully isolate the impacts due only to the presence of a bypass, according to Srinivasan and Kockelman.

Using traffic maps, sales data from the U.S. Economic Census, population data from the U.S. Census of Population (with population data from 1950-1990), and district traffic maps from the Texas Department of Transportation (TxDOT), Srinivasan and Kockelman constructed econometric, linear, random-effects estimation models with Aptech Systems's GAUSS, a matrix programming language, using time-series cross-sectional data for nine data years.

Economic impacts on four industry sectors were analyzed: total retail sales, gasoline station sales, restaurant sales, and service receipts. These sectors were thought to be most dependent on traffic levels. Among the findings (Srivivasan and Kockelman, 2001):

(1) The higher the traffic split, or extent of traffic shifting to the relief route, the "greater the adverse impact on the economy of the community," particularly within the retail sector.

(2) In contrast, total sales for eating and drinking places increased as the traffic split increased.

(3) Population demographics, such as income per capita and unemployment rates, were statistically significant in many of the models. 
(4) Economic impacts were more positive if a city were located close to a "large city." Impacts due to a small city's proximity to a large city sometimes outweighed the impacts of a bypass.

Regarding the use of models, the report cautioned "...such forecasts should be used with extreme caution, if at all. These models are developed based on past experiences, and similar conditions may not prevail in the future. Each city has its own unique characteristics that cannot be fully captured in models" (Srinivasan and Kockelman, 2001).

\subsubsection{Kentucky}

A key component of the March 2001 report The Impact of a New Bypass Route on the Local Economy and Quality of Life entailed the use of "matched counties" for the sake of comparison to "bypassed counties." The Mahalanobis matrix approach, was used to analyze potential "matched" counties based on a number of criteria. A few examples of these criteria include the following:

(a) County population

(b) Importance of mining (which can be "translated" to importance of manufacturing and/or agriculture to make it more applicable to Indiana)

(c) Retail activity

The matrix approach used in the study determines "similarity" between bypassed and matched counties based on "aggregate economic distance." This is a measure of similarity among bypassed and matched counties in terms of key economic measures, such as the share of manufacturing, mining, and service industries. 
The approach was used to ascertain which counties were manufacturingoriented, mining-oriented, and service-oriented. The study noted that the growth rates of each industry impact the county population growth rate, with the slow growth of mining corresponding to slower growth in mining-based counties, and some manufacturing-oriented counties growing faster than other counties (Thompson et al., 2001).

The five key economic measures used to measure the economic distance were:

(a) Distance to nearest large town (not explicitly defined in study)

(b) Population

(c) Share of employment in mining

(d) Share of employment in manufacturing

(e) "Retail capture," a measure that "compares actual retail employment in a county relative to the level of retail employment that would be expected given population and per capita income levels in the county," (Thompson et al., 2001). This value is nonnegative and can exceed 1 .

Growth rates of bypassed and matched counties were also compared using the following criteria:

(a) Population, industry, employment growth rates in five years before the bypass in a bypassed county was built

(b) Population, industry, employment growth rates in five years after the bypass in a bypassed county was built

(c) Change in employment growth and change in population growth

(d) Change in overall retail sales 
Relative growth rates for employment, population, and retail sales, among other factors, of bypassed and matched communities were regressed using the following three variables:

(a) Population of bypassed community based on 2000 Census

(b) Distance (in meters) from the bypass to each community's central business district (CBD)

(c) Whether or not the bypass had partial bypass control The overall impacts of bypasses on bypassed communities relative to matched communities were found to be generally positive. Further, the results imply that bypassed communities may experience faster total employment growth if there is total access control and if the bypass is built close to the bypassed town's CBD. The study notes that the small sample size (11 of 21 bypassed routes, for example) increased the likelihood of no statistically significant difference being identified for the above factors.

However, examination of the allocation of business activity revealed more varied impacts. A number of bypassed and matched communities were visited by the writers of the report to make three different comparisons between the downtown (CBD) areas of bypassed communities, the downtown areas of matched communities, businesses in the downtown areas of bypassed communities, and businesses along the bypass of bypassed communities.

The factors used for comparison were as follows:

(a) The number of vacant commercial properties in the downtown areas of bypassed and matched communities to determine each community's re- 
spective vacancy rate. This vacancy rate was calculated by dividing the number of vacant store fronts and dividing this number by the number of all store fronts in the CBD. The size of these establishments was not considered due to the difficulty in data collection.

(b) Change in business mix of central business district (in terms of \% retail, \% professional, \% personal services, \% government).

Calculations of the vacancy rate only accounted for street-level storefronts and did not consider the square footage of buildings. The study found that the vacancy rate of bypassed communities was 18.4 percent compared to 10.9 percent in matched communities, a 69 percent difference, found to be statistically significant.

Other factors used for comparison were:

(c) Population (size did not affect vacancy rate)

(d) Regional (county) economic growth (did not affect bypass's impact on vacancy rate)

(e) Age of bypass (vacancy rates were lower for communities with older bypasses compared to vacancy rates for communities with newer bypasses)

The business mix of the CBD of bypassed communities was decidedly different from the business mix of the CBD of matched communities and the business mix along the bypass of bypassed communities. Retail businesses comprised nearly 60 percent of the business mix along bypasses (versus 33 percent in the CBD of bypassed communities) whereas professional services comprised 26 percent of businesses in the CBD of bypassed communities (versus 11 percent along bypasses). 
Further, over 90 percent of retail businesses along bypasses were new to the area, while an average of only 7.6 percent of all businesses from the CBD relocated to the bypass. The percentage of relocated businesses (which, for the bypassed communities analyzed, was no larger than 25 percent) was found to be higher for communities smaller than 3,000 in population than in larger communities. As stated in the report: "The land adjacent to a bypass may become a competing business location for downtown spaces, but bypasses appear to primarily 'compete' for businesses newly locating in the community rather than drawing existing downtown businesses out to the bypass."

The study also found that "factories may be more likely to be among the first types of businesses to locate at the bypass, due to reduced travel costs" (Thompson et al., 2001).

\subsubsection{Kansas - Econometrics}

The 2004 report Case Studies of the Economic Impacts of Highway Bypasses in Kansas used ordinary least squares (OLS) regression to quantify the impact on annual average total employment in bypassed cities. Total employment of the bypasses cities were regressed with respect to total employment of corresponding control cities (all bypass cities had more than one control city) and an indicator variable indicating whether a bypass had been built. Control cities were chosen based on geographic location and similar economic characteristics (Babcock and Davalos, 2004).

Bypasses did not have a statistically significant effect on total employment. However, the majority (76 percent) of storeowners and managers interviewed believed that retail sales levels in bypassed cities would have been higher had 
the bypass not been constructed. While some of these establishments did adapt to the bypass's presence via the introduction of new products or services, the study noted that "the ability of a travel-related business to increase sales in a local market is limited... [t] he loss of transient auto traffic permanently reduces the demand for travel-related businesses in a bypass town" (Babcock and Davalos, 2004). The study further noted that these travel-dependent businesses also had the option of relocating to the bypass, though relocation may prove beyond the means of many storeowners. 


\subsection{State Agency Evaluations of Proposed Bypasses}

\subsubsection{Indiana Department of Transportation (INDOT) Policies}

The Bypass Project Selection Criteria (Policy 12) currently used by the INDOT Planning Oversight Committee (IPOC) focuses primarily on transportation efficiency. More points are awarded based on the number of congested areas avoided by a bypass, community size, average daily traffic, truck diversion, ADT diversion, and volume-to-capacity ratio. The policy also evaluated cost effectiveness and "percent complete in development."

Economic Development and Customer Impact Factors (Policy 6) are also emphasized when considering the construction of a bypass. The policy assigns a greater number of points to a greater number of jobs created and areas with high unemployment relative to the state. The scoring metric for Customer Input, as specified by the FHWA and Code of Federal Regulations, accounts for the sentiments of primary stakeholders. Slightly greater emphasis is placed on input from Metropolitan Planning Organizations (such as the Madison County Council of Governments) and Regional Planning Organizations (such as Region III-A). Points are also assigned based on local elected officials (mayors and county commissioners) and citizen and legislative input. Projects ranked in the "top 20 percent" for each agency receive a greater number of points.

These criteria do not directly address potential steps a city or county may have to take to "adjust" to the presence of a bypass. The declines of the downtowns of bypassed cities in Indiana are thought to have occurred partly due to ineffective planning policies. Comprehensive Plans for some cities were not updated for 
over 40 years. The lack of these planning policies could prove a hindrance to a city's continued economic development. Though hard to quantify, the "readiness" of a city and/or county to adapt should be addressed in IPOC Policy 12.

\subsubsection{Ohio Department of Transportation (ODOT) Policies}

The 1999 Ohio Department of Transportation report ODOT Process for Evaluating Requests for Bypasses outlines the agency's procedures for identifying the need for a bypass. Such a process could be combined with Policy 12 and the findings of this project to form a "Bypass Action Plan" that clearly defines the factors to be considered when a bypass is requested or posed. ODOT's procedures are outlined below:

\section{The First Meeting}

As defined by the policy, the purpose of the first meeting is to "...confirm and clarify the goals and need for the bypass as defined by local officials."

\section{Ohio Department of Transportation's Participants}

(1) ODOT Planning Administrator or District Deputy Director

(2) Evaluation team

(3) Local project sponsors

(4) Local elected officials with responsibility for the transportation system in the project areas.

\section{Proposed Additional Participants}

(5) Local chamber(s) of commerce

(6) Key members of local economic development foundations

(7) Local historian(s) 


\section{The Second Meeting}

This meeting would take the form of open house or public hearing held in the area of the proposed bypass, advertised through local media. Per the policy, additional meetings should be scheduled "if there is a significant difference between the two groups."

\section{Ohio Department of Transportation's Participants}

(1) Interested local public interest groups

(2) Regional planning and economic development agencies

(3) Local chambers of commerce

(4) Other potential stakeholders

\section{Proposed Modifications to Second Meeting}

(1) Broadcast to local stations, stream on Internet

(2) Post transcript or podcast on local websites

Motivation for moving participants (2)-(3) to first meeting: To allow parties with alternative perspectives to enter into the decision process earlier...get "the foot in the door."

\section{Letter Report}

The Letter Report, prepared by District Staff, prepares a report that clarifies and confirms the "locally defined need for and goals for the requested bypass." Requirements for the Letter Report are explicitly defined: "This report must be either countersigned or in some way acknowledged or further clarified in writing by the local elected officials including at a minimum the center city and county in which the bypass would be constructed." 


\section{Ohio Department of Transportation's Participants}

(1) ODOT District staff

(2) Local elected officials from minimum of center city and county

\section{Proposed Additional Participants}

(3) Key member of local economic development foundations

(4) Local chamber(s) of commerce

Motivation for proposed additional participants: To allow a more diverse array of parties to further participate in the decision process and "make it official."

\subsection{Identification of Issues to be Addressed}

The majority of the studies outlined above focused on travel-dependent businesses, in particular, eating and drinking places, gasoline service stations, and hotels and motels. These studies, in general, examined how retail sales were impacted as a result of a bypass's construction. In the short-term, traffic-related businesses located along an original alignment will likely suffer a decline in sales. If a city has a built-in local customer base, its downtown will continue to prosper. The improved geometry of bypasses will encourage development of basic industries. The literature review has raised the following questions:

1) What long-term, cumulative, and indirect impacts do bypasses have on economic development?

2) How are non-sales-related and non-traffic-dependent industries affected? 
3) How will the presence of a bypass impact a city or county's contribution to the entire state's economy?

4) How will employment levels in various industry sectors, payroll levels, and the number of establishments be affected?

5) For cities without bypasses but with heavy truck traffic, will its economy be adversely impacted if a bypass were not built?

6) If a city or county has an established diversified manufacturing presence, will the presence of a bypass encourage future growth?

7) What is the general time lag between a bypass's construction and the actual effects being realized?

8) Can a statistical link be established between the presence of a bypass and changes in employment and economic growth in general? And if so, can quantitative methods be used to predict the impacts of future bypasses?

9) Do the trends outlined in the literature review apply to cities and counties in Indiana?

10) When a city requests a bypass be built, what data can be used to help determine (a) whether a bypass would be appropriate for the city and (b) whether the construction of such a bypass is feasible.

These issues will be addressed in the following sections. The long-term impacts of communities with bypasses and communities without bypasses are discussed 
in the following chapter. The impacts on employment and payroll in various industry sectors are explored in Chapter 4. 


\section{CHAPTER 3. PROFILES OF AFFECTED CITIES}

\subsection{Introduction}

To capture the long-term effects of a bypass (or lack of a bypass), a two-pronged approach was undertaken. Econometric models were constructed in an attempt to establish a statistical link between the presence of a bypass and long-term changes in employment and other characteristics. These models and their implications are discussed in Chapter 4.

To obtain a complete and accurate picture of a bypassed city's changes over time, interviews were conducted with a sample of community officials, representing the interests of the community, the county, the region, local industry, and local and downtown businesses. Each city's profile will cover the following characteristics:

(1) A general background of the city, including principal industries and noteworthy attractions.

(2) Descriptions of how the city was impacted by the presence of a bypass or what impacts are expected if a bypass were to be built.

(3) What policies have been or will be adopted in response to the bypass's construction. 
A map of Indiana showing the location of each city selected for study is shown in Figure 3.1. 


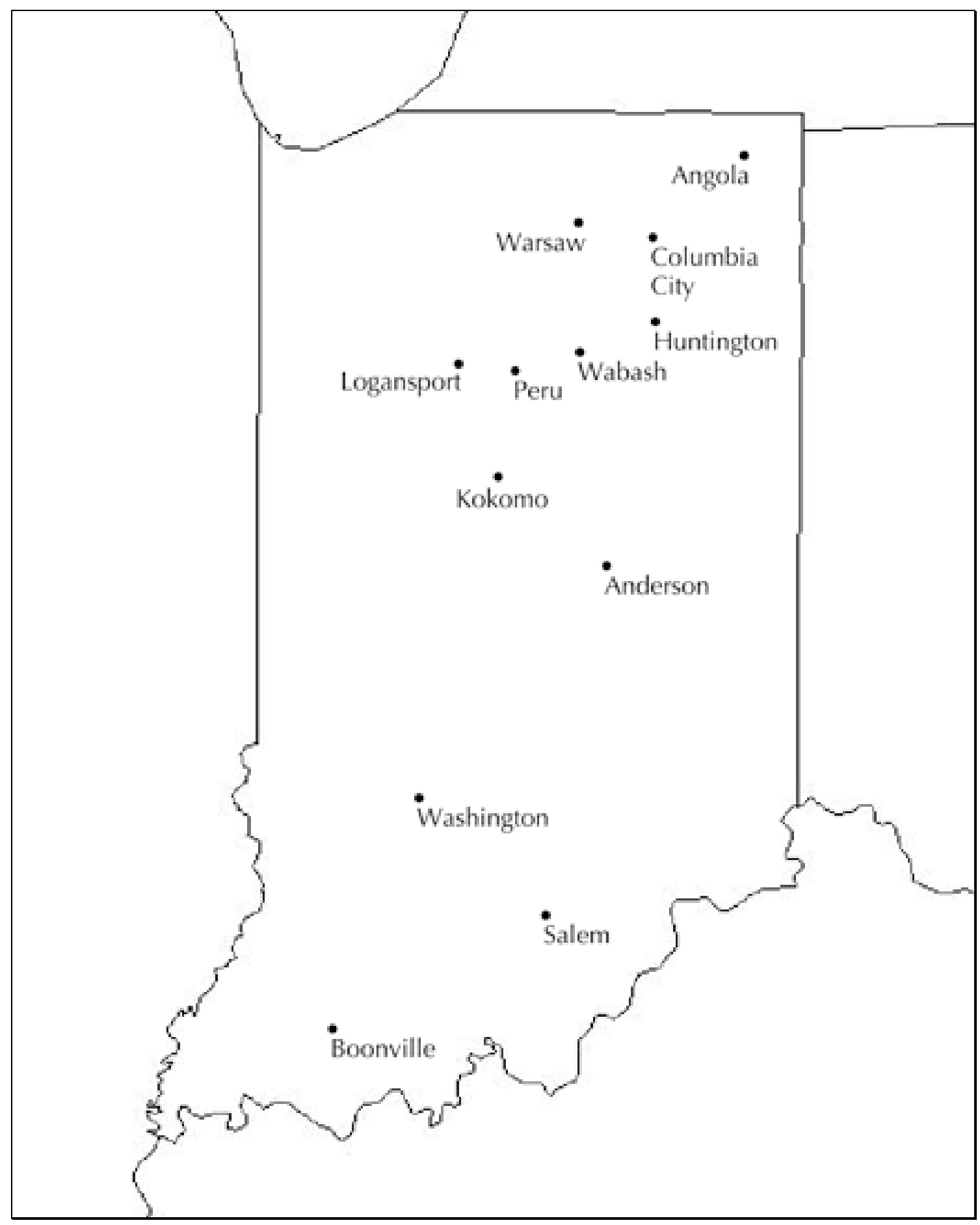

Figure 3.1 Approximate locations of cities selected for study. Map outline from http://z.about.com/d/geography/1/0/k///in.jpg. 


\subsection{Logansport}

\subsubsection{Background}

Logansport, located in Cass County, Indiana and bounded by the Wabash and Eel Rivers, serves as an intermodal regional hub for the north central Indiana area. US-24, historically the city's principal street, serves as one of the few eastwest corridors running through the region. The city has a more diverse economy than the typical Indiana town, with agribusiness, manufacturing (particularly the automobile industry), and distribution facilities. Prominent employers in the area include Tyson, Hanson Cold Storage, Federal-Mogul, and Small Parts Inc.

Historically, transportation has played an important role in maintaining economic vitality in Logansport; the Norfolk-Southern rail line runs through the downtown area, and in the 1920s, a Conrail rail line ran through Logansport, connecting St. Louis, MO, to South Bend, IN, Columbus, OH, Cincinnati, and Toledo. US-24 and US-30 to the north serve as the only major east-west corridors through north central Indiana.

The city also serves as an educational hub, with a 18 schools, a career center, and a planned $\$ 17$ million Ivy Tech campus, scheduled to open in 2011. The city also hosts a number of health care facilities, including a regional cancer center, a dialysis center, and senior housing, according to Dave Kitchell, formerly of the Pharos-Tribune newspaper.

The city is also home to two juvenile detention centers, the only such centers between Kokomo and South Bend. The regional airport has recently undergone an 
expansion. Several parks are near Logansport, including France Park, and a local carousel attracts visitors.

\subsubsection{Downtown Logansport}

In the past, retail stores were located in the downtown areas, together with institutional and professional/service centers. However, the majority of retail businesses have relocated to the eastern portion of the city, where a shopping mall and several strip malls had been built in the 1970s and 1980s, according to Shae Young, Executive Director of Logan's Landing, an organization focused on the redevelopment of downtown. Today, the downtown area serves mainly professional and institutional interests, with the majority of retail businesses located on the east side of the city.

Downtown as a whole began to deteriorate with the exodus of retail stores to the east side. No design guidelines were in place for downtown buildings in the 1970s and 1980s, Young said. Many of the existing buildings were torn down, leaving behind a large number of vacant lots, Young said. By the late 1980s, the vacancy rate had risen to $40-45$ percent, she added.

At present, many of the buildings are old and in poor shape structurally; this remains the case after the construction of the US-24 bypass. However, because the buildings in the downtown area are relatively inexpensive $(\sim 70,000)$, the central business district has attracted a number of entrepreneurs, according to Nolan "Skip" Kuker, director of the Logansport/Cass County Economic Development Foundation (LEDF).

The city has seen an influx of Hispanic population over the past eight years (due to the surplus of available jobs at the Tyson plant), and now Hispanic-oriented 
shops occupy a number of downtown buildings. According to Young, a number of jewelry stores, antique stores cell phone retail stores, and other stores with "specialized" stores have expressed interest in establishing a presence downtown. The vacancy rate has "decreased substantially," she said.

The LEDF has implemented a program to encourage entrepreneurs to base their startups in Logansport via a business plan writing contest entitled "Succeed" and dedicated "incubator" research space.

The relatively cheap building prices downtown have also attracted developers to the CBD. Recently, a developer from Los Angeles CA purchased and renovated a building located in the downtown area. According to Kitchell, this developer has plans to purchase additional properties. However, it is uncertain what role the bypass has played in attracting entrepreneurs and developers.

Since the construction of the bypass, truck traffic has decreased through the downtown area, although the decrease has not been as much as expected by local residents, because IN-25, IN-17, and Business US-24 continue to run through the town. Traffic is heavier downtown than it is on the bypass, Young said.

Figure 3.2 shows aerial photos of the Logansport area. Figure 3.3 shows samples of guide signage on the bypass. 

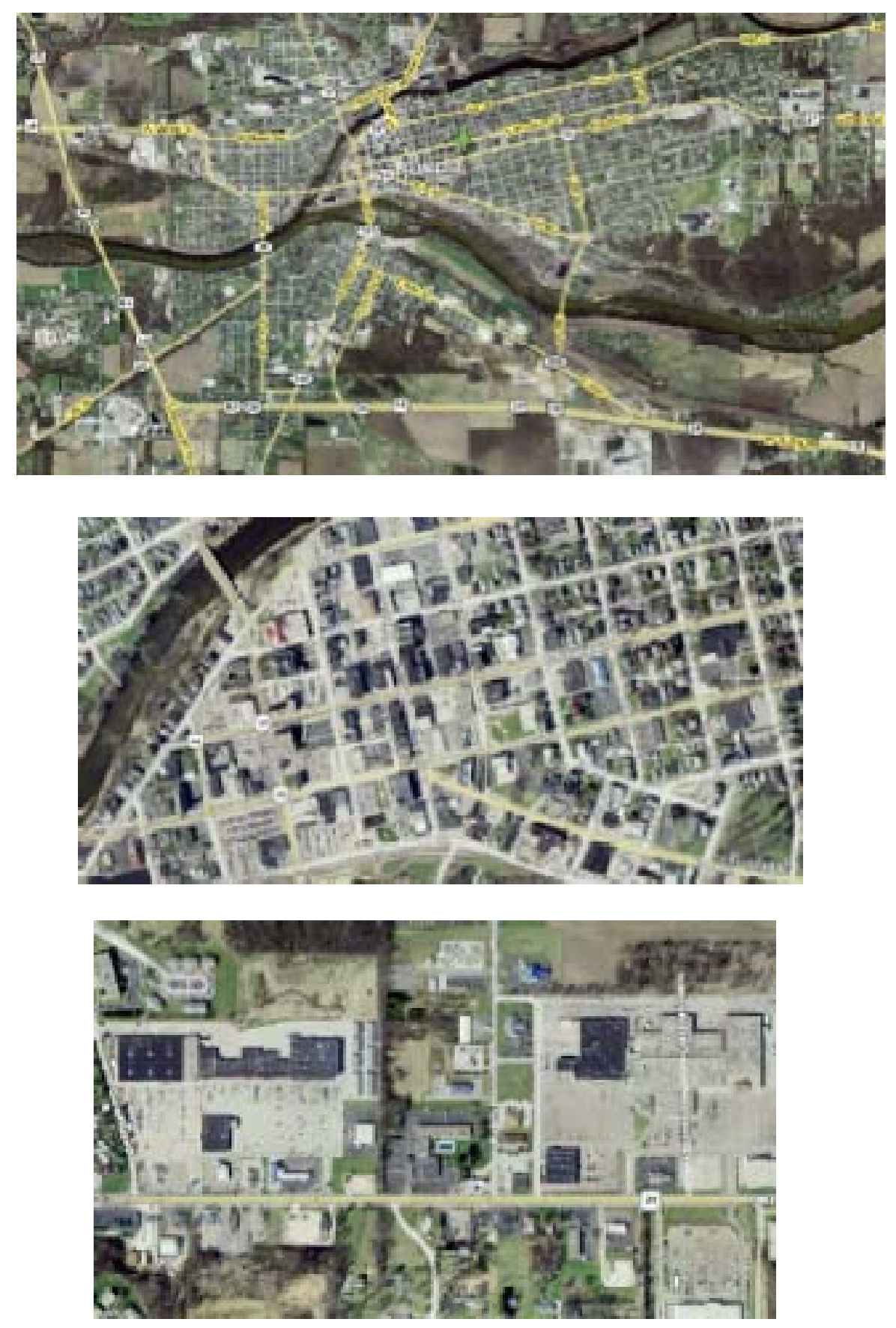

Figure 3.2 (Top) Aerial photo of Logansport. The US-24 bypass is located on the southern side of the city. (Middle) Inset of Downtown Logansport. Business US-24 runs along Broadway Street and Market Street. (Bottom) Inset of east side of Logansport. This area is dominated by retail businesses. Top photo from Google Maps. Middle and bottom photos from Google Earth. 


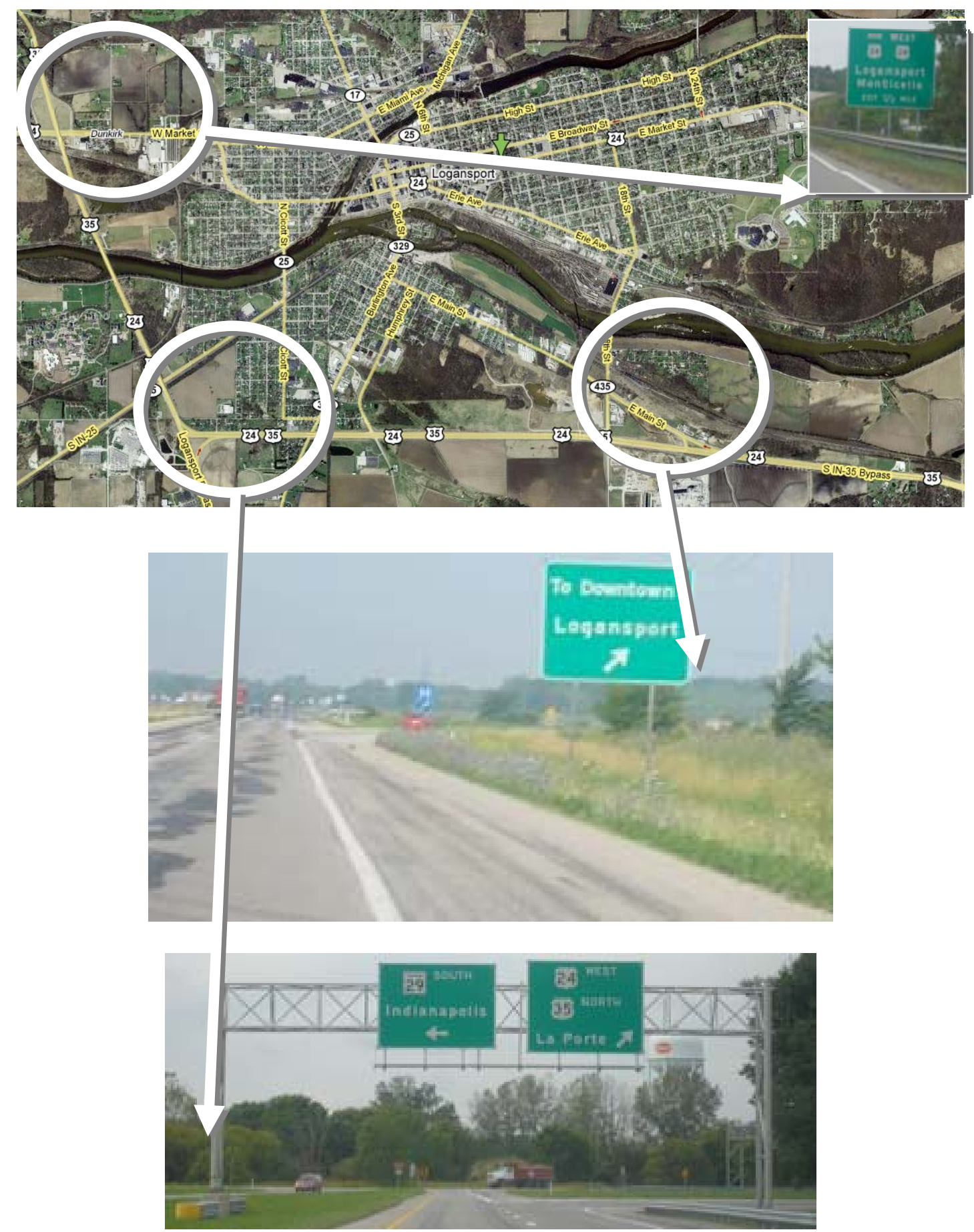

Figure 3.3 (Top inset) Guide sign near US-24, US-35 split, heading west on bypass. (Middle) Guide sign directing drivers to downtown Logansport. Note the awkward placement of "To Downtown" and the lack of specific service signs. (Bottom) Guide sign at US-24-35, IN-29 split. Note the Tyson plant in the background. Aerial photo from Google Maps. Guide sign photos by J. Mills. 


\subsubsection{US-24 in Logansport: Before and After}

US-24 originally ran along Market and Broadway Streets through Logansport. The US highway was relocated in 2001 with the construction of a four-lane, limited-access bypass, part of the Hoosier Heartland Industrial Corridor (HHIC), south of the city. The old alignment through Logansport is currently designated "Business" US-24.

\subsubsection{Impacts of the US-24 Bypass}

Local officials and industry representatives welcomed the construction of the bypass. The old two-lane alignment of US-24 through Indiana, built in the 1930s, was "terrible for commerce," according to local officials.

The bypass also facilitated additional industrial development. A new ethanol processing facility opened in Clymers in 2007, located just south of the bypass. This facility is projected to generate a large volume of trucks per day, to be served by the planned IN-25 component of the HHIC, according to local officials. A new industrial park recently opened close to the bypass, with such businesses as Federal-Mogul, Angle Trucking, a long-distance trucking company, and the international headquarters of Matthew Warren Co, a spring and fastener manufacturer.

East side businesses have been most affected by the construction of the bypass, particularly hotels, gas stations and fast food restaurants. Recent trips to the east side of Logansport have revealed a number of shuttered restaurants and gas stations. Steps were taken to mitigate the situation and ease concerns of east side business owners. A proposed Super-2 connecting the bypass to the east side of the city was tabled due to high financial costs. However, occupancy on the east 
side has been "heavily increasing" as of late, according to Kuker. At present, a $\$ 200,000$ Holiday Inn Express has been constructed on East Market Street. According to Kuker, the owner wanted the hotel to be located near local restaurants; no such restaurants (or any other type of commercial development) are located near the bypass. More development will occur when the remaining portion of the HHIC, the realignment of IN-25 between Lafayette and Logansport, is complete, Young said.

\subsubsection{Recent Developments}

In efforts to revitalize downtown, city officials, the LEDF, and the Logan's Landing Downtown Development Review Board have implemented several programs. These programs include the improvement of façades of downtown buildings, the implementation of design standards to give the town a main identity, the use of brick pavers, streetscapers, special benches, special lighting in the form of old-fashioned and more energy-efficient streetlights, and a proposed trail system running from the future Ivy Tech campus to nearby parks.

The local Chamber of Commerce has implemented plans to post wayfinder signage of one design and color. These signs will direct visitors to city attractions, such as the carousel, local parks, and governmental-type entities. According to Kuker, the use of uniform signage will make the community more visually appealing. Such signage also is planned to be posted on the US-24 bypass. However, the Chamber of Commerce is having difficulty negotiating with INDOT regarding the posting of these signs. INDOT regulations stipulate commonality and uniformity for all signage to avoid a "patchwork quilt." According to Kuker, if non-standard signs are not maintained, the state is held liable and will remove such signs. 
The Tourism Bureau has taken steps to market Logansport to outside tourists. Logansport needs a strategy to "pull people off [the bypass] easier," according to Kuker. Marketing of the city is funded by a "bed tax" for hotels in Cass County, which amounts to 3 percent of the room rate of hotels. The Tourism Bureau is marketing the town in the form of brochures and a website, advertising attractions such as the county parks systems. Other possible angles for advertising include a one-tank trip (an excursion that can be made from home and back on one tank of gas), a place to go after a Purdue home game, or a place to grab a meatball sandwich. Advertising is the key to attracting visitors to Logansport, according to Kuker.

\subsection{Peru}

\subsubsection{Background}

Peru's primary industries include agriculture, warehousing, manufacturing (particularly transportation manufacturing), and tourism. Prominent employers include Bryan Boilers, Orion Safety Products, ConAgra, and the Grissom Air Reserve Base. Tourist attractions include the Grissom Aviation Museum, the Cole Porter Birthplace, the Peru Amateur Circus, and the International Circus Hall of Fame.

\subsubsection{Impacts of the US-24 Bypass}

Principal routes in Miami County include US-24, US-31, and IN-19 (see Figure 3.4). The realignment of US-24 has occurred in several stages due to funding issues, with the most recent portion opening in 2000, according to James Walker, Mayor of Peru. The completion of the US-24 bypass in 2000 has provided the 
county with greater accessibility to other counties, according to Jim Tidd, Executive Director of the Miami County Economic Development Authority.

Both US-24 and US-31 represent critical components to the county's growth, he said. Recent locations of new businesses in the county have been based on the accessibility provided by both US highways to nearby interstates, according to Tidd. When the IN-25 component of the Hoosier Heartland Industrial Corridor is completed, thus providing a four-lane connection from I-65 to I-69, the positive effects are expected to expand. The segment of the HHIC between Lafayette and Logansport must be completed for the full benefits of the four-lane US-24 to be realized.

Additionally, development has been limited along the corridor, not because of a lack of interest, but due to its location in a floodplain, Walker said. The realignment of US-24 runs through a prairie ditch that has been designated as a floodplain by the Department of Natural Resources (DNR) and the Federal Emergency Management Agency (FEMA). The floodplain runs from the eastern edge of Peru and ties into the Wabash River near Logansport, Walker said. 


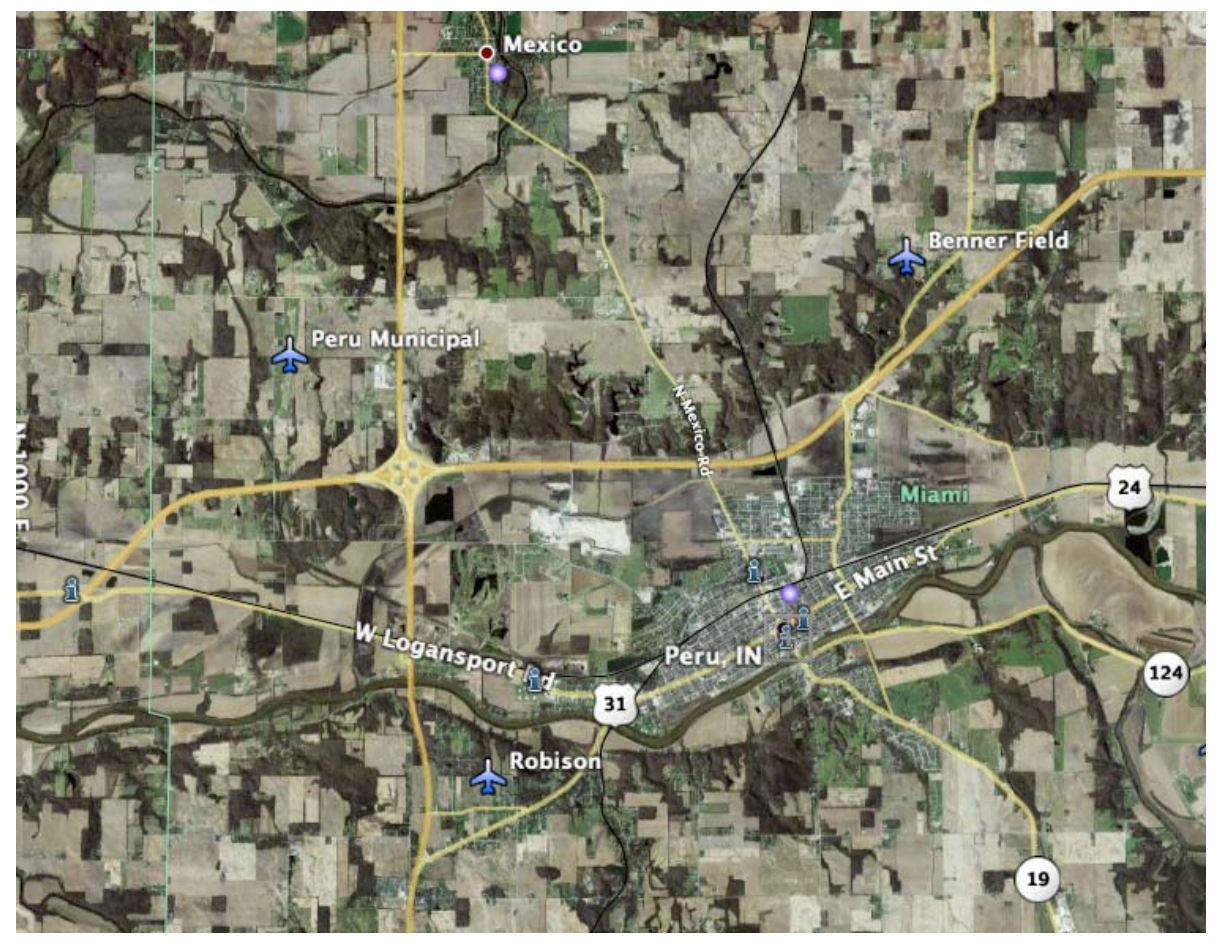

Figure 3.4 Aerial photo of Peru and surrounding area. The four-lane US-24 and US-31 bypasses run to the north and west of Peru, respectively. The old alignments of the two routes are shown on the aerial. Grissom Air Reserve Base (and the Grissom Aeroplex industrial park) are located to the south along US-31 (Source: Google Earth).

The city is currently undertaking research to show that the prairie ditch is not at risk for flooding. Development has been limited thus far due to potentially high insurance and construction costs associated with bringing a building site to elevation. The city has been proactive in attracting developers to the area. The city has seen a great increase in the number of interested developers in the past two years, Walker said.

Peru has experienced difficult economic conditions in recent years, Walker said. The realignment of the Grissom Air Force Base as an Air Reserve Base put a "big pinch" on the economy, as did the loss of a number of railroad jobs. The city, together with the MDECA, has been working to bring new development into the community. The construction of a prison near Peru has added 400 jobs, and local 
entrepreneurs are locating in the community. The city has a lot of new construction in the community, and the economy is heading in the right direction, Walker said.

In planning the rerouting of US-24, the City of Peru and Miami County have had representatives sit on the board of the Hoosier Heartland Industrial Corridor. Other board members include representatives from Logansport, Wabash, and Huntington. The board has helped to decide what path the realignment of US-24 should take and how the realignment will be funded. A lobbying group works with the HHIC board to petition lawmakers in Washington to ensure funding continues to take place. Public meetings asking for input have been held in the past, but these meetings have been sparsely attended on many occasions. Walker reasoned that the public in general wants to see better roads; citizens will only be inclined to attend a public meeting if they do not want a roadway coming through their property, Walker said.

The bypass has significantly impacted the CBD of Peru. Since its completion, retail businesses have begun to relocate closer to the bypass. The CBD currently has "a lot" of vacant and underutilized buildings, and the vacancy rate has increased over time, though Kroger and Marsh grocery stores located near the CBD have been successful, Tidd said. However, the close proximity of the bypass to the downtown is "fortunate," according to Walker, because the downtown could be continued out to the bypass. Walker envisions the corridor as becoming an extension of downtown instead of having separate patches of development. The city has faced the reality that the bypass is there and it's not going to change. The close proximity of the downtown to the bypass "erases" some of the potential negative effects on the downtown, Walker said. 
The MCEDA recently completed a strategy approximately a year ago that aims to attract more novelty and tourist-oriented shops to the downtown. The use of signage and branding is also outlined in the strategy, with the goal of attracting people from US-24 to the downtown. Part of the strategy includes making the intersection of North Broadway and US-24 into an "attractive gateway" to draw people into downtown Peru, Walker said.

On the positive side, the bypass has attracted retail and commercial development. The Bob Schwartz Ford dealership recently expanded, as well as the local credit union and bank. "Significant" retail development is expected in the future, Tidd said. Frontage roads were built to ensure US-24 remained limited-access and to limit the need for future cuts, Tidd said. Walker said that community officials are working with downtown merchants to ensure the downtown stays vibrant. A number of these merchants sit on the Mayor's Cabinet, which meets once a month. Continuing communication and working together is the key developing a plan so that no one is adversely affected, Walker said.

In response to the bypass's construction, the city has laid out plans and rezoned property to attract developers. Many properties have been rezoned from agricultural to business development. Once the floodplain issue is resolved, water and sewer lines may be extended out to the area, Walker said. Sixty acres have been annexed into the city.

The increased accessibility brought by the HHIC (of which the US-24 bypass to the north of Peru is a part) will also improve the local tourist industry. Most residents in the six-county region of Fulton, Cass, Howard, Tipton, Miami, and Wabash counties work within the region, according to Tidd. The decreased travel time (and consequently, decreased transportation costs) to and from Miami 
County and Peru with the presence of both US-24 and US-31 provide important selling points in attracting businesses to the area.

The bypass will allow for better economic times for the community. It will have a positive effect on the community's future, Walker said.

\subsection{Wabash}

\subsubsection{Background}

The county seat of Wabash County, the city of Wabash is located 16 miles east of Peru, 20 miles northwest of Marion, and 17 miles west of Huntington. Manufacturing and agriculture are the dominant industries in the county, accounting to William Konyha, President of the Economic Development Group of Wabash County. The city's economy was "robust" in the 1970s with the highest level of employment in its history, prior to the "rapid downward spiral" that took place in the 1980s, according to Konyha.

He attributed this decline to overdependence on the American automobile manufacturing industry. Community members were once reluctant to "alter our direction and seek more diversity," he said. The county has 1600 fewer jobs today than it did in 1990. The population has continued to decline and age rapidly, at rates higher than the state average, he added.

\subsubsection{Impacts of the US-24 Bypass}

The US-24 bypass has become a commercial corridor for the city, Konyha said. While the bypass has improved accessibility to Huntington and Fort Wayne, the route cannot be judged as successful until the final portion of the HHIC from Lo- 
gansport to Lafayette is completed, thereby connecting Interstate 65 to Interstate 69 , he said. While public sentiment toward the bypass is favorable, most people have not seen the benefit that was expected to be received, which Konyha said was understandable, given that the route provides "half an access" to only one Interstate highway.

Frontage roads were built to keep the bypass limited-access. The County Zoning Ordinance has been updated in response to the "bypass." Within a 2-mile limit, areas have been rezoned for commercial, retail, light industrial, and multi-family residential developments. The policies have been effective so far, according to Konyha.

Since the bypass's opening, various commercial and retail establishments (including a Wal-Mart Supercenter and strip malls) have established a presence near the bypass, and condominiums have also been built, Konyha said. However, the Comprehensive Plan has not been updated since 1968. Many people in the agricultural community find such plans to be a waste of time and money, he said, and past officials have not been forward-looking, Konyha said.

The improved travel times provided by the bypass have already benefited the Honeywell Center, an entertainment center that's part of an emerging entertainment district, according to Konyha. The center hosts a variety of events, ranging from ballet to county-western shows, which attract thousands of people into the community each year, he said. A side effect, however, has been the loss of retail businesses from the downtown Wabash as they relocate closer to the bypass. City officials want to further develop the entertainment district in downtown Wabash by attracting night clubs, an ice cream shop, and art galleries, he said. 
The city is now implementing asset-based economic development, which focuses on playing to the city's strengths in the manufacturing and agriculture industries and uses those assets as a resource in attracting businesses, Konyha said. Prior to the bypass's construction, the city had been competing with larger areas such as Indianapolis for businesses that depend on just-in-time delivery, which is characteristic of Tier-1 and Tier-2 manufacturing companies, according to Konyha.

Asset-based economic development was adopted to ensure economic growth in the county, even if immediate access to Interstate highways, a typical requirement for just-in-time delivery, was not available. Agriculture products typically do not require just-in-time delivery, so the EDG has been attracting businesses that specialize in agriculture, such as a bioenergy firm that is ready to be constructed, Konyha said.

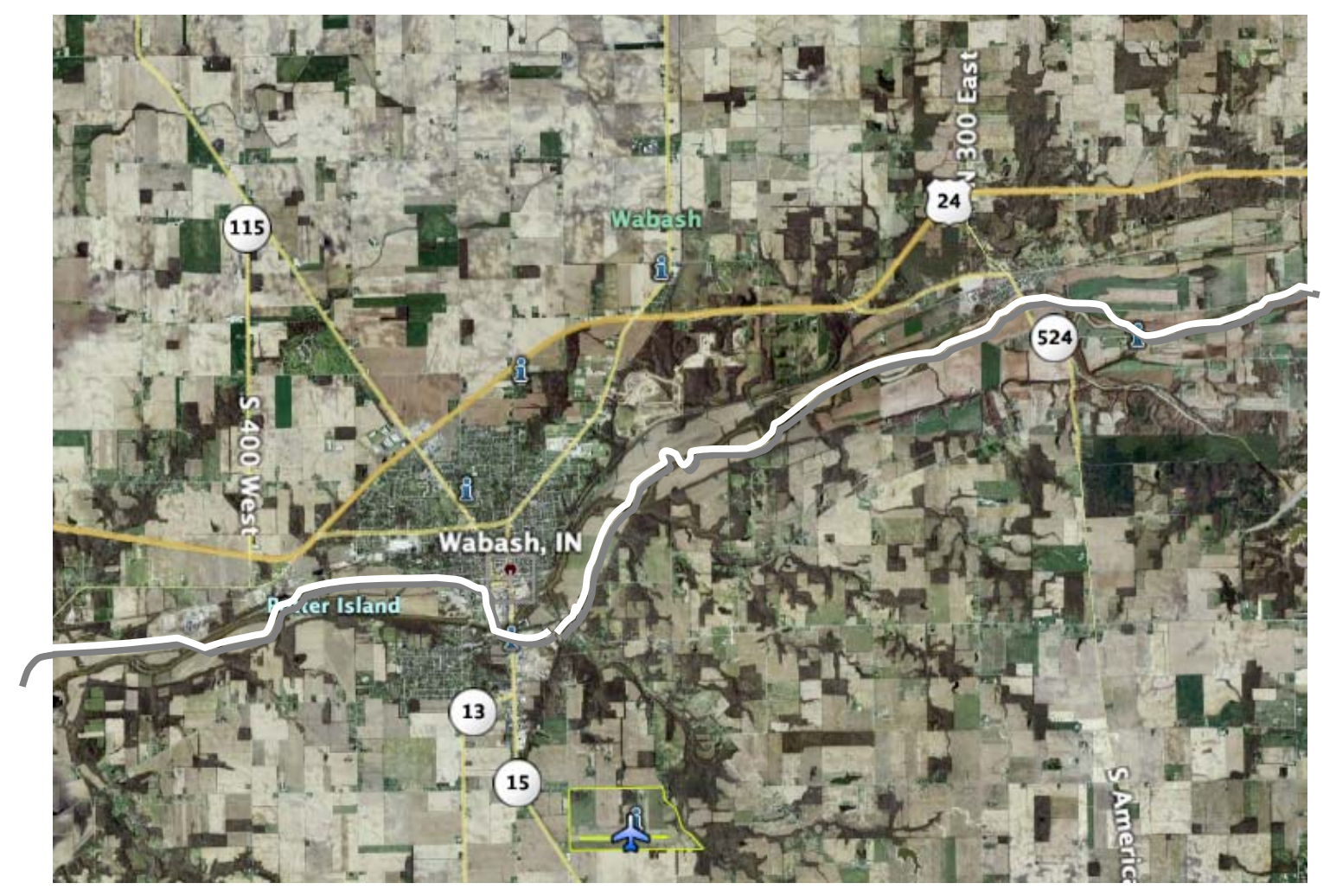

Figure 3.5 Aerial photo of Wabash. The white line denotes the approximate original alignment of US-24 (Source: Google Earth). 
The most significant impact of the bypass has been providing an easier and safer route to Fort Wayne. However, because the old alignment of US-24 was relinquished, the county has had to take over maintenance of the road. Because of how money is distributed, the maintenance budget for maintaining the original alignment has decreased every year, Konyha said. The city has not been able to take advantage of the bypass from a business standpoint and will not be able to do so until the final portion of the HHIC is completed, he said.

\subsection{Huntington}

\subsubsection{Background}

Located 20 miles southwest of Fort Wayne, Huntington County is host to a number of industries, particularly manufacturing, including sheet metal and aluminum operations, and electronic controls and sensors. A number of distribution and logistics centers are also located in Huntington County. Major employers in the area include Wabash Technologies, United Tech. Electronic Controls, and Bendix Comm. Vehicle Systems, according to Huntington County United Economic Development (HCUED).

Area attractions include J. Edward Roush Lake, the Salamonie Reservoir, Sunken Gardens, and the Dan Quayle Center \& Museum. J. Edward Roush Lake attracts thousands of visitors a year, according to local officials.

\subsubsection{Bypass Construction and Zoning Changes}

The current alignment of US-24 around the city of Huntington, completed in 1964, was intended to serve as a bypass. The original alignment ran through the 
central business district, south of the new alignment. According to Nate Schacht, director of the Huntington County Office of Community Development, the primary purpose of the bypass's construction was to remove heavy traffic from residential districts, along which the original alignment was routed.

Vibrations from jake brakes on semis accelerated wear and tear on the downtown's roads and were in particular breaking apart the historic castle located to the north of the CBD, Schacht said. Exhaust from the trucks was dirtying up downtown buildings. Huntington's economy was stagnant prior to the bypass's construction, Schacht recalled.

Large retail areas have built up around the bypass in the years following its opening. Residential development has occurred primarily to the north of the bypass, Schacht said. Recently, the Wal-Mart located near the bypass reopened as a Wal-Mart Supercenter, and a hospital recently moved from downtown to the bypass due to reduced travel times, according to Schacht. At present, the new US24 "bisects" Huntington, with two major shopping areas near the route, according to Robert Brown Jr., President of the Huntington County Chamber of Commerce.

Huntington differs from other towns bypassed by US-24 in that through travelers see the city from the view of US-24, according to Brown. Retail development along the bypass began about 13 years ago with the construction of a Wal-Mart near the bypass. Other developments near the area include K-Mart.

Low-intensity commercial districts were established following the bypass's construction. In the late 1960s, community officials added more intense commercial areas and established an office park (currently at 50 percent capacity) and two 
industrial parks (currently at 85-90 percent capacity), according to Schacht. In the present day, the industrial parks are host to eight different industries, each of which employs an average of 100-200 jobs, he said. Economic growth in the city has been driven primarily by expansions of existing industry in the area, according to Brown.

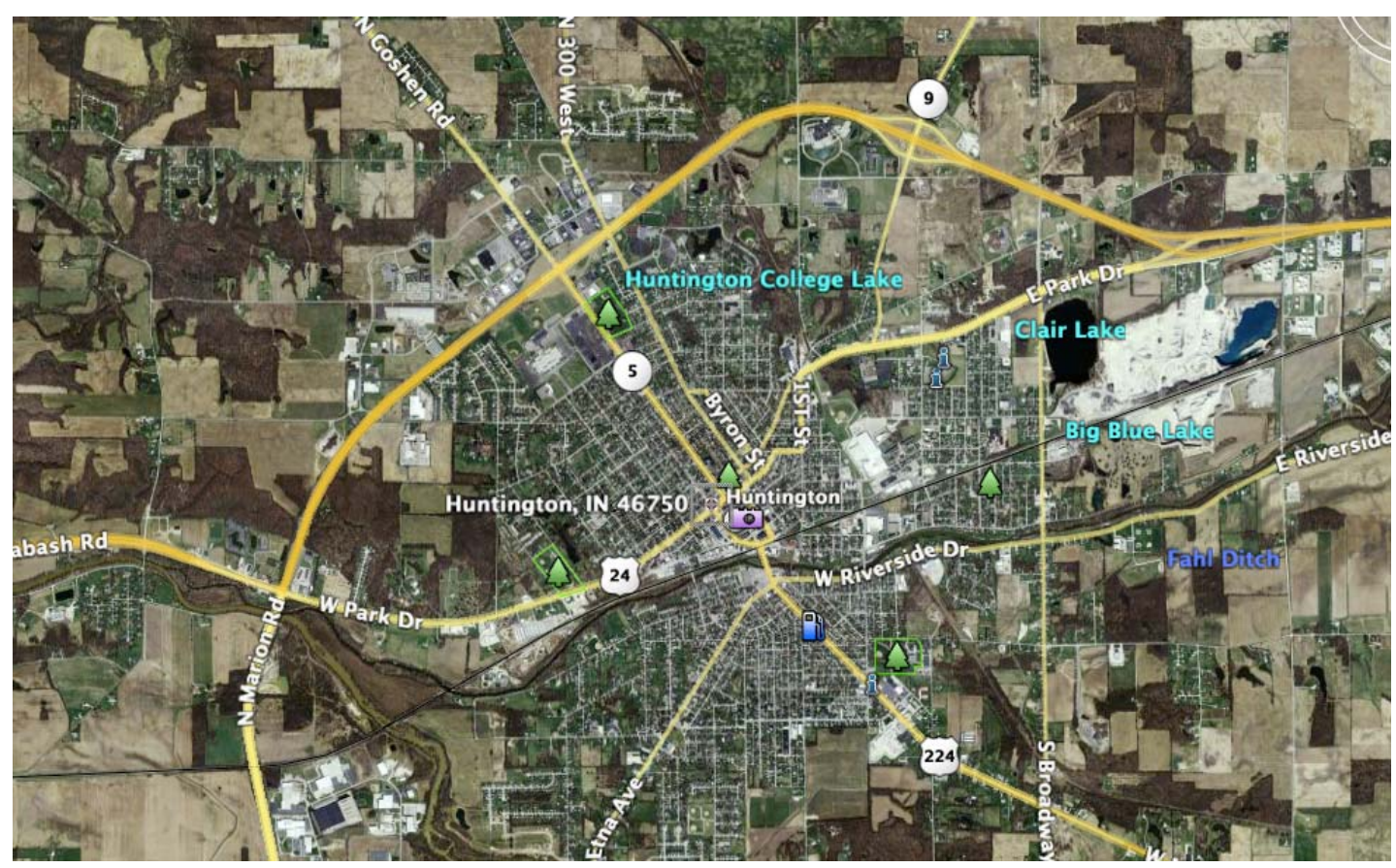

Figure 3.6 Aerial photo of Huntington, IN. US-24 bypases the CBD to the north. US224 terminates at US-24 (Source: Google Earth). 


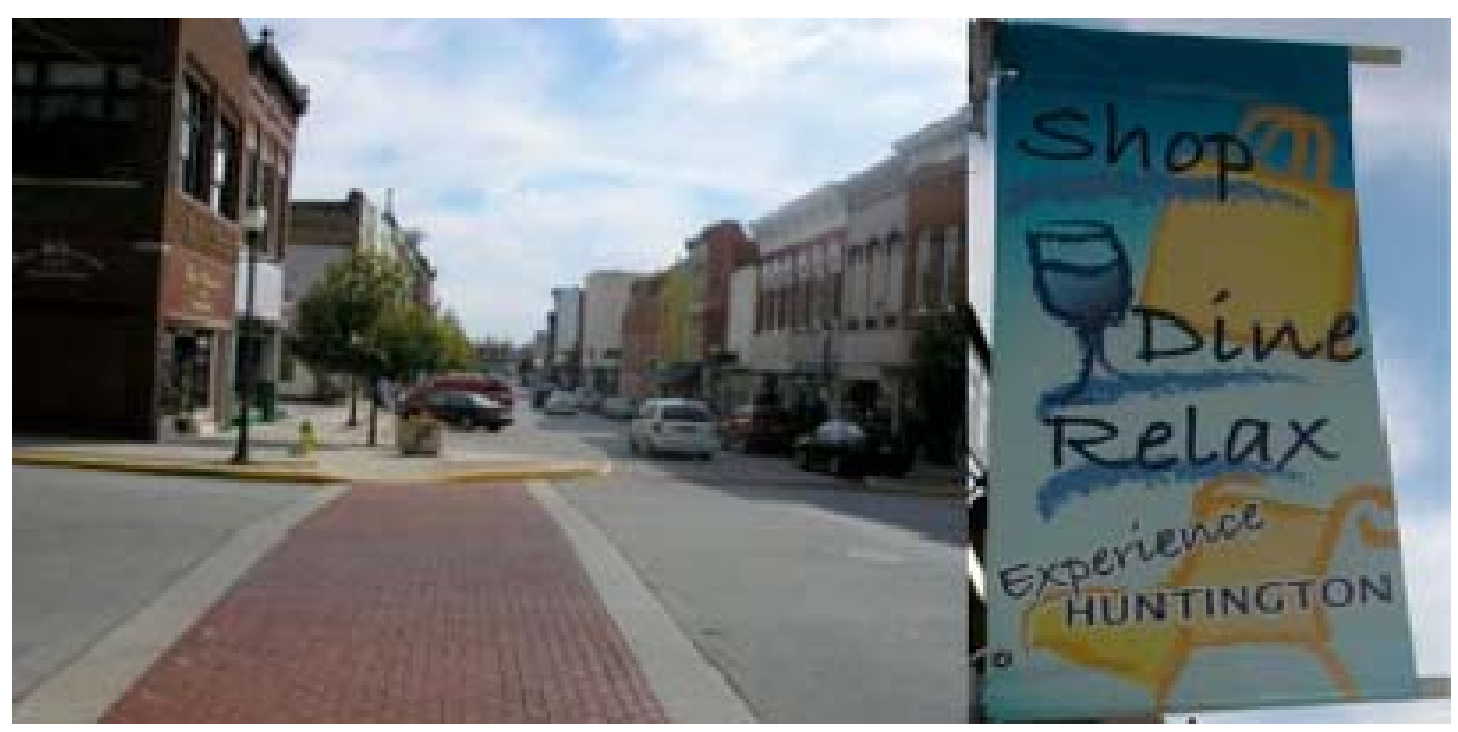

Figure 3.7 (Left) View of Jefferson Street in downtown Huntington. (Right) Sign promoting the shops of downtown Huntington (Photos by J. Mills).

\subsubsection{Impacts on Businesses and Residents}

The downtown used to be a hub where people would go for grocery shopping, according to Schacht. Traffic-dependent businesses were most impacted by the opening of the US-24 bypass, according to Brown. Over time, retail businesses located in the CBD closed or relocated near the bypass, creating a void for downtown businesses. "Specialty markets" including insurance companies, legal services, and arts \& crafts moved into the CBD as time progressed (see Figure 3.7, above). Not-for-profit organizations were the first to establish a presence along the limited-access bypass, with retail business moving in later. Big-box retail stores began to establish a presence on the bypass whereas the CBD became more service-oriented.

According to Brown, the vacancy rate within the CBD remained constant or decreased slightly following the bypass's construction. Many of the buildings in the CBD are 2-3 stories. The occupancy of the first floor of these buildings is close to 90 percent, a slight decrease, whereas the second and third floors average 40 per- 
cent occupancy, a major decrease, according to Schacht. The second and third stories of many of these buildings served as apartments for the local shopkeepers, he said.

Parking has historically been one of the issues affecting the downtown. This problem may have been exacerbated when Huntington decided to turn the downtown into a pedestrian mall. This was done by blocking off two streets, allowing only pedestrian traffic. This proved problematic for retail stores, particularly grocery stores, given that most customers would not want to carry large bags of groceries long distances on foot. The grocery stores found the land near the bypass to be far more accessible and relocated there. The establishment of the pedestrian mall (no longer there) altered the downtown to the greatest extent, Schacht said, whereas the bypass had the biggest positive impact on the total economic development on the city of Huntington, he said. Service-oriented businesses, such as doctors' offices, which are more pedestrian-oriented, located downtown over time. To cope with limited parking, doctors' offices schedule appointments based on how many parking spaces will be filled at a given time. Restaurants remaining in the area only open in the evenings so they do not have to compete with all-day restaurants located on the bypass, Schacht said.

Despite the decline of downtown Huntington, the easy access of US-24 to I-69 and Fort Wayne, the limited number of traffic lights on the bypass (three signalized intersections, compared to ten signalized intersections on the original alignment, according to Schacht), and the presence of big-box stores are used as selling points for attracting industry. The city is currently trying to persuade Lowe's and Home Depot to locate to the city, using the bypass and Wal-Mart Supercenter as selling points. A large portion of market analysis, when industries are in the site selection process, is based on existing retail and commercial pres- 
ence as well as the strength of local transportation networks, Schacht said. He cited the example of Home Depot, which had expressed in building a store in Huntington; development effects were hindered by the fact that the Wal-Mart was not a Supercenter.

Frontage roads were constructed in areas of retail development with the goal to allow strong traffic flow, thereby minimizing the number of conflict points. The bypass has only five conflict points compared to the original route's thirty conflict points, Schacht said.

The bypass has had an overall positive impact, according to Schacht, in that it has "opened up doors" for marketing and provided new ground for industry to build. Schacht stated that, while some communities feel that bypasses draw away a large enough volume of traffic such that it leaves a void in the downtown (which was also the case with Huntington), the city has been successful in filling that void, thus offsetting the burden on taxpayers.

Schacht wants to provide incentives for developers to locate new businesses in the $\mathrm{CBD}$ and invest in the downtown. Many of the downtown buildings were built in the 1800s; developers are starting to purchase such historical properties, according to Schacht, who also sits on the local historical review board. The city wants to offer incentives such as renovating the existing infrastructure to provide high-speed Internet, he said.

\subsubsection{Mobility Issues}

Huntington's close proximity to Fort Wayne has attracted increased residential development, making the city a "bedroom community," Brown said. However, 
according to Schacht, mobility issues related to the bypass have arisen. Extensive residential development has occurred north of the bypass, but the majority of schools, including Huntington University, are located south of the bypass, as is the new YMCA. The area is "segregated" with respect to how people can get from their residences to points south due to the geometry of the bypass. Students do not have the luxury of walking to school, Schacht said. If people who live on the north side of the city want to go someplace, they have to drive and use the bypass, he said. Crossing the bypass on foot is not a viable option for doing so is like playing a game of Frogger, he added.

The situation of segregated mobility did not happen intentionally; residents and officials alike did not expect development to occur so quickly. Much of this development occurred in the 1980s during a boom, which was unusual in that recessions were occurring at the same time, Schacht said. City officials are currently attempting to add to the city's outdated comprehensive plan to improve pedestrian mobility. Options discussed in the past included constructing a pedestrian and bicycle walkway across the bypass and building a tunnel where a railroad line was once located, Schacht said.

\subsubsection{Missed Opportunities}

Huntington would have been a "little worse off" had the bypass not been constructed, according to Schacht. Like many cities in Indiana, Huntington's economy relied heavily on the automotive industry. Cities that stay with the status quo "tend to die," he said. The Huntington bypass represented a new investment by the state. 
However, the city and county at large have missed opportunities for greater growth due to the "failures of people involved in economic development," Schacht stated. The city was at one time on a list of possible locations for a WalMart distribution center. Representatives from the company approached someone in economic development, but these efforts were rebuffed with the response that the required 100 acres of ground were not available.

The errors made by officials occurred in the way in which negotiations were approached. Officials should have replied, "Give us 14 days and we'll get the ground for you." Schacht stated that he personally knows a lot of farmers who would not initially sell (because many of these farms had been family-owned for over 100 years), but once they hear a dollar amount and the fact that Wal-Mart is interested in purchasing their property, "they'll sell in a heartbeat." In the end, the distribution center was built in Gas City to the south.

Schacht cited another case of a rubber company that was looking to locate along the bypass. Their proposal was met by a "small group of very vocal citizens who did not want them," and in the end "chased them to Peru," Schacht said. A primary reason some businesses have not located to the city is that a every time a company or industry expresses interest in developing along the bypass, efforts are hindered a small group of vocal citizens who want the city to be a bedroom community. This sentiment is shared by only 2 percent of the population whereas the other 98 percent want the city to grow, Schacht said.

As a result of these missed opportunities, more checks and balances were added to the economic development department, of which Schacht's Office of Community Development is a component. Whenever industry or a developer expresses interest in Huntington, Schacht and other officials in the economic development 
office relay the information to the county commissioners and try to "work hand in hand on opportunities." These checks and balances were implemented in early 2006, after the Wal-Mart distribution center expressed interest in Huntington, Schacht said.

\subsubsection{Overall Impacts}

The US-24 bypass has had an overall positive impact on the city and the county, according to Brown. This sentiment is shared by residents of the city, according to Schacht. The opening of the Wal-Mart 15 years ago was met with excitement by the community at large, according to Schacht. The Wal-Mart's grand reopening as a Wal-Mart Supercenter in 2006 was met with similar sentiments. Schacht stated he knows few communities that "party" when a Wal-Mart converts to a Supercenter. He stressed that the conversion to a Supercenter would likely not have occurred had the bypass not been present.

While drive-by traffic has increased, no major problems with congestion or safety have emerged, Brown said. However, the city needs a major north-south connector to facilitate freight movement to and from biofuels industries located north of the city, according to Brown.

\subsection{Anderson}

\subsubsection{Background}

Located 25 miles northeast of Indianapolis, Anderson was once a manufacturing powerhouse. General Motors used to be the primary employer in Madison County, of which Anderson is the county seat. Its mass layoffs in the late 1970s and early 1980 s cost the area 27,500 jobs. Primary employers in the area include Red 
Bull and the future Nestle Plant, but in general, the city is economically depressed.

\subsubsection{History and Impacts of the Relief Route}

As shown in Figure 3.8, IN-9 used to run through downtown Anderson, west of the bypass. Its current alignment runs along former two-lane IN-109, which now terminates at the interchange with Interstate 69 . The corridor was widened to a four-to-five-lane road in 1973, according to Jerry Bridges, Executive Director of the Madison County Council of Governments. The relief route was constructed primarily to handle traffic generated by the local General Motors plant, Bridges said.

The bypass's opening accelerated a decline in the downtown already started by the opening of the Mound Mall in the 1960s along then IN-109, still a two-lane road at the time. This was the first enclosed mall in Indiana, Bridges said. In earlier years, Anderson was neighborhood-oriented, with corner bakeries, grocery stories, and pharmacies. High school students walked downtown for lunch, and in general, much of the traffic downtown was pedestrian-oriented. Following national trends, as per capita income rose and the automobile became the mode of transportation of choice, residents of Anderson began to move farther and farther out of the city.

The Mound Mall, owned by Simon, began to draw retail businesses, including JC Penny and Sears, out of the downtown. With the opening of Interstate 69 in 1969 and the relief route in 1973, more businesses established a presence along the relief route. Retail businesses in the area became more regionally oriented, drawing in customers from nearby Hancock, Henry, and rural Madison counties. 


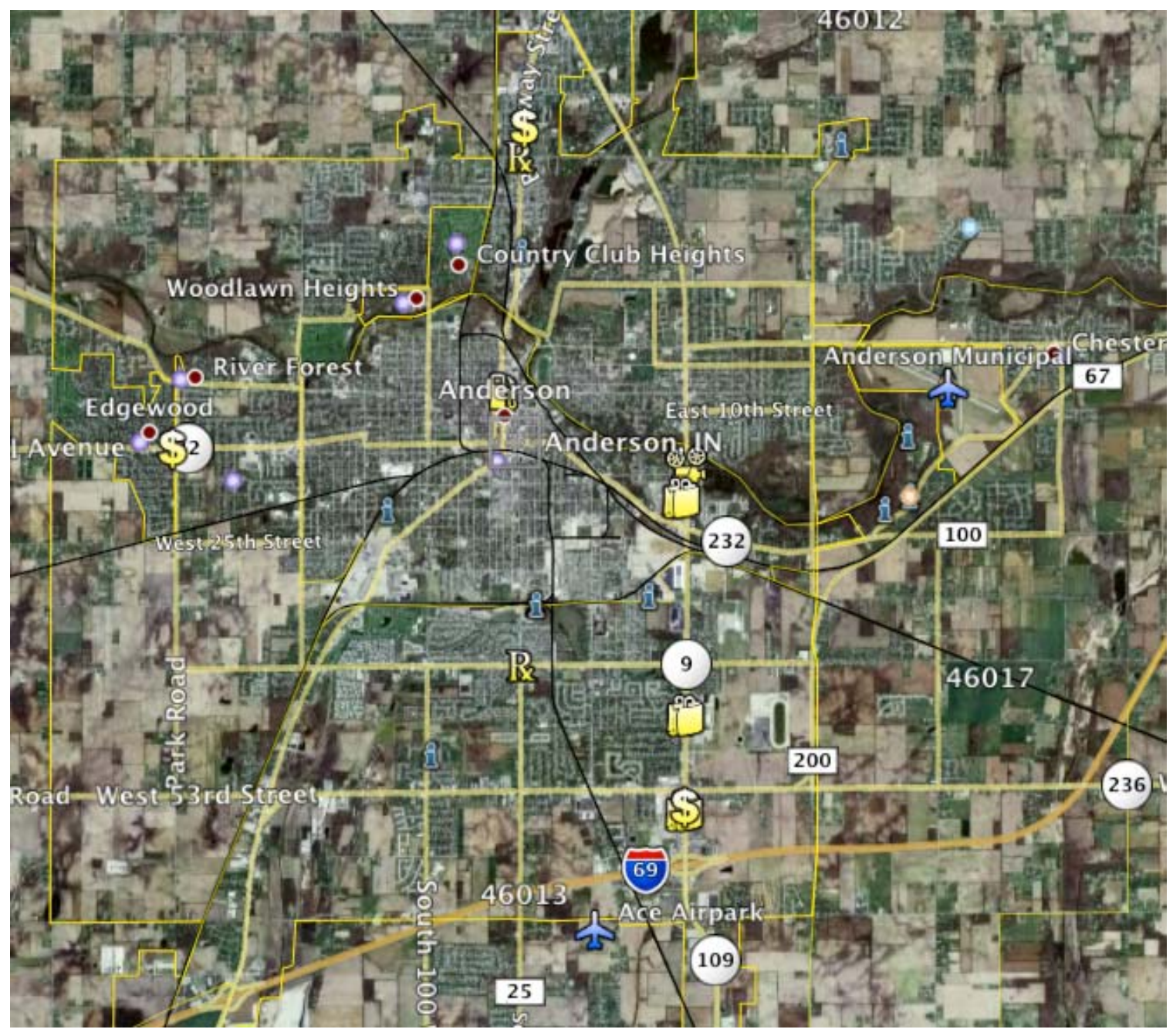

Figure 3.8 Aerial photo of Anderson. The current alignment of IN-9 was reconstructed in 1973. Over time, new retail development sprouted up along the corridor (Source: Google Earth).

Local corner stores found it difficult to compete with the newly established bigbox stores on the IN-9 corridor, including Wal-Mart, Target, and Lowe's, and began to close. Remaining businesses on the north side of the city are currently struggling to stay open, Bridges said. The growth of the Indianapolis metropolitan area and the city's proximity to Muncie has also contributed to the general decline in the retail sector. Residents on the west side tend to shop in Fishers and 
Noblesville in nearby Hamilton County, and residents on the north side tend to shop in Muncie, Bridges said. To compound matters, the more diverse shopping opportunities at nearby Keystone at the Crossing and Castleton in Indianapolis have drawn away customers from the Mound Mall. Few clothing stores remain at the mall today, Bridges said.

The decline of the Mound Mall is also likely due to efforts by Simon to build a new mall south of the city, near Exit 26 off Interstate 69. Local merchants were afraid that the new mall would further damage their businesses, and the requested rezoning for the proposed mall was not approved. Today, residents who want more diverse shopping opportunities shop everywhere but Anderson, Bridges said.

External economic changes brought about the eventual closing of the Anderson General Motors plant as an indirect result of the oil embargos. The oil embargo took place in 1973, the same year the bypass opened. No one foresaw the oil embargo and its effects on the automobile industry, including General Motors, at the time the relief route opened, Bridges said. The city was adversely impacted by the mass layoffs from General Motors that took place between 1978 and 1983, according to Bridges. During those years, the city lost 15,000 jobs due to the layoffs, and the city had the nation's largest unemployment rate of 25 percent in 1981. The city once had one of the highest per-capita income figures in the state. Within a period of 30-40 years, the city now has one of the lowest per-capita income figures.

These external economic factors, combined with the consolidation of schools, the growth of the Indianapolis metropolitan area, and the general retail movement toward big-box stores, led to the decline of downtown Anderson. 


\subsubsection{Land Use Policies and Traffic Issues}

Anderson's Comprehensive Plan went without a significant update for 43 years; the city updated its plan in 2005. The old 1962 plan did not anticipate the opening of Interstate 69 south of the city, and at the time, IN-9 still ran through the downtown and IN-109 was a rural two-lane road. Much of the land south of the city was zoned residential, according to Bridges. Spot zoning was used by the city when retail businesses wanted to come to Anderson. A Business Zone was created to make it easier for homes to be torn down. Certain types of businesses, such as service stations, could not be built in this zone. These practices allowed for the development of big-box stores with outlots. Many of these businesses did not have direct access to the IN-9 corridor.

Accidents occur frequently on the IN-9 corridor. Fifteen of the twenty-five highest-accident locations in urbanized areas in Indiana were located on the relief route. The route has 14-15 signalized intersections along a four-mile stretch of the corridor. Some of these signalized intersections do not have a protected left-turn phase, worsening matters. The high signal density hinders progression, and traveling this stretch can take upwards of 45 minutes during the peak hour, Bridges said. The corridor's cross-section is inconsistent through its 7-mile routing prior to meeting up with former Business IN-9 north of the city; some sections have continuous left-turn lanes whereas other sections have divided medians with wide right-hand shoulders which often function as right turn lanes. Some sections are curbed, whereas other sections are uncurbed. The sections with continuous left-turn lanes have a larger number of head-on crashes, Bridges said. 
In general, the IN-9 corridor is poorly designed and poorly maintained, Bridges said. Its inconsistent design confuses out-of-town drivers and senior citizens. The frequent delays and congestion that occur along the corridor are inconsistent with the typical traffic patterns of a city with a decreased job base. In other words, the average travel times and delays along the corridor are much higher than they should be, given the city's size and depressed economy, Bridges noted.

Efforts have been made to limit access along the corridor, but these efforts have been met with resistance from businesses who want direct access to the road. Frontage roads and back frontage roads have been built to accommodate business-oriented traffic, but these measures have not substantially reduced traffic along the corridor.

The city has gone from being a "net importer" to a "net exporter" of customers and jobs, Bridges said. The city's "retail dollar leakage" rate is around 60 percent, an alarmingly high figure for a city of its size. The construction of subdivisions on the southwest side of the county are due to growth from the Indianapolis metropolitan area, not the city of Anderson, Bridges said.

Even though Anderson is not officially part of the Indianapolis Metropolitan Statistical Area (MSA), the city and county, which once aligned themselves firmly with the East Central Indiana MSA, are now working more closely with Central Indiana in the form of the Central Indiana Corporate Partnership (CICP). Several Anderson citizens sit on the CICP board, Bridges said.

Anderson has gone from being an economic powerhouse to a suburban satellite of Indianapolis, Bridges said. The current economic patterns are not expected to change anytime soon, he added. 


\subsection{Warsaw}

\subsubsection{Background}

The county seat of Kosciusko County, Warsaw is located 40 miles west of Fort Wayne and 45 miles southeast of South Bend. According to the city's website, Warsaw is the "Orthopedic Manufacturing Capital of the World." The county is host to three of the five largest orthopedic corporations in the country: DePuy, Zimmer, and BioMet. Products produced in Warsaw include cranial, dental, and spinal implants. The city also houses Da-Lite, the largest projection screen manufacturer in the world, Art-Donley, one of the world's largest printing presses and producer of catalogs for JC Penny, Land's End, and Eddie Bauer, and Little Crow Foods, manufacturer of CoCo Wheats.

Kosciusko County is home to 103 lakes, including Lake Wawasee, a center for gambling in the 1920s and 1930s, attracting famous tourists including Clark Gable and Louis Armstrong, according to the website for the Kosciusko County Convention \& Visitors Bureau. Today, the county's many lakes continue to draw tourists, providing ample recreation.

\subsubsection{US-30 Bypass: Construction and Opening}

Prior to the bypass's construction in the late 1960s and early 1970s, US-30, the Lincoln Highway, ran through the CBD of Warsaw (see Figure 3.9).

Opened on August 4, 1972, according to the 2004 Warsaw Times-Union article "Timeline from the Past to the Present," the US-30 bypass travels north of the $\mathrm{CBD}$. The apparently high truck volumes through the city appear to have been 
the primary raison d'être for the bypass's construction, as shown from this excerpt from the article (Priser, 2004):

"So long truckers ... happy driving on new bypass," proclaimed a sign in downtown Warsaw today and it pretty well expressed the sentiments of all residents following formal opening of the new U.S. 30 bypass.

Governor Edgar D. Whitcomb and other state and local dignitaries were on hand for the formal ribbon-cutting ceremonies at 11 a.m. opening a 10.38-mile stretch of the new highway -- the final segment of four-lane pavement linking two of the state's larger cities -- Fort Wayne and Gary.

The highlighted portion of the excerpt implies that the US-30 bypass of Columbia City in Whitley County, east of Kosciusko County, was constructed prior to the US-30 bypass of Warsaw.

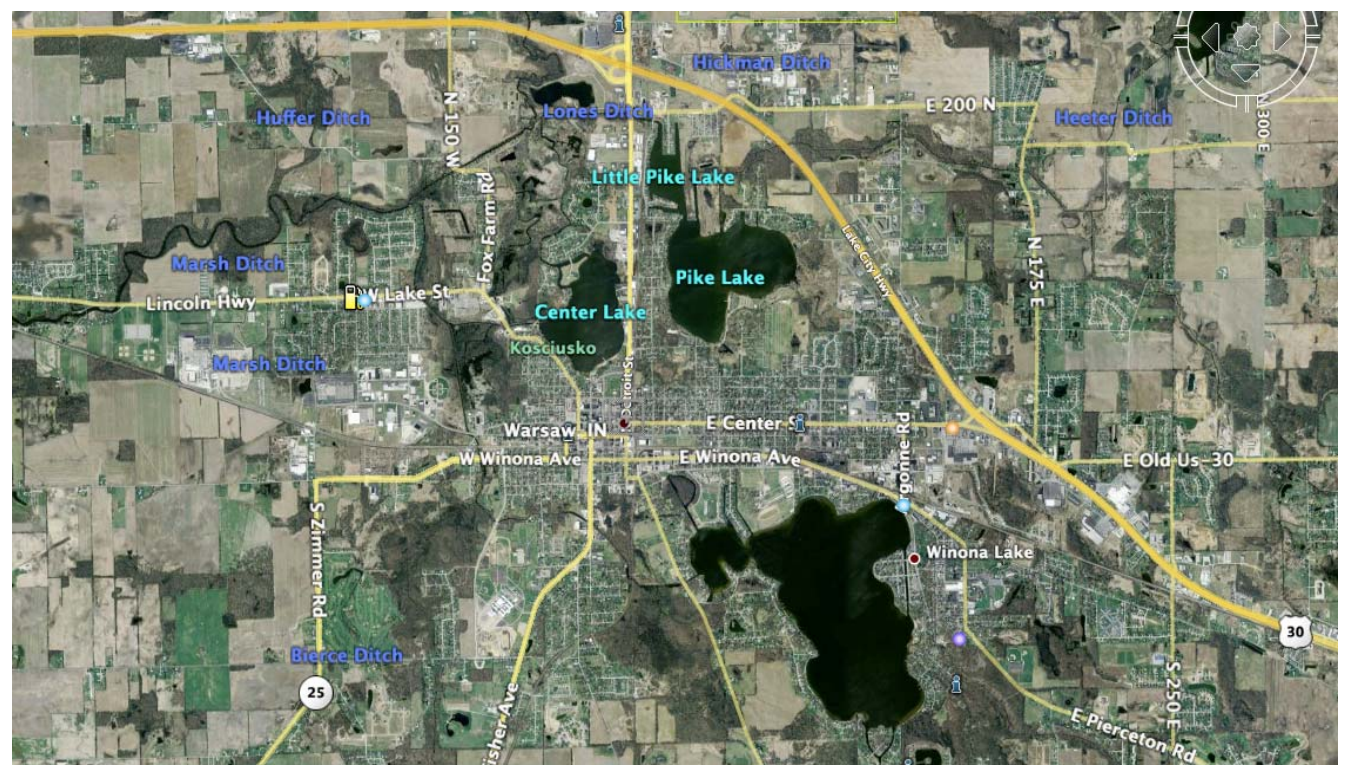

Figure 3.9 Aerial photo of Warsaw. The original alignment of US-30 ran along E. Center St and Lincoln Highway. As shown on the aerial, the city is surrounded by four lakes. The northern terminus of IN-25 is located in the CBD, at the junction with IN15. With the exception of the folded-diamond interchange with IN-15, all intersections with the highway are at-grade. (Source: Google Earth)

Development in anticipation of the bypass's construction occurred as early as 1968, according to an August 22, 1968 Times-Union article: "The major project being planned for building within the next few years is a deluxe large motel, with 
plenty of space that would attract conventions to Warsaw. The motel is to be built just northeast of the present restaurant [the popular Wagon Wheel Restaurant and Playhouse], where the new U.S. 30 bypass will curve to the north." Extensive industrial and commercial development occurred in the years following the bypass's construction, with companies DePuy Orthopaedics, Indiana Coated Fabrics, and L.M. Berry Company establishing facilities near the bypass. Numerous retail stores dot the landscape along the bypass, particularly along the east side of the city, with stores including K-Mart, J.C. Penny, Elder-Beerman, and Pier 1 Imports. Areas on the east side along the bypass began to be annexed by the city as early as June 8,1973 , according to the Times-Union article. Additional areas were annexed by the Warsaw Common Council (including a "high accident area" near the Lakeview Shopping Center) on August 16, 1977. Numerous residential subdivisions also grew around the bypass on the northeast side of the city.

The US-30 bypass serves as the main artery through the city of Warsaw, according to Joy McCarthy-Sessing, President of Kosciusko Development, Inc., and the Warsaw-Kosciusko County Chamber of Commerce. Because much of the industrial presence is still located on the old alignment of US-30, south of the bypass, extensive signage has been placed on the bypass to indicate to truck drivers where they should turn, according to McCarthy-Sessing.

\subsubsection{Benefits of the US-30 Bypass}

The bypass has largely benefited the community, McCarthy-Sessing said. The four-lane highway allows residents to reach other destinations in Indiana, such as Fort Wayne, more quickly. A hospital was constructed near the bypass due to easy access. When certain medical care cannot be obtained in the city, the bypass 
allows for a safer and quicker trip to nearby cities. The bypass has particularly benefited industrial developments in the area. Truck traffic to and from various plants in the city has increased over the years, and the presence of the bypass has minimized the number of trucks traveling through downtown, according to McCarthy-Sessing.

Had the bypass not been constructed, DePuy's expansion would have been limited, she said, and its current owners, Johnson \& Johnson, could have chosen to relocate the company to a location where trucks could more easily get in and out. Downtown roads provided only 80 feet of right-of-way as compared to 160 feet of right-of-way along the bypass, making turns downtown more difficult for trucks, according to Jeremy Skinner, the City of Warsaw City Planner. The downtown would have degraded in quality if trucks were forced to travel through downtown, had a bypass not been constructed. Because of the bypass, established companies in the area have expanded their operations substantially, in turn bringing additional employment to the area, according to McCarthySessing.

\subsubsection{Current Issues with the US-30 Bypass}

The number of at-grade access points on the bypass has proven to have a downside, however. The only full interchange along the bypass is located at IN-15. Four other principal intersections are signalized, according to Skinner. Initially, the bypass was intended to separate thru traffic from local traffic, but over time, the high volumes of traffic using the bypass piqued the interests of commercial developers. Over time, big-box stores began to be located near the bypass, which in time warranted the installation of traffic signals, according to Skinner. Mini- 
mal land use policies were in place at the time of the bypass's construction, Skinner said.

Primary conflicts have arisen due to speed limit differences. Outside of the city, US-30 carries a $60 \mathrm{mph}$ speed limit, whereas around developed areas, the speed limit drops to $45 \mathrm{mph}$. Because US-30 traverses the entire state and serves as an alternative to the Indiana Toll Road, a sizable portion of the traffic (perhaps 20 percent) is thru traffic trying to get through Warsaw as quickly as possible, Skinner said. Many of the accidents that occur along the bypass are due to semitrucks running red lights, according to McCarthy-Sessing and Skinner. The situation is such that when one is about to cross US-30 at one of its many access points at a signalized intersection, one must look to ensure traffic along US-30 does indeed stop, McCarthy-Sessing said.

When it comes to planning a major throughfare through or around a city, one of the most important impacts is realizing what conflict points will be created, Skinner said. Such impacts were not addressed well in the planning of the bypass, according to Skinner. Roads will always be "cut" by access points, but it is how these cuts are handled that will affect future traffic conditions, he said. The current problems on US-30, particularly at the intersection at Center St. and US30, could have been avoided had these impacts been addressed better, he said. Zoning and land use issues must be addressed before a bypass is built, so they do not have to come up with fixes in the future, he said. Failure to do so could result with "more nightmares than what you originally had," according to Skinner.

Reducing the number of traffic signals or constructing interchanges, Skinner said, could reduce some of the existing conflicts. Tactics currently employed in- 
clude timing traffic lights to ensure smooth progression and posting signs warning of a "congested area ahead," he said. Frontage roads were constructed in the late 1980s and early 1990s near heavily traveled retail centers and the local hospital.

\subsubsection{The "Western Corridor" - Proposed IN-15 Bypass}

Currently in the planning stages is a proposed western bypass of current IN-15. County commissioners have discussed the project since the 1990s, according to McCarthy-Sessing and Skinner. The current alignment of IN-15 runs through downtown Warsaw and includes two 90-degree turns. These sharp turns have proven difficult for through trucks and mobile homes being transported from Elkhart County and northern Kosciusko County, McCarthy-Sessing said. Additionally, delivery trucks and residents coming out of commercial retail establishments and truck traffic from a nearby foundry and an orthopedic manufacturer also travel along IN-15, she stated. Many trucks currently roll over the curbs along these turns, and accidents are frequent at points where vehicles turn on and off the road, according to McCarthy-Sessing and Skinner.

Truck traffic along IN-15 will increase with the construction of a biodiesel plant in the southern part of the county, she said. The current routing of IN-15 cannot be expanded or widened without great expense due to the property acquisitions that would be required, worth about $\$ 15$ million, according to Skinner. The proposed bypass would eliminate through traffic along IN-15. The curves themselves will be widened by INDOT in the future, but this is only a "temporary fix," he said.

The western corridor project is currently not listed on INDOT's 10-year or 20year long-range plan, primarily due to financial matters and the fact that IN- 
DOT's traffic counts do not warrant such a road, McCarthy-Sessing and Skinner said. The proposed bypass would facilitate through truck traffic and also tourist traffic traveling to lake houses. Extensive traffic backups often occur at noon, McCarthy-Sessing said. Currently, certain studies must be performed before funds are committed to the project, Skinner said. 


\subsection{Columbia City}

\subsubsection{Background}

The county seat of Whitley County, Columbia City is located 20 miles west of Fort Wayne and 20 miles east of Warsaw. The city's principal industries include agriculture and manufacturing. Prominent employers in the area include Reelcraft Industries, Inc., UnderSea Sensor Systems, Inc., and Acme Industrial Maintenance \& Machine.

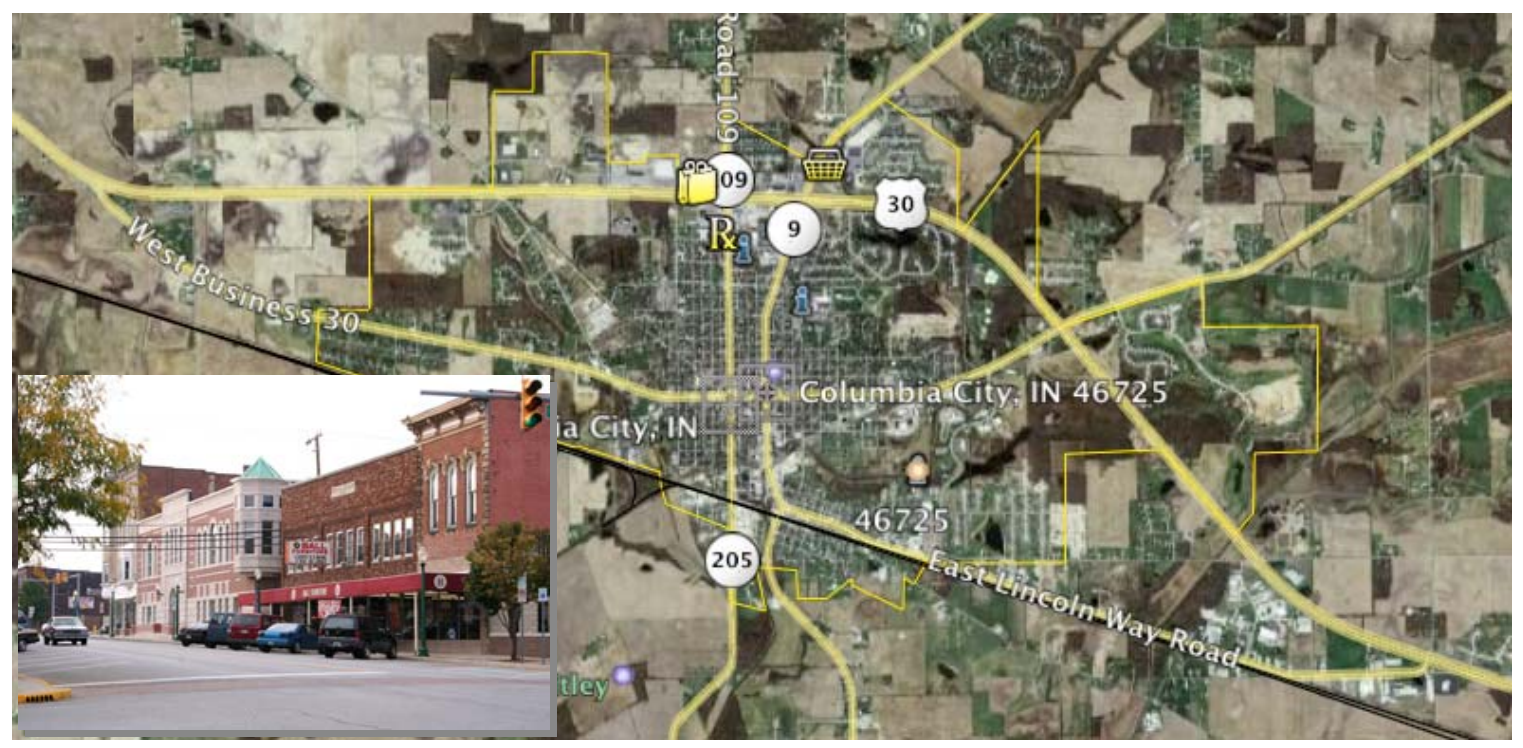

Figure 3.10 Aerial photo of Columbia City. The original routing of US-30 ran along East Lincoln Way Road and West Business 30 and is currently signed as Business US30 (Source: Google Earth). (Inset) Photo of downtown Columbia City (Source: http://upload.wikimedia.org/wikipedia/commons/f/f1/Columbia-city-downtown.jpg).

\subsubsection{Impacts of the US-30 Bypass}

The original routing of US-30 ran south of the current bypass through the CBD of Columbia City (see Figure 3.10, above). The original routing, now designated Business US-30, is a two-lane road through downtown with angled parking. The 
bypass has had a "two-edged effect" on Columbia City, according to Lowell Teska, President of Whitley County Economic Development Corporation. While the downtown has declined, the bypass has served as a means of attracting additional businesses that are dependent on through traffic. A row of chain restaurants and hotels runs along US-30 on frontage roads. The retail that established a presence in Columbia City may not have located there had they been limited to a downtown location, Teska said.

The relocation of most commercial activity to the bypass resulted in less emphasis placed on maintaining the downtown building stock. Many buildings in the downtown have remained empty over several years and are not up to date, Teska said. As a result, many of the buildings downtown have become rundown and have structural issues. A number of these buildings are privately owned; many of their owners also have properties along the US-30 bypass, and these owners want to invest any spare funds into the locations along US-30 to generate revenue, he said. Businesses that have remained downtown include attorneys, doctors' office, and restaurants that cater to the downtown lunch crowd.

Public perception of the bypass is primarily positive due principally to the convenience factor of having stores and restaurants adjacent to each other, Teska said. On the flip side, older residents of the community do not appreciate having to cross US-30 to get from their homes to stores and services. Most of the city's residences are located south of the bypass, whereas most stores and restaurants are located north of the bypass.

The presence of frontage roads limits the number of curb cuts, and the US-30 bypass has only 4-5 traffic signals, according to Teska. However, traffic on US-30 is 
usually congested, and it can be "tough" to go through more than one intersection at a time, he added.

Columbia City has grown since the bypass was opened, Teska said, but as a result, there are "two forces working against each other." Manufacturing companies and other local industry appreciate the routing and geometry of the bypass due to decreased travel time and consequently decreased transportation costs, but at the same time, with the city growing toward the bypass, the US-30 bypass is in danger of becoming a part of the downtown, Teska said.

The scenario of US-30 becoming a part of downtown is unlikely, according to Teska, due to several factors. Businesses want visibility along the bypass, driving up land prices (because land owners want a large return on their investment) to the point that only wealthy businesses, which happen to be big-box stores such as Wal-Mart, can afford the land. Smaller businesses are consequently forced to locate 3-4 blocks away from the bypass. The market conditions work to prevent a "mass exodus from the downtown area," Teska said.

As a result, the high land prices along the bypass have separated small and large businesses, each of which have a separate customer base, according to Teska. Larger businesses have more immediate access to the bypass, thus giving them a competitive edge over smaller businesses dependent on through traffic. Teska outlined a hypothetical scenario in which a local customer is shopping for shoes at a big-box store but does not want to drive to the downtown shoe stores. The customer finds a pair of shoes that is not exactly what he wanted but will suffice. This pattern is repeated by additional customers. The manager of the big-box store catches onto this trend and expands its shoe section. Business is then drawn away from the smaller shoe stores. 
As outlined before, the bypass has played a factor in the city's continuous growth. A new business district has been created as through traffic and, consequently, the customer base has grown. The city "live[s] bigger than it really is," with services that could have never before been economically justified, Teska said. Before the bypass was built, the city was not large enough to warrant attention from many national chains such as Blockbuster Video, Teska said. As the community grew, businesses looking for new markets in which to compete, such as Blockbuster, locate on the bypass, resulting in similar chain stores, such as Family Video, locating along the bypass. Only the chain stores can afford the land. The chain video stores are more conveniently located than the old momand-pop video stores, and eventually the mom-and-pop video stores are driven out of business. The bypass has provided "more convenient traffic flow for commercial products" and resulted in the relocation of companies that might have otherwise relocated to a different city. While smaller businesses have been put at a disadvantage or have gone out of business altogether, the bypass has helped expand the business district of Columbia City, thus promoting additional jobs, Teska said.

The pattern of urban sprawl and the pattern of relocated businesses has resulted in the downtown losing its position as a central hub and a central core of activity, causing the city to become an "amorphous blob," Teska said. Residents running errands have to drive to one store on the extreme west side of town and then drive to another store on the extreme east side of town. Urban sprawl has also increased utility costs for residents. Typically, to attract businesses, the city provides a discount on utilities. As a result, the parties who have caused utilities to become more expensive end up paying less than long-time residents, according to Teska. 
To ensure continued job growth and to keep younger people in Columbia City, a Tax Increment Financing (TIF) district was established near the US-30 bypass, the largest such TIF district in the state, according to Teska. A business park providing "shovel-ready" building sites was built in this district, attracting businesses such as the Steel Dynamics, Inc. plant, which employs hundreds of people. As described earlier, the flip side of these new developments is that, due to incentives provided to attracting businesses, residents may end up paying increased utility bills and increased taxes.

\subsection{Washington}

\subsubsection{Background}

The county seat of Daviess County in southern Indiana, Washington is located in Amish country, 15 miles east of Vincennes, 60 miles southwest of Bloomington, and 50 miles northwest of Jasper. Local attractions include the Gasthof Amish Village, the nearby Hoosier National Forest, and French Lick, 45 miles southeast. Prominent industries in the area include grain processing (the local corn wetmilling plant processes 85,000 bushels of corn a day), a Perdue foods processor that processes 30,000 turkeys a day, and several small manufacturing companies that each employ between 50 to 125 people, according to Ron Arnold, Executive Director of the Daviess County Economic Development Corporation.

\subsubsection{Construction of the Bypass and Its Impacts}

The US-50 bypass of Washington, which runs south of the city and does not enter the city, was completed around 1991-92, Arnold said (see Figure 3.11). The US 
route used to run through the $\mathrm{CBD}$, but semi traffic and coal truck traffic caused extensive congestion downtown and inconvenienced residents, causing many people to avoid the area because traffic problems were so bad, Arnold said. The bypass had been in the works for 20-30 years. The bypass, which ran from the existing 4-lane segment in Wheatland (seven miles west of Washington) to approximately three miles east of the $\mathrm{CBD}$, diverted much of this truck traffic. While a few citizens were initially concerned about possible impacts of the bypass, traffic in Washington along the old alignment has actually increased, according to Arnold. The diversion of trucks allowed for more local traffic to more easily get in and out - local traffic no longer has to "fight trucks," Arnold said. In short, the bypass and resulting truck diversion has allowed commerce to take place, according to Arnold, thereby improving the opportunity for business. The Wal-Mart located on the east side, the surrounding hotel and half dozen restaurants, as well as a drive-in restaurant partly owned by Arnold have all done well following the bypass's opening, he said.

Since the bypass's opening, Washington has established a 2-mile zoning radius within the city limits. The ground was initially zoned residential, but city officials decided the land would be better used if zoned commercial, Arnold said. 


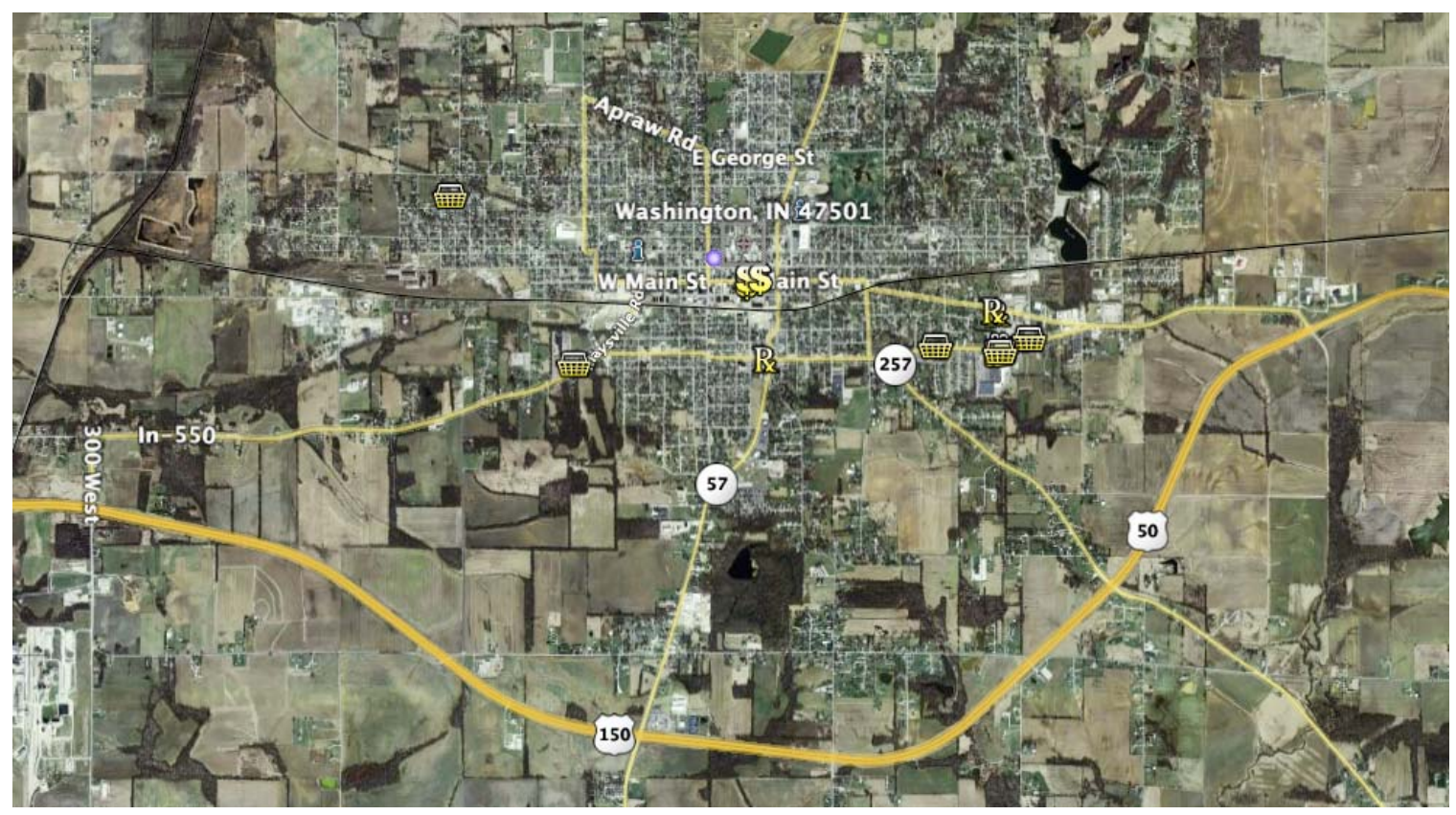

Figure 3.11 Aerial of Washington and surrounding area. The US-50 bypass (duplexed with US-150 through the county) runs south of the CBD. Coal trucks that traveled through downtown caused endless headaches for local residents prior to the bypass's construction.

Much of the retail development is located east of the CBD and has fared well since the opening of the bypass. Traffic on the original alignment has increased since the bypass's construction due to improved accessibility because of the diversion of trucks, according to Arnold.

Industry has established a presence on both sides of the bypass, with the $\$ 300$ million GPC grain processing facility and MacAllister Equipment (a coal mining equipment repair center) located on the west side and an implement dealer located on the east side. Traffic-oriented businesses have established a presence at the junction of the bypass an IN-57, Arnold said. These businesses include an Amoco service station, a Baymont hotel, a Burger King, a hardware store, and a Ponderosa Steakhouse. Arnold stressed that without the bypass, it is likely that three-quarters of this development would not have occurred. 


\subsubsection{Safety Issues}

The bypass has not come without its downsides. INDOT is currently investigating the unusually large number of fatalities that have occurred on the bypass at different intersections, particularly the junction with IN-57. Arnold theorized that this may be due to the large number of elderly drivers who do not understand the concepts of turn lanes or four-lane highways.

\subsubsection{Downtown Impacts}

The bypass has not substantially impacted the downtown, Arnold said. Downtown Washington was more greatly affected by the advent of strip malls and discount stores that appeared on the east side of the bypass beginning in the 1960s. The majority of retail stores in the downtown (which once included JC Penny, Sears, and Montgomery Ward) have disappeared, since replaced by a drugstore, a couple of restaurants, and assorted mom-and-pop stores.

However, compared to most downtowns, Washington is not too bad off, due partly to the attitudes of city officials and residents, Arnold said. The city has always taken a pro-active approach, according to Arnold. Officials have faced the reality that retail will not return to downtown to the level of presence it had in the 1950s. Like other communities such as Lafayette, upper floors of existing downtown building stock are being converted to housing, with focus on niche marketing, representing a throwback to years ago, prior to larger retail coming into the area.

The added investment in the area would not have been made had the bypass not been built - the bypass has allowed whole areas not related to the community to be developed. Hotel occupancy rates are better than 90 percent, Arnold said, due 
to the healthy state of Amish tourism and the number of business travelers. The tax base would not be at the same level had the bypass not been built, according to Arnold. The bypass was an important factor for GPC locating to Daviess County. The proposed Interstate 69 corridor will serve as an additional selling point for attracting businesses once it is constructed, he said.

\subsection{Angola}

\subsubsection{Background}

Angola is located in northeastern Steuben County, approximately 85 miles east of South Bend and 60 miles north of Fort Wayne. The city is host to a number of industries, including Powerscreen, a manufacturer of portable screening equipment for waste reprocessing, metal spinning companies, and a number of transportation equipment companies. Local attractions include Hamilton Lake and Pokagon State Park.

Principal routes through the city's CBD include US-20, IN-127, and IN-827. Travelers through the CBD must pass through the traffic circle in the center of town, located at the junction of US-20 and IN-127 (see Figure 3.12). Throughout the city, US-20 is a two-lane highway with no center turn lane, with parallel parking on the west side and angled parking near the Monument Circle. 


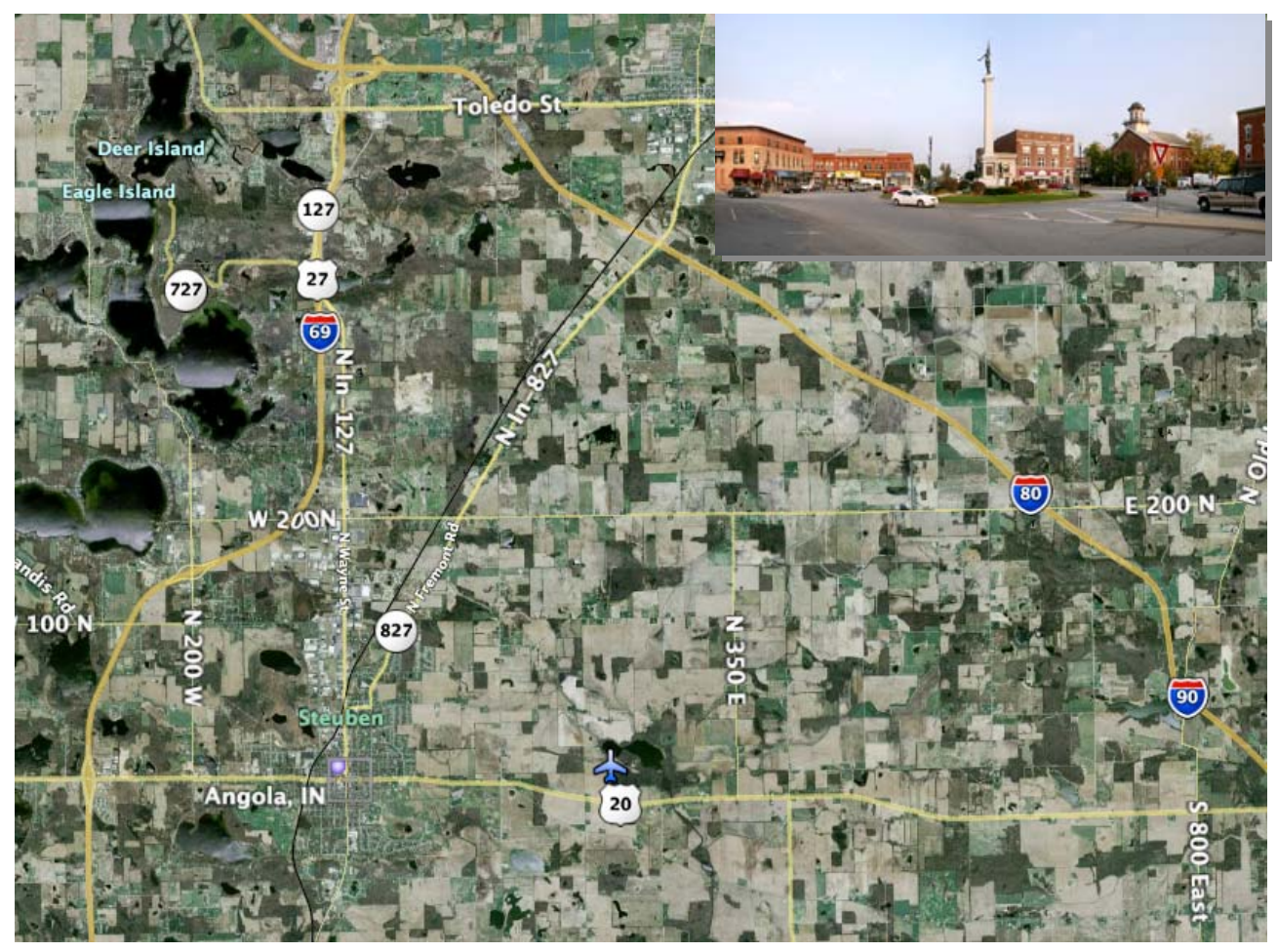

Figure 3.12 Aerial photo of Angola and surrounding region (Source: Google Earth). (Inset) Photo of traffic circle, Monument Circle located in Angola's CBD. The geometry of this traffic circle often causes problems for thru truck traffic (Photo source: Wikipedia).

\subsubsection{The Need for a Bypass}

A combination of local industry and increasing costs on the Indiana Toll Road (to the north) had led to an increase in truck traffic on US-20 over the years. Recent counts averaged 1,419 semi trailers per day, according to the Regional Planning Organization study Semi Tractor Traffic Binder (Region III-A, 2005). Many of these trucks carry hazardous materials filled with liquid and gases, according to Mayor Richard Hickman. The trucks travel past the local middle school, the high school, two hospitals, and around the traffic circle in the CBD. The truck traffic poses problems for local residents traveling to the CBD, he said. 
Drivers often experience great difficulty when getting in and out of both parallel and angled parking spots. The trucks hinder pedestrian traffic. The local residents have grown accustomed to the semis, but one can tell when "somebody new is in town," Hickman said. The trucks move at a "pretty good clip" and also cause issues for school traffic in the morning, according to Hickman. Additionally, the trucks tear up roads and have damaged the mound in the center of the traffic circle, Hickman said. The noise from the use of jake brakes when slowing down frequently disrupts conversations for residents.

No "tragic" incidents have occurred, but there have been a "series of mishaps" involving semis and automobiles, Hickman said. Hickman noted a recent incident in which two semis collided in front of the hospital and blocked the entrance to the emergency room. Only one semi-related fatality has occurred, he said. Given the situation and the nature of the cargo the trucks carry, the city is one accident away from disaster, he said.

Discussions for a bypass around Angola began as early as 15 years ago, Hickman said. When Hickman first came into office in 2001, he held two meetings with the public and a private meeting with Congressman Mark Souder. He found that most residents agreed that a bypass was needed, though a few citizens voiced concern about the downtown dying as a result of the bypass's construction. For a study commissioned by INDOT, an Indianapolis-based consulting firm was hired to facilitate a series of meetings to determine the principal problems caused by the trucks, possible ways of rerouting a portion of the semis, and possible alignments of the bypass.

3.9.3. Recent Developments and Future Actions 
At a recent meeting between local officials and INDOT, it was learned that, after analyzing the results of the study, the plans for the bypass would not proceed, due to a lack of money. Hickman said that he was quite surprised at the decision, as were members of the public. General public sentiment was that "something was going to happen," Hickman said. However, the bypass idea is not a "dead issue," according to Hickman.

The project is currently listed in the "Unfunded Long Range Plan Projects" for the Fort Wayne District. Another project listed in this document calls for US-20 to be widened from 2 to 4 lanes from the junction with IN-127 in downtown Angola to I-69 (see Figure 3.13, below).

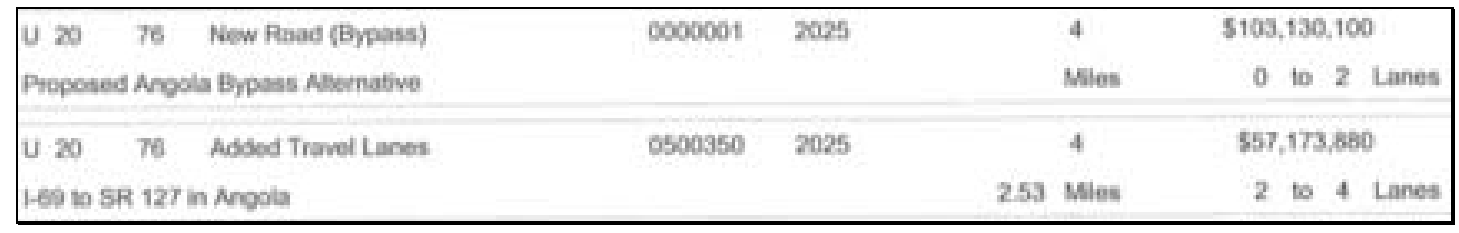

Figure 3.13 Project listing for US-20 bypass and added travel lanes on existing US-20 from Unfunded Long Range Plan Projects, INDOT, Fort Wayne district (INDOT, 2007)

The bypass is also discussed in INDOT 2016 Long Range Project Review and 2017-2030 Long Range Project Meeting Notes under the heading “2016 IPOC Candidate Projects," dated May 8, 2006 (INDOT, 2006a):

Study is still in the delayed corridor planning process with BLA. Outside legal counsel is being consulted on truck tolls only. The county roads proposed for the bypass will require extensive improvements to be able to handle truck traffic.

Currently, the city is in the middle of a revitalization program to enhance the attractiveness of the downtown, Hickman said. Many of the buildings feature a New England motif, and many of the buildings are quite old. However, even though the bypass has been tabled for the time being, plans are currently under- 
way to lessen the problems caused by the truck traffic. This sentiment is highlighted in the Angola Downtown Action Agenda 2006: "The leadership of the community should be commended for their diligent efforts to have a truck route created. However, it should be realized that - if, for some reason, the truck route does not become a reality - Downtown Angola can still be enhanced so that it is a thriving business district" (HyettPalma, 2006).

The study recommended the following "traffic-calming measures" to lessen the impact of truck traffic:

(1) "Strenuous" enforcement of speed limits.

(2) Installation of "more visible" pedestrian crosswalk signage, including signage instructing drivers to yield to pedestrians

(3) The possible installation of pedestrian-activated lights in the CBD.

\subsection{0. $\underline{\text { Boonville }}$}

\subsubsection{Background}

The county seat of Warrick County, Boonville is located approximately 20 miles east of Evansville. A heavy concentration of coal-fired power plants is located in this area. Some of the largest power plants in the world are located near Boonville, according to Greg Wathen, Executive Director, Economic Development Coalition of Southwest Indiana, and Jim Holderread of the Posey County Chamber of Commerce. A Duke Energy power plant is one of the five largest plants in the world, and the Vectren power plant provides power to an eleven-county region, they said. 
Coal mining is the primary industry in the area. Many of the citizens of Boonville work at the nearby Alcoa plant. Areas surrounding Boonville are used for both strip mining and underground mining. Trucks move most of the coal for the power plants, Holderread said.

Following the construction of the 2000-acre Alcoa facility in 1958, IN-61 was widened from rural road to a Super-2 between IN-66 and IN-62 (formerly US-460, the primary east-west corridor connecting Louisville to St. Louis prior to the construction of Interstate 64). The road remains a rural two-lane highway north of the city (see Figure 3.14).

\subsubsection{Impacts of Truck Traffic on Downtown Boonville}

Because of the city's layout, all through traffic is "funneled" through downtown, according to Holderread. Through traffic must navigate through two sharp turns to follow IN-61, passing through the center of town, around the courthouse square. Approximately 400-500 coal trucks travel through downtown Boonville each day via IN-61 and IN-62, Holderread said. Drivers are paid by the amount of coal they haul each day, creating hazardous conditions downtown. The speed limit is seldom followed, according to Holderread. Auto traffic is forced to travel higher speeds to stay on the main roads, creating a logistical nightmare.

The large volume of trucks and accompanying exhaust, noise, and impact on the infrastructure has had a detrimental effect on the downtown, Holderread said. Residents along the main roads have "given up" trying to maintain the exteriors of their houses that are dirtied by the coal trucks' exhaust. Retail stores are practically nonexistent in the CBD. City streets are under a constant state of repair due to the wear-and-tear from the trucks. Retail stores that were once located 
downtown have closed down or moved to the outskirts of the city. The coal trucks are hazardous to other cars; the windshield replacement industry is vibrant in the area, Holderread said.

The problem will be exacerbated when the four-laning of IN-62 between Boonville and Evansville is complete, Holderread said. "Interstate volumes" of traffic will be forced to travel the narrow streets of downtown Boonville, thus significantly worsening traffic conditions downtown, he said.

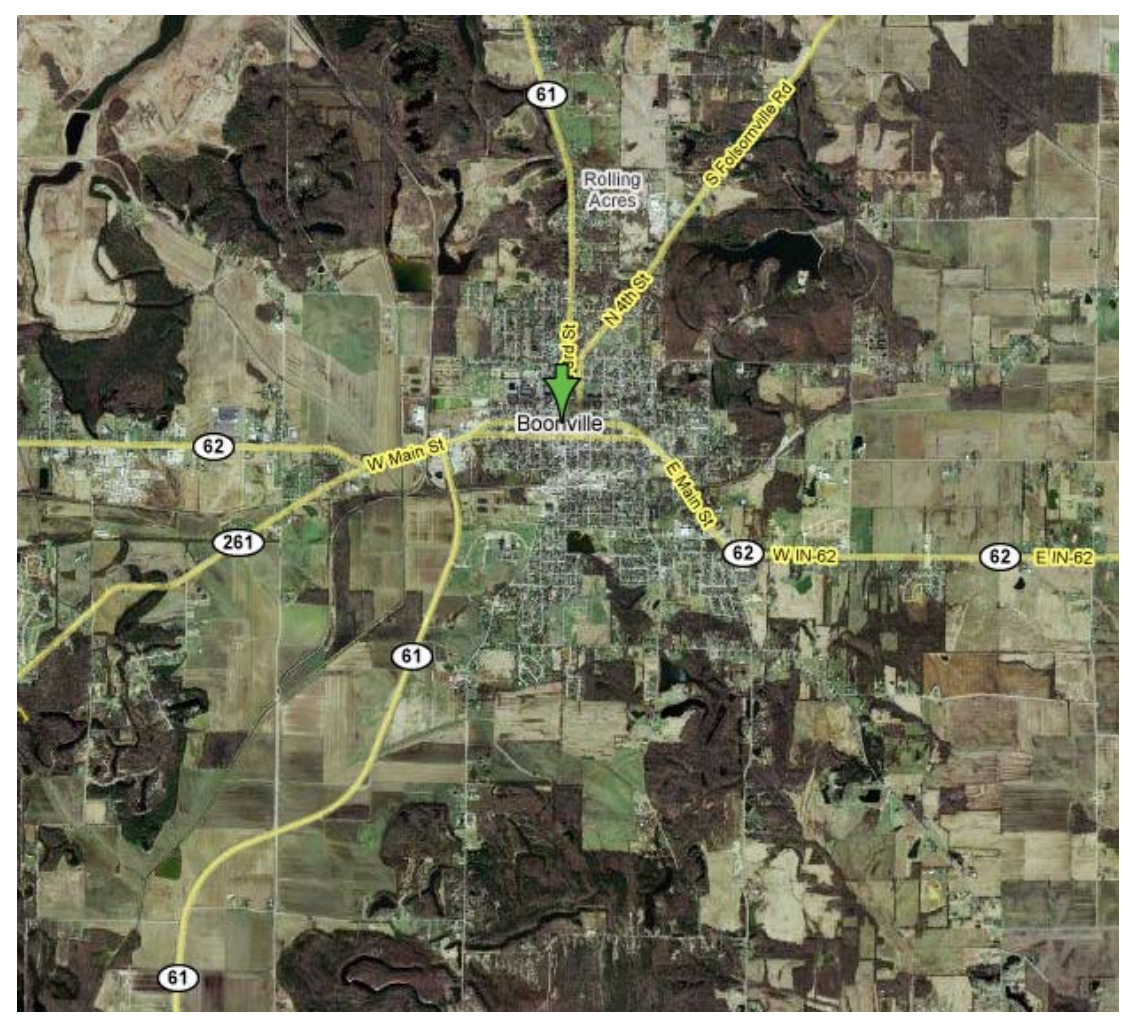

Figure 3.14 Aerial photo of Boonville (Source: Google Maps).

3.10.3. Proposed Bypasses

A bypass around Boonville was proposed soon after IN-61 was rebuilt as a Super-2. INDOT had acquired the right-of-way for the bypass but did not do anything with the land for 15-20 years, Holderread said. Local residents became vo$\mathrm{cal}$, and the bypass project was scrapped. The acquired land was consequently 
sold off. The current proposed bypass, scheduled for completion in 2012, is described in the Evansville Metropolitan Planning Organization Draft 2035 Transportation Plan Recommendations as: "The construction of a new two-lane facility connecting SR 61 west of Boonville with SR 61 north of Boonville will alleviate traffic congestion through downtown Boonville and provide through truck traffic on SR 61 with a more direct travel route." The bypass will begin at IN-62, west of the city, and will terminate at IN-61, north of the city.

Because of the uncertainty as to exactly when the bypass will be completed, officials from the Warrick County Redevelopment Commission have proposed a "reliever bypass" out of concern that some kind of relief route must be built. The bypass would begin around the Wal-Mart on IN-62 west of the city and would terminate at IN-61 to the north, with an estimated price tag of $\$ 5$ million.

The bypass will enhance economic development in the area, Holderread said, but the enhancement would be greater if the bypass construction project were coupled with the reconstruction of IN-61 north of Boonville. The road is currently a hilly, windy two-lane road not built to AASHTO standards, Holderread said. Little industrial or commercial development is expected along the bypass, Wathen said; much of the land the bypass traverses has been strip mined, making it unattractive for such development. The bypass is "desperately needed" by the city, according to Wathen. 


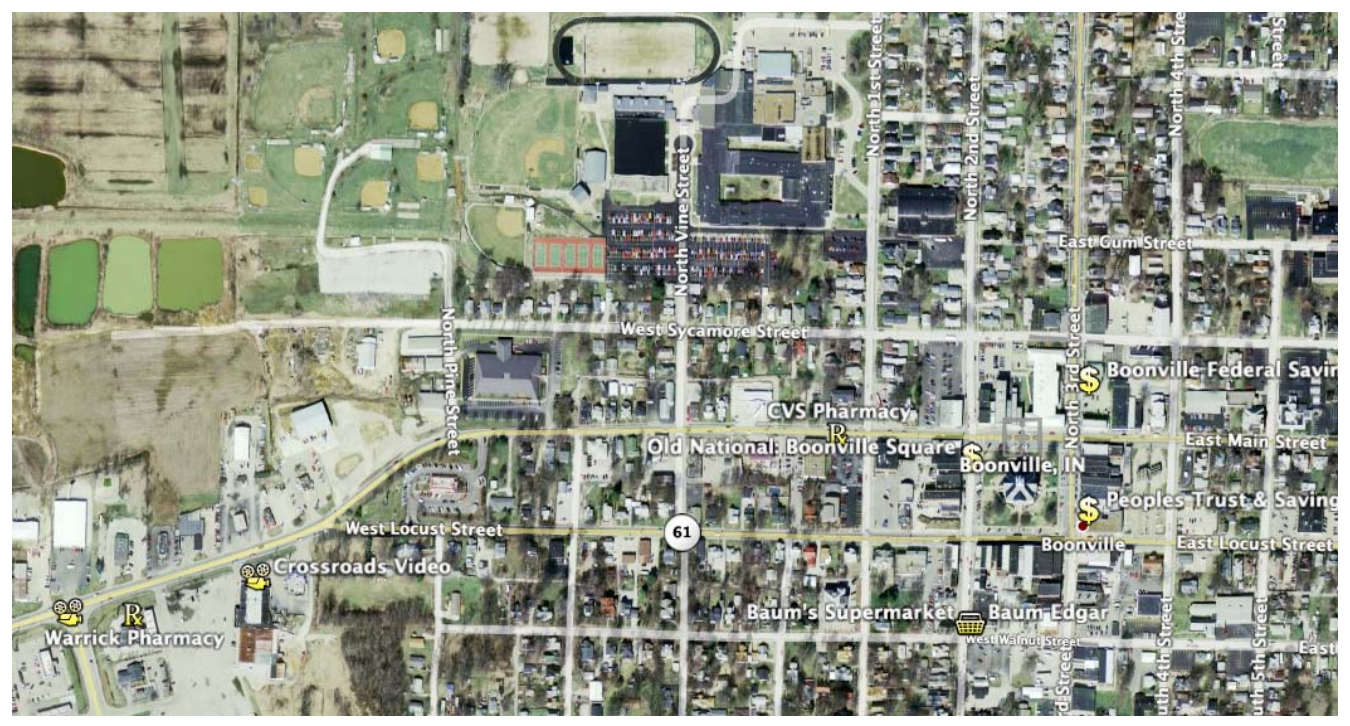

Figure 3.15 Aerial photo of downtown Boonville. Traffic following IN-61 southbound must make a sharp turn near the Warrick Pharmacy. Thru traffic use the one-way pair and make at least one sharp turn to continue northbound on IN-61 to Interstate 64 . The large amount of traffic generated by the local coal mining industry has proved detrimental to downtown Boonville (Source: Google Earth).

\subsection{Salem}

\subsubsection{Background}

The county seat of Washington County, Salem is located 35 miles northwest of Louisville. Principal industries in the area focus on the automotive and wood product manufacturing sectors. Other industries in the area include small machine shops, printing companies, and advertising agencies.

Major employers in the area include Kimball International (which is based in nearby Jasper), GKN Sinter Metals, Tecumseh Power Company, and Jean's Extrusions. Local tourist attractions include the Jon Hay Center, the Salem Speedway, and the Courthouse at Salem Square. 


\subsubsection{Proposed Bypass}

The idea of a Salem bypass has been discussed as early as the late 1960s, according to City Attorney Drew Wright. The Chamber of Commerce initiated efforts for a bypass, but due to a lack of agreement in the community regarding the location of the bypass, the project never received funding from INDOT. The bypass idea resurfaced in 1989 following a 1987 study by INDOT's Carter Keith analyzing travel patterns in Salem. The study concluded that most of the heavy traffic downtown is locally generated; therefore, a relief route would not result in a decrease in traffic through downtown Salem.

By late 1990, with the encouragement of a local support group, the city of Salem had signed a contract with consulting engineer Jim Rice. The original routing of the bypass rerouted IN-60 to the south and west of its current alignment, Wright said. However, because the proposed bypass was outside of the city limits, it became a Washington County project between 1996 and 1998. The bypass once again became a state project in 1999 with the help of Crowe Chizek and Co., a consulting firm. Following a karst topography issue that surfaced during the course of the environmental studies being undertaken, the routing of the bypass changed significantly.

The current alignment of the proposed relief route, now a "truck route," will begin at its southern terminus at IN-135 on the east side of the city, intersect with IN-60 southeast of the city, intersect with IN-56 east of the city, and then follow IN-56 westward to the north of the CBD. The relief route, which will be a Super-2 due to environmental issues, will only be a truck route due to its planned limited-access characteristics. The only access points will likely be located at the eastern and western termini, according to Bill Nolting, Executive Director, Wash- 
ington County Economic Growth Partnership, Inc. Construction on the Salem bypass will begin in 2009, according to the Major Moves Major New Highway Construction listings (INDOT, 2006b).

Currently traffic must pass through the CBD of Salem and negotiate the two traffic circles surrounding the courthouse (see Figure 3.16). The unusual geometry of the two concentric loops poses great difficulty for the large number of logging trucks traveling through downtown Salem, according to Nolting. Merging traffic from the inner circle (typically courthouse visitors and employees) must yield to through traffic in the outer circle.

Inner circle traffic must back out into the outer circle; sight distance is limited until drivers have pulled out halfway into the outer circle, Nolting said. The mechanics of getting in and out of the two circles can be confusing to visitors. The situation is worsened by the railroad track a few blocks south of the square; traffic backs up into the square when a train is passing through, Nolting said. 


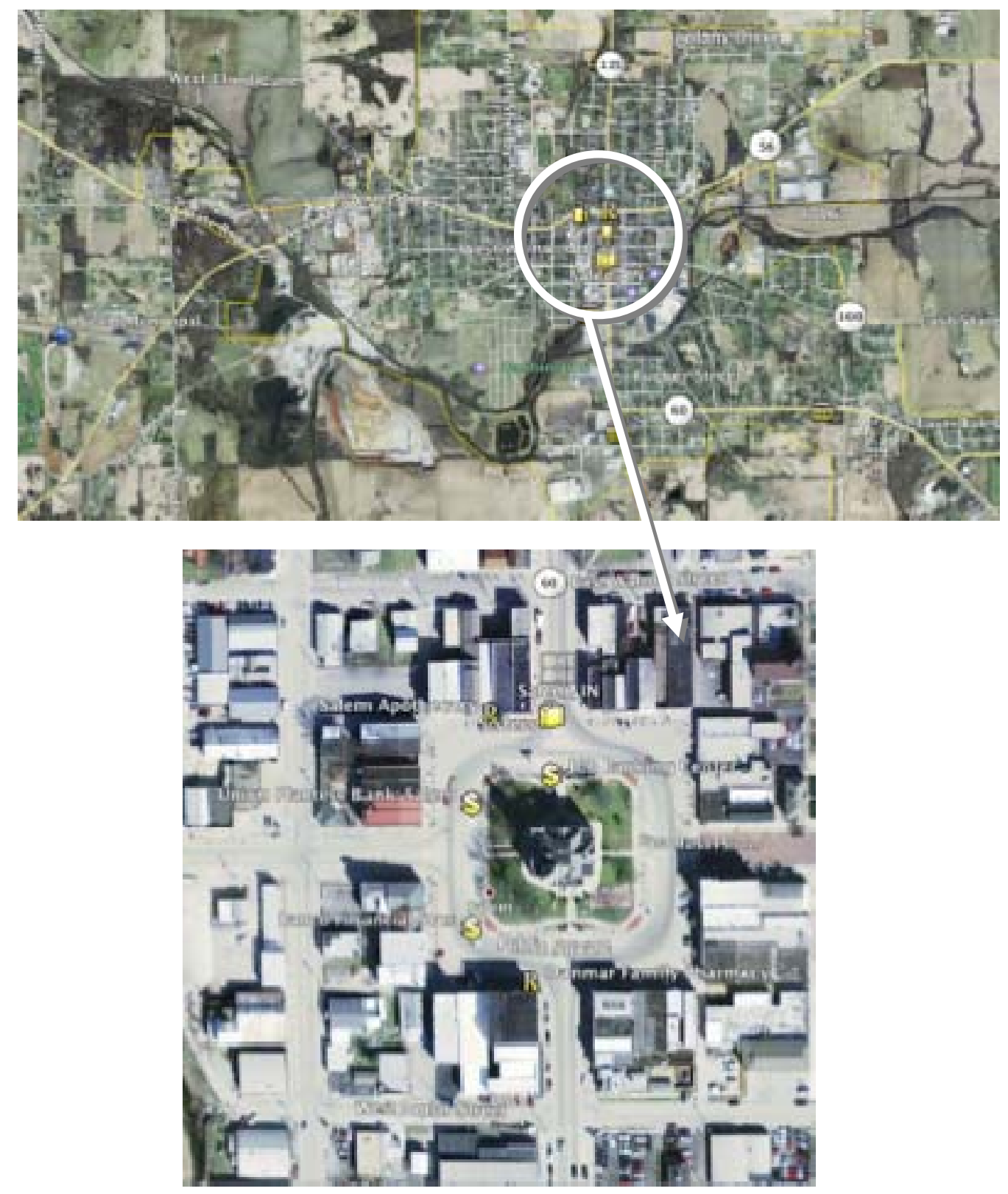

Figure 3.16 (Top) Aerial of Salem and surrounding area. The proposed bypass will run from IN-56 on the west side to IN-60 on the southeast side. (Bottom) Detailed view of the downtown. The courthouse, pharmacies, attorneys' offices, and a number of banks are located in the CBD. Negotiating the square and its two traffic circles can be difficult, particularly when a railroad is passing through three blocks south of the square. (Source: Google Earth) 
The downtown is busy on a typical day. Businesses in the area include a two banks, two pharmacies, various speciality retailers, physical therapy office, a title company, two taverns, attorneys' offices, a coffee shop, restaurants, a rental store, and an art studio. A mix of residential and commercial uses, according to Nolting, occupies the second and third stories. Many of these businesses have expressed concern regarding the impacts the bypass could have on their revenue. However, residents will be more inclined to travel downtown once truck traffic is diverted, Nolting said.

Because of parking issues, most of the major retail businesses moved out of the downtown. The advent of better roads has resulted in commerce being regionalized to a great extent. As a result, the retail sector in Salem has "taken a hit in recent years," Wright said. Many residents, he added, drive to nearby retail stores in Scottsburg, 20 miles to the east, and to Clarksville and Louisville, 35 miles to the southeast.

The truck route is expected to improve public safety in the CBD and stimulate economic development on the east side of the city, where an industrial park will be located near the eastern terminus of the relief route. Much of the expected development has been "deferred" for years, Wright said. Salem and Washington County have been in "pause mode" for ten years while waiting for decision regarding whether the truck route would become a reality, he said.

\subsection{Greencastle}

\subsubsection{Background}


The county seat of Putnam County and the home of DePauw University, Greencastle is located 7 miles northwest of Interstate 70 and 30 miles east of Terre Haute. Prominent industry sectors in the area include manufacturing, distribution, and transportation products. Major employers in the area include a WalMart Distribution Center, Crown Equipment, and Chiyoda USA.

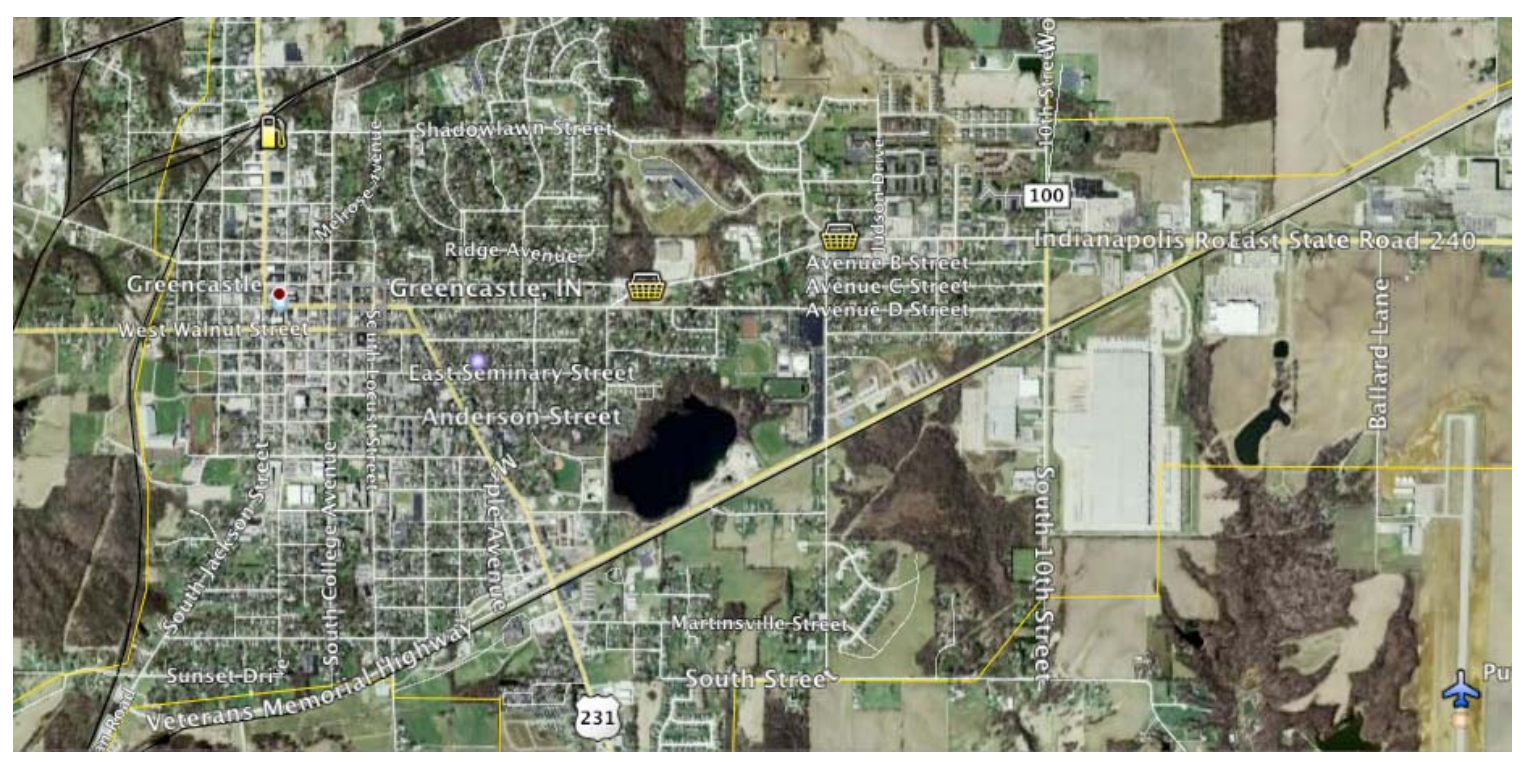

Figure 3.17 Aerial photo of Greencastle. Much of the commercial and industrial development is along IN-240, the principal east-west corridor through the city. For this reason, all proposed alignments for the proposed US-231 bypass travel to the east of the city (Source: Google Earth).

\subsubsection{The Need for a Bypass}

Currently, both local and thru traffic must travel through the CBD of Greencastle via US-231 and IN-240 (in Figure 3.17). Thru traffic must make two sharp turns to follow two-lane US-231 through the CBD, according to William A. Dory, Jr., Executive Director of the Greencastle/Putnam County Development Center. Because of the heavy truck traffic along these routes, a bypass of US-231, to the east of the city, has been proposed with an estimated cost of $\$ 100-120$ million, according to the Final Report of the 2003 Environmental Assessment/Corridor Study: U.S. 
231 from I-70 to I-65. The Corridor Study outlines the following proposed improvements for the bypass (Corradino Group, 2003):

(1) The bypass should be a four-lane, divided limited-access facility with interchanges at US-40 and IN-240.

(2) The existing alignment of US-231 "should be rehabilitated to 4R standards" with grade-separated railroads.

(3) The existing alignment should have partial access control.

The southern terminus would be just north of I-70, and the northern terminus would be located just south of US-36. One of the proposed alignments is shown in Figure 3.18.

The City of Greencastle Comprehensive Plan, dated October 2001, discusses the proposed bypass, outlining how the "heavy" truck traffic "divides" the older neighborhoods and negatively impacts "neighborhood quality and pedestrian safety." Regarding the routing and characteristics of the proposed bypass, the Plan recommended (Ratio Architects, 2001):

This Comprehensive Plan promotes the construction of a limited-access by-pass, either within or near the current city limits. The preferred by-pass route is that which results in the most minimal loss of farmland, avoids the Greencastle wellfields capture area, protects the interests of existing businesses, and creates the fewest opportunities for sprawl development.

The Comprehensive Plan also recommended the creation of a "truck routes plan" to "identify appropriate routes for through trucks."

Currently, the project is not listed under Major Moves new construction projects. Community officials have been assured by INDOT that the Greencastle bypass would be added to the next revision of Major Moves, Dory said. 
At present, truck traffic is negatively impacting the downtown to the point that traffic conditions discourage people from coming downtown. Turning movements through the city are awkward, getting in and out of parking spaces is dif-

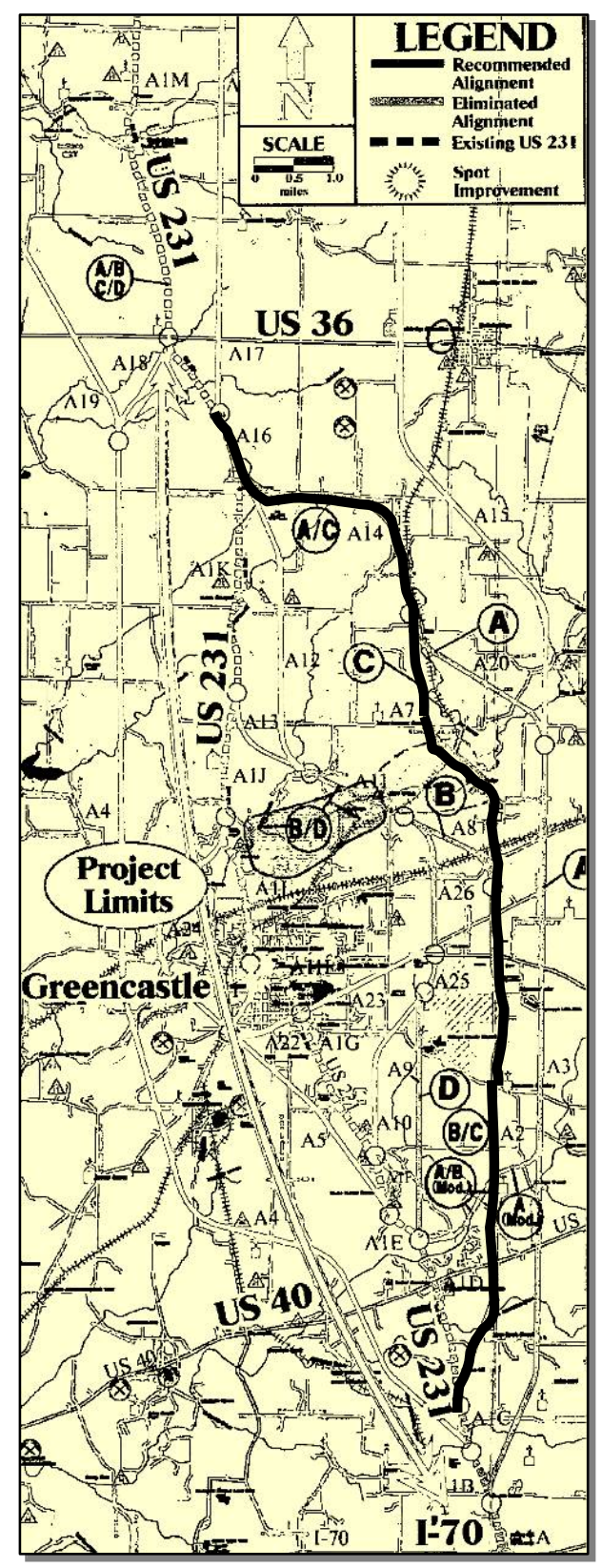

Figure 3.18 Proposed alignment of bypass, shown by the thick black line (Corradino Group, 2003). ficult, and pedestrians often have difficulty crossing streets, according to Dory. Concerts take place at a plaza at the north end of town, but the performances can be hard to hear due to the trucks, he added. A number of retail stores and restaurants are located in the CBD (Wal-Mart and other chains are located to the east, along IN-240), and the upper levels of many downtown buildings have been remodeled for apartments. Much of the truck traffic originates in Greencastle due to the large industry presence in the area, Dory said.

The bypass will not be the "savior of downtown," but its construction will remove a "significant detriment," Dory said. However, the downtown will not improve unless "the business community steps up to take advantage" of the reduction of truck traffic, he said. The bypass will help open up ground for additional industrial development. The city will be able to use the four-lane, limited-access road as a selling point in attracting industry to the area. In terms of the bypass's character- 
istics, officials have been looking at limited-access bypass projects in Wisconsin that are built almost like parkways, with an emphasis placed on aesthetics and control of development, Dory said.

These case studies have outlined the unique characteristics of each affected community that can never be captured in a numerical model. The statistical models developed in Chapter 4 will build upon these case studies. These models will quantify long-term economic changes that have taken place. 


\section{CHAPTER 4. ECONOMETRIC ANALYSIS OF PANEL DATA}

\subsection{Introduction}

The case study approach helped to gain insight into the unique characteristics of each community that can never be captured in a numerical model. A number of bypasses in Indiana are more than 30 years old. Analysis of the economic characteristics of these bypassed communities could reveal the long-term economic implications of constructing a bypass. To determine these long-term impacts on a bypassed community's economy, econometric methods were used.

\subsection{Economic Data Selected for Analysis}

Previous studies relating to bypasses have focused primarily on the impacts on traffic-dependent businesses, such as hotels, gasoline service stations, and restaurants located along the bypassed route. In particular, many of these studies analyzed how sales at each of these businesses changed over time.

The number of data points for many of the models developed in previous studies that were described in the literature review was fairly small. Srinivasan and Kockelman's models had nine data points, for example, while Burress's model had four data points. The small number of data points stems primarily from the limitations of the sources of data. For example, Srinivasan and Kockelman's population data were culled from the U.S. Census of Population, published de- 
cennially. The intervening years were linearly interpolated. The sales data used in the model were taken from the U.S. Economic Census, published every five years.

This project's approach to modeling differs in several ways from previous studies:

(1) Impacts on employment and payroll in various industry sectors would serve as the main focus of the modeling process.

(2) Sources of such data were published on an annual basis. These data were collected for an extended time frame to provide ample numbers of data points.

(3) In addition to analyzing "absolute" numbers (such as manufacturing employment in a given county), economic data were normalized against the state to account for external economic factors.

Economic data were collected from County Business Patterns (CBP), a publication released by the U.S. Census Bureau on an annual basis beginning in 1964. Previous years were published on an irregular basis, starting in 1946. County Business Patterns provide data for the following characteristics for various industry sectors:

(1) Employment: These figures account for all employees of an establishment, including executives, as of March 12 of the given year. These figures do not account for "proprietors and partners of unincorporated businesses" (Census, 2007). 
(2) Payroll: These figures, taken for the first-quarter (January to March) and annually, account for salaries, wages, tips, contributions to pension, pay for sick-leave, and "taxable fringe benefits." The figures reported do not include deductions for Social Security, insurance, and other such deductions. Like the employment figures, payroll figures in CBP do not account for unincorporated businesses.

(3) Establishment/Reporting Unit: An establishment, as defined by the Census Bureau, is "a single physical location at which business is conducted or services or industrial operations are performed." Prior to 1974, the term "reporting unit" was used in place of "establishment." The term "establishment" is more restrictive than the term "reporting unit," as the term "establishment" refers to one physical location. Entities with more than one physical location report each location as a separate establishment. Direct time-series comparisons from years prior to 1974 with years 1974 onward can be made only for the manufacturing sector, whereas direct comparisons cannot be made for all other sectors. The use of county-to-state ratios helps to clarify the differences.

Additional economic data were collected from STATS Indiana, a website administered by the Indiana Business Research Center at the Indiana University Kelley School of Business. Annual earnings and employment data were compiled by STATS Indiana from the U.S. Bureau of Economic Analysis (BEA). These data differ from the County Business Patterns payroll data somewhat in that earnings data include earnings of sole proprietorships (that is, unincorporated businesses). These data form the components of personal income: Wage and salary disbursements, supplements to wages and salaries (which includes employee contribution to Social Security, etc), and proprietors' income. 
Annual population estimates for each county were also collected from STATS Indiana for years 1970-1997; the website compiles these data from the U.S. Census Bureau. Other population estimates were acquired directly through the U.S. Census Bureau archives website.

Limitations on the time frame of analysis were as follows:

(1) Prior to 1998, industry classification was based on the Standard Industrial Classification (SIC). Data for years 1998 onward in County Business Patterns are classified based on the North American Industrial Classification System (NAICS). Reconciling differences between the two systems is difficult. Because of the difficulty in reconciling the differences between the two classification systems, 1997 is the last year in the analysis time frame.

(2) Annual population data on a county basis were available on STATS Indiana only beginning in 1970. Because of this restriction, 1970 is the first year in the analysis time frame.

\subsection{Selection of Counties for Analysis}

Shown below in Table 4.1 are the opening dates for selected bypasses in Indiana. 
Table 4.1 Opening dates of bypasses

\begin{tabular}{lll} 
City & County & Year Opened \\
\hline Logansport & Cass & 1999 \\
Washington & Daviess & 1991 \\
Kokomo & Howard & 1951 \\
Huntington & Huntington & 1964 \\
Warsaw & Kosciusko & 1972 \\
Anderson & Madison & 1973 \\
Peru & Miami & 1979 \\
Wabash & Wabash & 1979 \\
Columbia City & Whitley & $1968^{*}$
\end{tabular}

The opening date for Columbia City is approximate. The counties shown in bold were selected for statistical analysis. As learned from the case studies, Anderson (Madison County) was adversely affected by the decline of the auto industry to a much greater degree than the IN-9 bypass affected it. For this reason, Madison County was excluded. The Logansport bypass opened outside of the analysis time frame and was thus excluded from the study.

\subsection{Modeling Form}

Panel data combines both time-series data (in this case, for years 1970-1997) and cross-sectional data (in this case, for seven counties). Panel data are typically analyzed in two ways that account for data heterogeneity: one-way error component models (which account for either cross-sectional effects or time-series effects) or two-way error component models (which account for time-series effects, or serial correlation, and cross-sectional effects). Both one-way and two-way error component models can be specified under fixed effects or random effects. 
Fixed-effects models differ from random-effects models in that any inferences made from a fixed-effects model "are conditional on the particular crosssectional units sampled," (Washington et al., 2003). Random-effects models, on the other hand, assume the cross-sectional units are randomly drawn from a "large" population. Fixed-effects models cannot be generalized to other crosssectional units outside the sample. Such is not the case with random-effects models. In other words, for this study, the random-effects model would be more appropriate; the findings from a random-effects model can be generalized to other counties outside the sample; that is, other counties that have bypasses.

Srinivasan and Kockelman's models utilized a one-way random-effects specification, which accounted only for cross-sectional effects. For this study, a two-way random-effects specification was deemed most appropriate for modeling. This model takes the form:

$$
\begin{aligned}
& Y_{i t}=\alpha+\mathbf{X}_{i t}^{\prime} \beta+\mu_{i}+\lambda_{t}+v_{i t} \\
& u_{i t}=\mu_{i}+\lambda_{t}+v_{i t} \\
& i=1, \ldots, N, t=1, \ldots, T
\end{aligned}
$$

where

$Y_{i t}$ is the dependent variable,

$\alpha$ is the intercept,

$\mathbf{X}_{i t}^{\prime}$ is the vector of explanatory variables with coefficients $\beta$,

$u_{i t}$ is the disturbance term,

$\mu_{i}$ represents unobserved cross-sectional-specific effects,

$\lambda_{t}$ represents unobserved time-series effects, and

$v_{i t}$ represents random disturbances. 
Under the random-effects specification, it is assumed that $\square$ are independent of $\square, \square$, and $\square$ for all cross-sections $(\mathrm{N}=7)$ and years $(\mathrm{T}=28)$. Error terms $\square, \square$, and $\square$ are assumed to be independently and identically distributed (IID) with zero means and variances $\sigma_{\mu}^{2}, \sigma_{\lambda}^{2}$, and $\sigma_{v}^{2}$, respectively (Washington et al., 2003). The sum of these variances is equal to the variance of the overall disturbance term $\square$; in other words, the disturbance variance is homoscedastic.

The statistical package LIMDEP was used to develop the two-way randomeffects models. The program first estimates the model under the fixed-effects specification by using ordinary least squares and dummy variables. The model is then estimated under the random-effects specification through feasible, two-step generalized least squares (FGLS); that is, the variance components from the residuals from ordinary least squares (OLS) regressions are used to estimate FGLS coefficients.

\subsection{Statistical Tests for Random Effects}

\subsubsection{Lagrange Multiplier Test}

To determine whether classical regression (with one constant term) should be used instead of a fixed or random effects specification, the test, developed by Breusch and Pagan, tests for correlation of error terms as follows (Greene, 2003):

$$
\begin{aligned}
& H_{0}: \operatorname{CORR}\left[u_{i t}, u_{i s}\right]=0 \\
& H_{1}: \operatorname{CORR}\left[u_{i t}, u_{i s}\right] \neq 0
\end{aligned}
$$


The test statistic has a chi-square distribution with one degree of freedom under the null hypothesis and is calculated as follows:

$$
L M=\frac{n T}{2(T-1)}\left[\frac{\sum_{i=1}^{n}\left(T \bar{e}_{i}\right)^{2}}{\sum_{i=1}^{n}\left(T \bar{e}_{i} \cdot\right)^{2} \sum_{t=1}^{T}\left(e_{i t}^{2}\right)}-1\right]^{2}
$$

Where $e$ represents the residuals from least squares regression. If the test statistic exceeds the critical value, the classical regression model should not be used.

\subsubsection{Hausman Test for Random Effects}

With the random-effects specification, it is assumed that individual effects are not correlated with the regressors (Washington et al., 2003). The test developed by Hausman and Taylor, often referred to as the Hausman test for random effects, tests:

$$
\begin{aligned}
& H_{0}: E\left(u_{i t} \mid \mathbf{X}_{i t}\right)=0 \\
& H_{1}: E\left(u_{i t} \mid \mathbf{X}_{i t}\right) \neq 0
\end{aligned}
$$

If the null hypothesis holds, the coefficients under LSDV (least-squares with dummy variables, i.e. the fixed-effects specification) and GLS (the random-effects specification, estimated with two-step FGLS) are consistent and asymptotically efficient, whereas under the alternative hypothesis, only the LSDV (fixed-effects specification) is unbiased and consistent (Washington et al., 2003). In other words, if the null hypothesis is rejected, the fixed-effects specification should be favored over the random-effects specification. 
The test statistic is:

$$
h=\left(\hat{\beta}_{G L S}-\hat{\beta}_{L S D V}\right)\left[\operatorname{VAR}\left(\hat{\beta}_{G L S}-\hat{\beta}_{L S D V}\right)\right]^{-1}\left(\hat{\beta}_{G L S}-\hat{\beta}_{L S D V}\right)
$$

The test statistic is chi-squared distributed with degrees of freedom equal to the number of parameters in the model. A p-value associated with this test statistic less than 0.1 (90 percent confidence level) favors the random-effects specification over the fixed-effects specification (Washington et al., 2003).

\subsection{Measures of Industry Economic Characteristics}

Dependent variables in the models fall roughly into two categories:

(1) Absolute figures: These figures represent employment in a given SIC sector, such as manufacturing employment in Daviess County in 1971.

(2) County-to-state ratios: These figures divide employment or payroll figures against corresponding values for the state overall. For example, the county-to-state ratio of manufacturing employment for Daviess County in 1971 is computed as the ratio of manufacturing employment in the county that year to manufacturing employment in the entire state that same year.

The use of county-to-state ratios have the following advantages:

(1) When examining payroll or earnings figures, normalizing against the state cancels out inflation. 
(2) Normalizing county figures against the state accounts for external economic factors, such as recessions and overall industry trends, such as the decline of the American auto industry.

County-to-state ratios provide insight into how much each county is contributing to the entire state's economy. For example, if Kosciusko County has a 1 percent manufacturing employment county-to-state ratio in 1985, the county contributes 1 percent to the state's economy with respect to manufacturing employment for that year.

Because they normalize out a number of externalities, county-to-state ratios have greater practical meaning than the absolute figures, particularly in the manufacturing sector.

For modeling purposes, the manufacturing sector was chosen as a starting point. Manufacturing employees make up part of what is referred to in the literature as basic workers, or workers who "are employed in industry, commercial, and office facilities whose location selections are based on considerations other than locally required access," (Brail, 1987). Basic industries, when deciding where to locate, are sensitive to a number of factors outlined by officials interviewed in the previous chapter, such as market and labor access, transportation costs, and the availability of "shovel-ready" sites.

Service employees, in contrast, "are employed in firms which derive income from proximity to basic industry," according to Brail. Examples of service industries include offices and retail trade (which includes eating and drinking places). Numerical models such as the Lowry Model illustrate the relationship between basic industries and service industries. 
Accounting for these relationships between basic and service workers, most models for service industries include some aspect of the manufacturing industry as an explanatory variable.

\subsection{Industry Sectors selected for study (by SIC)}

\subsubsection{Manufacturing (SIC 20-39)}

This sector includes metal, tobacco, furniture, concrete, paper, leather, electronics, watches, and other industries relating to "establishments engaged in the mechanical or chemical transformation of materials or substances into new products," (OSHA, 2007). The Manufacturing division also includes food and kindred products, which includes the meatpacking industry.

\subsubsection{Construction (SIC 15-17)}

This division includes establishments for general contractors, special trade contractors, and other establishments who primarily specialize in construction.

\subsubsection{Retail Trade (SIC 52-59)}

According to OSHA, the retail trade division "includes establishments engaged in selling merchandise for personal or household consumption and rendering services incidental to the sale of the goods." Examples of such establishments include grocery stores, gasoline service stations, and eating and drinking places (SIC 58). 


\subsubsection{Wholesale Trade (SIC 50-51)}

This division differs from the Retail Trade division in that establishments under this heading generally sell merchandise to other businesses, particularly retailers, industry, contractors, or professionals. Establishments included under this division also may act as "agents or brokers" who buy or sell such merchandise to and from the aforementioned industries, according to OSHA. Such establishments act as a bridge between basic and service industries.

\subsubsection{Transportation and Public Utilities (SIC 40-49)}

This division includes water, electric, gas, communications and other public utilities, as well as the United States Postal Service and Motor Freight Transportation and Warehousing (SIC 42). The Transportation and Warehousing major group includes warehousing, storage, and terminal facilities for trucks.

\subsubsection{Agricultural Services (SIC 07)}

This major group includes establishments that specialize in such areas as soil preparation, landscaping, farm labor contracting, and crop planting, harvesting, and preparation.

\subsubsection{Health Services (SIC 80)}

This major group includes offices of doctors, dentists, chiropractors, podiatrists, psychiatric hospitals, general hospitals, nursing homes, and kidney dialysis centers. 
Mid-March employment, first-quarter payroll, and number of establishments data were compiled from County Business Patterns for total employment, manufacturing, wholesale trade, retail trade, and eating and drinking places. Annual employment and earnings data from STATS Indiana were compiled for construction, transportation and public utilities (employment only), trucking and warehousing (earnings only), agricultural services (earnings only), and health services (earnings only).

\subsection{Explanatory Variables}

Employment, payroll, earnings, and establishment data (absolute figures and county-to-state ratios) serve as both dependent and explanatory variables in the models (accounting for the aforementioned relationship between basic and service industries). Additional types of explanatory variables used are detailed below.

\subsubsection{Nearest large city characteristics}

These variables describe the characteristics of the county with the nearest large city, in particular population and distance from the nearest large city to the central business district (CBD) of the study city. Through trial and error, various ratios relating the large city to its distance from the study city were used as explanatory variables; in general, it was found that a nonlinear relation (such as taking the natural log of the distance) provided a more statistically significant result. 
Table 4.2 shows the bypassed cities that are included in the models and their associated nearest large cities.

Table 4.2 Nearest large cities of bypassed counties.

\begin{tabular}{lllll}
\hline City & County & City-Large & County-Large & Distance (mi) \\
\hline Washington & Daviess & Evansville & Vanderburgh & 55 \\
Kokomo & Howard & Indianapolis & Marion & 63 \\
Huntington & Huntington & Fort Wayne & Allen & 25 \\
Warsaw & Kosciusko & Fort Wayne & Allen & 45 \\
Peru & Miami & Fort Wayne & Allen & 65 \\
Wabash & Wabash & Fort Wayne & Allen & 46 \\
Columbia City & Whitley & Fort Wayne & Allen & 20 \\
\hline
\end{tabular}

4.8.2. Bypassed county characteristics

These characteristics include the affected county's population, the ratio of the affected county's population to the nearest large city, and the ratio of the population of the affected county to the population of the county with the nearest large city. Other indicators include the distance from the CBD of the bypassed city to the bypass along the original route and the number of turns in the CBD along the original route. For example, a driver must make four turns to follow the original routing of US-24 in Wabash. The number of turns was determined by examination of Google Earth aerial photos.

\subsubsection{Statewide characteristics}

These include statewide figures for employment, payroll, earnings, and establishments, as well as population. 


\subsubsection{Bypass characteristics}

In some models, an indicator variable was used to denote the presence (or lack thereof) of a bypass. This indicator was set to 1 the first year the bypass was open and all years thereafter, and set to 0 otherwise.

\subsection{Methodology for Estimation of Impacts}

Through trial and error, it was found that the usage of additional indicators representing the bypass's age provided more meaningful results than the use of a continuous linear or nonlinear function representing the number of years the bypass has been open. These age indicators were grouped into different age groups, the size of each age group also determined by trial and error for each model. To illustrate, consider a county that has had a bypass open for 13 years. Assume this county has three separate bypass age indicators, one indicator for years 1-5, another indicator for years 6-10, and another indicator for years 13-15. The indicator for years 1-5 would be set to 1 for the first 5 years the bypass is open. Thereafter, the indicator would be set equal to 0 . For the next 5 years, the age 6-10 indicator would be set to 1 . This indicator would then be set to 0 after those 5 years. For the final 3 years, the age 13-15 indicator would be set to 1 . This brief example shows that only one indicator is "switched on" for a given observation.

\subsection{Sensitivity, Elasticity, and Pseudo-Elasticity Analysis}

To ascertain the overall impact of the various regressors on employment and payroll in the selected industry sectors, elasticity and pseudo elasticity techniques were employed. Predicted values generated by LIMDEP were used to cal- 
culate the percentage change when one variable was modified while keeping all others constant. The methods used are detailed below:

\section{Employment and payroll figures (absolute and county-to-state ratios), pop-} ulation figures: The given variable was increased by 1 percent. The modified predicted value was compared to the original predicted value as follows:

$$
\% \text { change }=100 \cdot \frac{\begin{array}{c}
\text { Modified predicted value } 1 \% \text { change in regressor } \\
\text { with } 1 \% 44447_{i} 4444448 \\
\text { Original predicted value }
\end{array}}{\begin{array}{c}
\text { Original predicted value } \\
\text { from LIMDEP for given model }
\end{array}}
$$

Bypass age indicators: Any instance in which the age indicator was set to "1" was set to " 0. " The elasticity was then calculated as follows:

$$
\begin{aligned}
& \text { Modified predicted value ___ Original predicted value }
\end{aligned}
$$

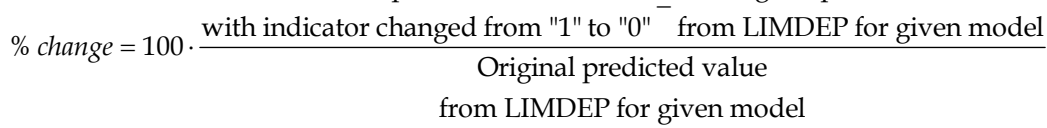

The percentage change calculations were performed only for the observations in which a change was made. In several cases, the natural logarithm of the dependent variable was estimated in the event the given model yielded negative predicted values (such values would be illogical; a county cannot have negative employment). When this was the case, the regression equation was modified as follows:

$$
\begin{aligned}
& L N\left(Y_{i t}\right)=\alpha+\mathbf{X}_{i t}^{\prime} \beta+\mu_{i}+\lambda_{t}+v_{i t} \\
& Y_{i t}=e^{\alpha+\mathbf{X}^{\prime}{ }_{i t} \beta+\mu_{i}+\lambda_{t}+v_{i t}}
\end{aligned}
$$


For explanatory variables, when the natural logarithm of an economic variable (such as payroll) was taken, the elasticity was calculated as:

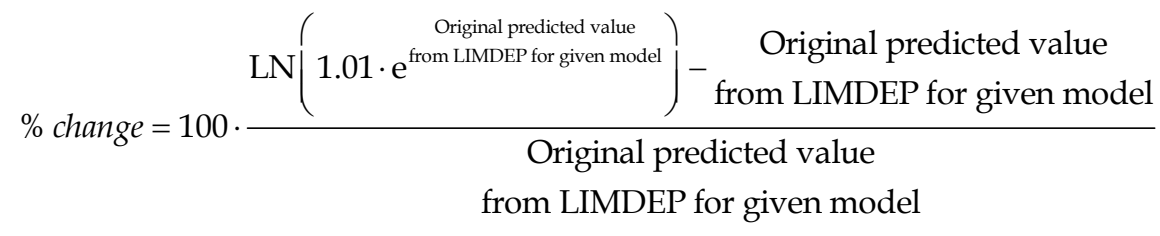

Resulting percentage changes for age indicators indicate how employment or payroll would be affected if a bypass were not constructed (for years 1-6, 1-10, 115 , or 1-20 indicators) or if the bypass were opened five years prior (for all other indicators). Elasticity and pseudo-elasticity calculations are included in the results under the general heading "Elasticity."

\subsection{Results}

The results of the modeling process are discussed in the following sections. The implications of the results will be covered in Chapter 5 . 


\subsubsection{Total Employment: County to State Ratio (Natural Log)}

\begin{tabular}{lccr}
\hline Variable & \multicolumn{2}{c}{ Coefficient } & \multicolumn{2}{c}{ Elasticity } \\
\hline LLPLD & $1.44 \mathrm{E}-05$ & 6.779 & $1.34 \%$ \\
POPSL & $8.50 \mathrm{E}+00$ & 11.001 & $1.15 \%$ \\
US30 & $-1.32 \mathrm{E}-01$ & -2.188 & $14.14 \%$ \\
BCBD & $-4.21 \mathrm{E}-02$ & -4.048 & $-0.13 \%$ \\
BNUM & $-5.19 \mathrm{E}-02$ & -5.214 & $-5.06 \%$ \\
Z123 & $2.27 \mathrm{E}-01$ & 5.975 & $-20.35 \%$ \\
Z4 & $1.84 \mathrm{E}-01$ & 5.338 & $-16.82 \%$ \\
Z5 & $1.44 \mathrm{E}-01$ & 4.429 & $-13.43 \%$ \\
Z6 & $2.24 \mathrm{E}-01$ & 7.042 & $-20.08 \%$ \\
Z7 & $1.91 \mathrm{E}-01$ & 5.860 & $-17.38 \%$ \\
Constant & $-7.52 \mathrm{E}+00$ & -29.727 & \\
\hline Lagrange Multiplier Test & \multicolumn{4}{c}{$372.560(0.000)$} \\
Hausman Test & & $6.280(0.791)$ \\
R-squared & \multicolumn{4}{c}{} \\
\hline
\end{tabular}

P-values for the statistical tests are shown in parentheses. As indicated by the bypass age indicators, total employment (relative to the state) is positively impacted by the presence of a bypass. The presence of a nearby larger city also positively contributes to employment. Even with the US-30 indicator in place, which could be expected to produce a lower p-value for the Hausman test, the test statistic still factors the random-effects specification. The coefficient of the indicator is positive. Being located on the same corridor as other cities (e.g., Columbia City and Warsaw both reside on US-30) positively impacts total employment (relative to the state). The variable's negative coefficient reflected unobserved characteristics of the bypasses along US-30 not captured by the model. Total employment (relative to the state) would be approximately 20 percent lower without the bypass, as shown by the elasticities. As indicated by the negative coefficient on the number of turns variable, even with the bypass in place, the harder it is to get through the affected city's CBD, the more negative the impact on total employment. The magnitude of the bypass age indicators are similar, showing that the 
presence of a bypass will benefit total employment (relative to the state) in the long term.

4.11.2. Proprietors' Employment, County to State Ratio (Natural Log)

\begin{tabular}{lccr}
\hline Variable & \multicolumn{2}{c}{ Coefficient } & \multicolumn{2}{c}{ t-statistic } & \multicolumn{2}{c}{$0.42 \%$} \\
LSPLD & $3.64 \mathrm{E}-05$ & -615 & $-0.16 \%$ \\
LWHOESTR & $-1.65 \mathrm{E}-01$ & -4.368 & $0.08 \%$ \\
RETESTR & $9.52 \mathrm{E}+00$ & 1.162 & $-1.17 \%$ \\
POP_IN & $-2.14 \mathrm{E}-07$ & -2.981 & $1.86 \%$ \\
Z123 & $-1.84 \mathrm{E}-02$ & -1.727 & $2.96 \%$ \\
Z4 & $-2.92 \mathrm{E}-02$ & -2.002 & $9.72 \%$ \\
Z5 & $-9.27 \mathrm{E}-02$ & -5.422 & $14.04 \%$ \\
Z6 & $-1.31 \mathrm{E}-01$ & -7.626 & $16.51 \%$ \\
Z7 & $-1.53 \mathrm{E}-01$ & -7.963 & \\
Constant & $-4.77 \mathrm{E}+00$ & -11.083 & \\
\hline Lagrange Multiplier Test & \multicolumn{4}{c}{$839.770(0.000)$} \\
Hausman Test & \multicolumn{4}{c}{0.514} \\
\hline R-squared &
\end{tabular}

Proprietors' employment represents the number of sole proprietorships and partnerships in a given county or city. Such establishments are often mom-and-pop businesses and other smaller business operations. Consolidation has occurred to a large extent in the retail trade. With this fact in mind, it is expected that the bypass age indicator variables will have negative coefficients. That is confirmed as shown above. Strangely, the number of wholesale trade establishments (relative to the state) negatively impact proprietors' employment. As expected, the larger the affected city, the greater the proprietors' employment.

The increasing magnitude of the elasticities shows that the negative impact of a bypass on proprietors' employment becomes more prevalent. Previous studies showed that the majority of businesses that establish a presence near the bypass are new to the area. As is the case with Columbia City, many of these businesses 
are established chain stores. Smaller stores on the original route, such as momand-pop stores, often have difficulty competing with their larger counterparts and end up closing down. This model is normalized against the state. Even when accounting for the general overall trend of retail consolidation, there is still a noticeable decrease in the magnitude of sole proprietorships. The implications of this model will be discussed in the following chapter.

\subsubsection{Manufacturing Payroll: County to State Ratio (Natural Log)}

\begin{tabular}{|c|c|c|c|}
\hline \multirow{2}{*}{$\frac{\text { Variable }}{\text { LLPLD }}$} & Coefficient & t-statistic & Elasticity \\
\hline & 1.67E-05 & 4.146 & $1.54 \%$ \\
\hline POPSL & $1.17 \mathrm{E}+01$ & 5.547 & $1.58 \%$ \\
\hline $\mathrm{HHIC}$ & $2.76 \mathrm{E}-01$ & 4.340 & $-24.10 \%$ \\
\hline LTRUCKR & $-1.43 \mathrm{E}-01$ & -1.783 & $-0.14 \%$ \\
\hline LWHOPAYR & $-1.10 \mathrm{E}-01$ & -2.558 & $-0.11 \%$ \\
\hline LRETPAYR & 8.84E-01 & 4.598 & $0.88 \%$ \\
\hline $\mathrm{Z3}$ & $-7.36 \mathrm{E}-02$ & -1.851 & $7.63 \%$ \\
\hline Z5 & $-9.70 \mathrm{E}-02$ & -2.090 & $10.19 \%$ \\
\hline $\mathrm{Z7}$ & $2.02 \mathrm{E}-01$ & 2.790 & $-18.28 \%$ \\
\hline Z8 & 1.51E-01 & 1.675 & $-13.99 \%$ \\
\hline Constant & $-5.02 E+00$ & -3.482 & \\
\hline Lagrange $\mathrm{M}$ & olier Test & 392.700 & \\
\hline Hausman Te & & 4.000 & \\
\hline R-squared & & 0.852 & \\
\hline
\end{tabular}

The coefficient of the study city to large city ratio is positive. This shows that manufacturing payroll (relative to the state) will be more positively impacted as the affected city grows over time. The positive coefficient on the large city distance ratio indicates that the closer a larger city is the more positive the impacts on manufacturing payroll. As expected, higher earnings in wholesale trade and warehousing negatively impact manufacturing payroll. The coefficients on bypass age indicators are negative for years 11-15 and 21-25 (indicators in between these years were not statistically significant). This shows that payroll will be negatively im- 
pacted for the first couple of decades the bypass is open. However, after the bypass has been open for 30 years, the impacts on payroll (relative to the state) become positive. Note the magnitude of the elasticities, which are greater for years 31-35 and 36-40 than for earlier years. This suggests that even though the initial impacts on manufacturing payroll are negative, as the bypass ages and industry has time to construct facilities near the bypass, there will be long-term benefits. As learned from interviews with various officials, lower transportation costs provide ample incentive for industry to pick one place over another to construct a facility. The ease of access to major travel corridors, such as Interstates and arterials serves as an important selling point for economic development organizations. The positive coefficient and double-digit elasticity of the US-24 indicator reflects the importance of this fact. A bypassed city will benefit from being located on the same route as several other cities.

4.11.4. Manufacturing Employment: County to State Ratio

\begin{tabular}{lccr}
\hline Variable & \multicolumn{2}{c}{ Coefficient } & \multicolumn{2}{c}{ Elasticity } \\
\hline POP_IN & $-9.53 \mathrm{E}-09$ & -6.437 & $-7.25 \%$ \\
RETEMP & $2.60 \mathrm{E}-06$ & 9.603 & $0.71 \%$ \\
CONEMPR & $3.06 \mathrm{E}-01$ & 1.904 & $0.22 \%$ \\
WHOEMP & $1.32 \mathrm{E}-06$ & 2.471 & $0.09 \%$ \\
PROPEMPR & $4.36 \mathrm{E}-01$ & 2.164 & $0.53 \%$ \\
YR5 & $3.18 \mathrm{E}-03$ & 5.283 & $-31.19 \%$ \\
Z1 & $1.42 \mathrm{E}-03$ & 2.990 & $-25.01 \%$ \\
Z2 & $-8.43 \mathrm{E}-04$ & -1.981 & $11.75 \%$ \\
Z4 & $9.61 \mathrm{E}-04$ & 2.352 & $-9.83 \%$ \\
Z5 & $2.56 \mathrm{E}-03$ & 5.860 & $-19.35 \%$ \\
Z6 & $3.64 \mathrm{E}-03$ & 7.255 & $-28.37 \%$ \\
Z7 & $5.55 \mathrm{E}-03$ & 8.386 & $-30.40 \%$ \\
Constant & $4.62 \mathrm{E}-02$ & 5.690 \\
\hline Lagrange Multiplier Test & \multicolumn{4}{c}{$485.470(0.000)$} \\
Hausman Test & \multicolumn{4}{c}{0.949} \\
\hline R-squared &
\end{tabular}


In contrast to the corresponding payroll model, the coefficients of all bypass age indicators (except for years 6-10) are positive. When compared with the corresponding model in 4.11.3, it can be observed from the signs of the coefficients and the magnitude of the elasticities that manufacturing employment will benefit from the presence of a bypass much sooner than manufacturing payroll. The lag of payroll behind employment may reflect unobserved characteristics of the manufacturing sector. As explained in 4.7.1, the Manufacturing SIC definition includes meatpacking establishments, which are often lower-paying jobs. A bypass, in the initial years it is open, could be attracting such establishments, as well as other lower-paying manufacturing jobs, in part due to the possible lack of presence of labor unions. County Business Patterns data for payroll also include salaries of executives. Newly opened manufacturing establishments could have fewer executives, who tend to earn more than rank-and-file employees. Overall, however, the manufacturing industry is positively impacted by the presence of the bypass.

4.11.5. Manufacturing Employment (Natural Logarithm)

\begin{tabular}{lccr}
\hline Variable & Coefficient & \multicolumn{2}{c}{ t-statistic } \\
\hline LLPLD & $1.15 \mathrm{E}-05$ & 2.776 & $1.07 \%$ \\
MFGESTR & $3.79 \mathrm{E}+01$ & 2.473 & $0.35 \%$ \\
LCONEMPR & $-1.83 \mathrm{E}-01$ & -1.560 & $-0.18 \%$ \\
TPEMP & $4.48 \mathrm{E}-04$ & 4.980 & $0.37 \%$ \\
WHOEMP & $9.33 \mathrm{E}-05$ & 1.550 & $0.06 \%$ \\
Z1 & $6.96 \mathrm{E}-02$ & 1.786 & $-6.72 \%$ \\
Z5 & $7.71 \mathrm{E}-02$ & 1.806 & $-11.81 \%$ \\
Z6 & $1.79 \mathrm{E}-01$ & 3.738 & $-16.40 \%$ \\
Z7 & $2.21 \mathrm{E}-01$ & 3.569 & $-19.82 \%$ \\
Constant & $5.75 \mathrm{E}+00$ & 7.256 & \\
\hline Lagrange Multiplier Test & \multicolumn{4}{c}{$893.250(0.000)$} \\
Hausman Test & \multicolumn{4}{c}{$11.620(0.235)$} \\
R-squared & 0.788 \\
\hline
\end{tabular}


When comparing the model for absolute employment to the model for employment relative to the state, similar conclusions can be drawn. The coefficients for the bypass age indicators are positive and have negative elasticities. Both increase in magnitude over time. Whether considering absolute employment figures or accounting for the "background noise" of the state, the presence of a bypass positively impacts manufacturing employment. The construction, warehousing, and wholesale trade sectors positively impact manufacturing employment. Interestingly, the coefficients of the wholesale trade variables in both manufacturing employment models are positive, whereas the coefficient of the corresponding variable in the manufacturing payroll model is negative. This shows that the wholesale trade sector also has mixed effects on the manufacturing industry.

4.11.6. Annual Earnings, Health Services, County to State Ratio

\begin{tabular}{lccr}
\hline Variable & \multicolumn{2}{c}{ Coefficient } & \multicolumn{2}{c}{ tstatistic } & $-2.07 \%$ \\
\hline ELPLD & $-1.12 \mathrm{E}+05$ & -1.733 & $-11.52 \%$ \\
POP_IN & $-2.56 \mathrm{E}-09$ & -6.771 & $0.16 \%$ \\
WHOPAYR & $5.88 \mathrm{E}-02$ & 3.429 & $0.52 \%$ \\
MFGEMPR & $1.17 \mathrm{E}-01$ & 3.967 & $0.71 \%$ \\
EATEMPR & $2.07 \mathrm{E}-01$ & 3.842 & $8.64 \%$ \\
Z12 & $-1.98 \mathrm{E}-04$ & -1.808 & $-7.31 \%$ \\
Z6 & $4.91 \mathrm{E}-04$ & 2.720 & $-6.94 \%$ \\
Z7 & $4.48 \mathrm{E}-04$ & 1.919 & \\
Constant & $1.63 \mathrm{E}-02$ & 7.253 & \\
\hline Lagrange Multiplier Test & \multicolumn{4}{c}{$615.430(0.000)$} \\
Hausman Test & \multicolumn{4}{c}{$0.050(0.261)$} \\
\hline R-squared & \multicolumn{4}{c}{0.765} \\
\hline
\end{tabular}

Healthcare has grown in magnitude in recent years and is therefore covered here. The coefficient of the year 1-10 age indicator is negative, showing that there is an initial negative impact on earnings. Strangely, none of the age indicators for 
years 11-25 were statistically significant. Beginning with the $26^{\text {th }}$ year after the bypass was open, healthcare earnings impacts become positive. This could indicate a lag in development. A number of newer-looking healthcare establishments were observed along US-24 bypass (opened in 1979) on the outskirts of Wabash, for example. Oddly, the larger the population of the entire state, the lower the annual earnings in healthcare (relative to the state), as indicated by the negative coefficient of the Indiana population variable. As reflected by the corresponding elasticity value, when the population of Indiana increases by 1 percent, annual earnings decrease by almost 12 percent. This is likely representative of unobserved heterogeneity in the healthcare sector. In addition, the presence of a larger city appears to negatively impact healthcare earnings (relative to the state). Larger cities tend to have higher-quality healthcare facilities than smaller cities.

4.11.7. Retail Trade Employment: County to State Ratio

\begin{tabular}{lccr}
\hline Variable & \multicolumn{2}{c}{ Coefficient } & \multicolumn{2}{c}{ Elasticity } \\
\hline LLPLD & $6.40 \mathrm{E}-08$ & 7.801 & $0.91 \%$ \\
BNUM & $-2.37 \mathrm{E}-04$ & -2.962 & $-4.53 \%$ \\
BCBD & $-3.51 \mathrm{E}-04$ & -4.085 & $-0.21 \%$ \\
BYPASS & $1.27 \mathrm{E}-03$ & 3.045 & $-21.06 \%$ \\
MFGESTR & $8.51 \mathrm{E}-02$ & 1.996 & $0.13 \%$ \\
HEALTHR & $3.03 \mathrm{E}-01$ & 6.296 & $0.19 \%$ \\
TRUCKR & $5.47 \mathrm{E}-02$ & 1.612 & $0.05 \%$ \\
Z56 & $4.04 \mathrm{E}-04$ & 4.064 & $-4.81 \%$ \\
Z8 & $3.21 \mathrm{E}-04$ & 1.355 & $-1.88 \%$ \\
Constant & $-1.38 \mathrm{E}-03$ & -1.480 & \\
\hline Lagrange Multiplier Test & \multicolumn{4}{c}{$211.990(0.000)$} \\
Hausman Test & \multicolumn{4}{c}{$0.220(0.333)$} \\
\hline R-squared & 0.905 \\
\hline
\end{tabular}

As shown by the negative coefficient of the number of turns variable, a harder-tonavigate downtown will negatively impact retail trade employment (relative to the state), even with a bypass in place, though the impact is not severe. For every 
turn added, retail trade employment (relative to the state) will decrease by approximately 4.5 percent.

As expected, the presence of basic industry and other industries positively impact retail trade employment, because workers in these industries form the local customer base. Strangely, none of the bypass age indicators for years 1-20 were statistically significant. The coefficients of the 21-30 and 36-40 age indicators and the bypass indicator are positive, showing that the presence of a bypass will positively impact retail trade employment (relative to the state). This is evident when one drives down US-31 in Kokomo, US-30 in Columbia City, or US-24 in Huntington; these bypasses have all attracted development from large retail chain stores such as Wal-Mart. The presence of a nearby large city will also positively impact retail trade employment (relative to the state). This is also logical, because the population of these larger cities also constitute a portion of retail's customer base. The positive bypass indicator and associated double-digit elasticity reflect unobserved heterogeneity not captured in the model.

\subsubsection{Retail Trade Employment}

\begin{tabular}{|c|c|c|c|}
\hline Variable & Coefficient & t-statistic & Elasticity \\
\hline ELPLD & $-3.83 E+10$ & -1.965 & $-0.16 \%$ \\
\hline HEALTHR & $125,583.14$ & 4.767 & $0.21 \%$ \\
\hline MFGPAYR & $49,151.58$ & 7.119 & $0.16 \%$ \\
\hline WHOPAYR & $15,209.58$ & 2.058 & $0.03 \%$ \\
\hline Z1234 & 170.53 & 3.125 & $-10.22 \%$ \\
\hline $\mathrm{Z5}$ & 109.29 & 1.567 & $-4.17 \%$ \\
\hline $\mathrm{Z7}$ & -482.75 & -5.306 & $10.63 \%$ \\
\hline SYRSOPEN & 1.96 & 14.731 & $0.51 \%$ \\
\hline Constant & 983.67 & 3.404 & \\
\hline \multicolumn{2}{|c|}{ Lagrange Multiplier Test } & \multicolumn{2}{|c|}{$407.950(0.000)$} \\
\hline \multicolumn{2}{|c|}{ Hausman Test } & \multicolumn{2}{|c|}{$7.560(0.478)$} \\
\hline \multicolumn{2}{|c|}{ R-squared } & \multicolumn{2}{|c|}{0.968} \\
\hline
\end{tabular}


This model includes a continuous function for the number of years a bypass has been open. With this function present, the age indicators become "correction factors" for the function. As with the corresponding model normalizing employment figures against the state, the presence of other industries positively impacts retail trade employment, although for this model, the presence of a nearby large city negatively impacts retail trade employment. The variable in this model raises the distance from the affected city to the larger city to a power of 10. In other words, the negative impact rapidly decreases as the distance between the study city and the larger city increases. The corresponding elasticity, on the other hand, that a 1 percent change in the larger city's population will not have a noticeable impact on retail trade employment.

The initial impact on retail trade employment is positive, and the impacts become more positive over time until, curiously, the bypass has been open more than 30 years. The elasticities of the age indicators show that the benefits will lessen over time, and then the impacts will become negative. Much of the retail trade is centered around shopping malls. Consumers tend to be finicky and want to shop at "fashionable malls." Many of older shopping malls, some of which may have opened along a bypass, have dated infrastructure and often experience declining occupancy rates. This trend may be captured by the negative coefficient of the age 31-35 indicator. 


\subsubsection{Retail Trade Payroll: County to State Ratio}

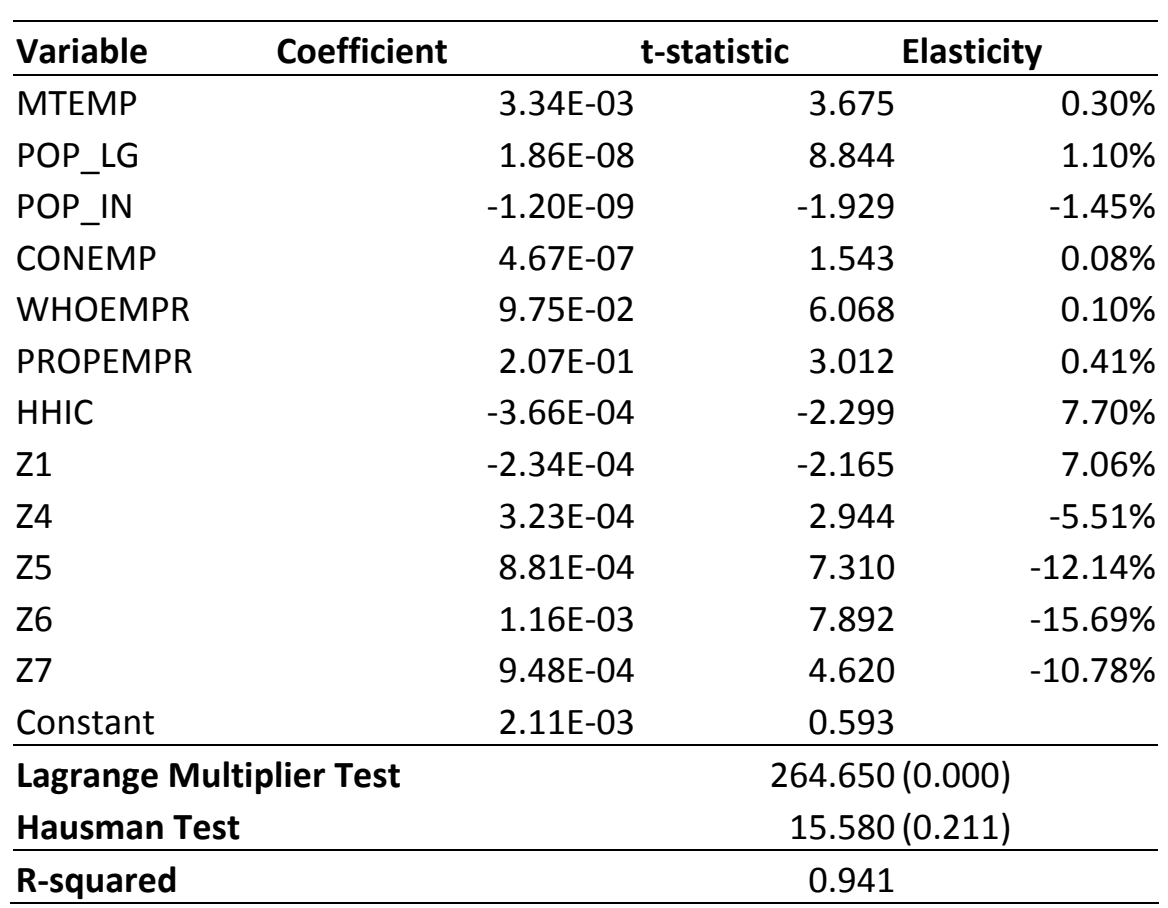

As with the other retail trade models, the presence of other industries positively impacts retail trade payroll. The presence of a bypass negatively impacts retail trade payroll (relative to the state) for the first five years the bypass is open, and then becomes statistically insignificant for the next ten years. Impacts become positive for years 16-35, indicating the presence of a time lag, as observed in the model for healthcare. Interestingly, the coefficients of the age indicators become more positive until peaking in years 26-30. The indicator variable for the cities located on US-24 is negative, indicating that retail trade payroll is lower if the affected city is located on a major arterial, though not to a great degree as observed by the corresponding elasticity. The presence of a larger city positively impacts retail trade payroll (relative to the state), but the increasing population of Indiana negatively impacts retail trade payroll (relative to the state). 
4.11.10. Retail Trade Number of Establishments: County to State Ratio (Natural Logarithm)

\begin{tabular}{lrcr}
\hline Variable & \multicolumn{2}{c}{ Coefficient } & \multicolumn{2}{c}{ Elasticity } \\
\hline ELPLD & $-1.45 \mathrm{E}+07$ & -2.900 & $-0.06 \%$ \\
HHIC & $-1.62 \mathrm{E}-01$ & -7.646 & $15.48 \%$ \\
LWHOEMPR & $2.42 \mathrm{E}-02$ & 1.345 & $0.02 \%$ \\
LMFGPAYR & $1.44 \mathrm{E}-01$ & 7.387 & $0.14 \%$ \\
PROPEMPR & $3.42 \mathrm{E}+01$ & 3.849 & $0.34 \%$ \\
Z2 & $2.33 \mathrm{E}-02$ & 1.633 & $-2.31 \%$ \\
Z4 & $-2.39 \mathrm{E}-02$ & -1.608 & $2.42 \%$ \\
Z7 & $3.91 \mathrm{E}-02$ & 1.576 & $-3.84 \%$ \\
Constant & $-4.23 \mathrm{E}+00$ & -23.147 & \\
\hline Lagrange Multiplier Test & \multicolumn{4}{c}{$246.470(0.000)$} \\
Hausman Test & \multicolumn{4}{c}{$11.720(0.164)$} \\
R-squared & & 0.897 \\
\hline
\end{tabular}

The presence of a bypass has mixed effects on the number of retail trade establishments. Initial impacts are positive, but these impacts become negative once the bypass has been open more than 15 years. No statistically significant impacts surface, however, until the bypass has been open more than 30 years. This "parabolic" impact trend may reflect unobserved characteristics of the retail trade. The trends may reflect the aforementioned onset of retail consolidation. If this is the case, as with the proprietors' employment model or the retail trade payroll model, the presence of a bypass may accelerate the trend of consolidation of retail and/or the closing of mom-and-pop retail stores. The upward trend as the bypass ages may reflect the opening of more specialized retail stores, such as antique shops. 
4.11.11. Eating \& Drinking Places Employment: County to State Ratio

\begin{tabular}{|c|c|c|c|}
\hline \multirow{2}{*}{$\frac{\text { Variable }}{\text { LLPLD }}$} & \multirow[t]{2}{*}{ Coefficient } & t-statistic & Elasticity \\
\hline & & 4.513 & $0.85 \%$ \\
\hline POP_IN & $-2.70 \mathrm{E}-09$ & -4.161 & $-3.23 \%$ \\
\hline BYPASS & 4.06E-03 & 5.635 & $-74.25 \%$ \\
\hline BNUM & $-8.02 E-04$ & -6.777 & $-14.68 \%$ \\
\hline $\mathrm{BCBD}$ & $-8.21 \mathrm{E}-04$ & -6.127 & $-0.56 \%$ \\
\hline MFGEMP & $3.52 \mathrm{E}-07$ & 8.419 & $0.35 \%$ \\
\hline $\mathrm{Z1}$ & $-6.16 E-04$ & -2.783 & $17.44 \%$ \\
\hline $\mathrm{Z2}$ & $-5.08 \mathrm{E}-04$ & -2.702 & $12.14 \%$ \\
\hline Z56 & $4.60 \mathrm{E}-04$ & 2.862 & $-5.01 \%$ \\
\hline Constant & $1.39 \mathrm{E}-02$ & 3.972 & \\
\hline Lagrange I & plier Test & 126.870 & $(0.000)$ \\
\hline Hausman & & 9.430 & $(0.399)$ \\
\hline R-squared & & 0.892 & \\
\hline
\end{tabular}

The coefficient of the bypass indicator is positive, but the coefficients for the year 1-5 and 6-10 indicators are negative, and the coefficient for the years 21-30 indicator is positive. Evidently, the presence of a bypass has mixed effects on eating and drinking employment (relative to the state), although the overall impact is positive, similar to the retail trade sector. As with the corresponding retail trade models, a larger number of turns along the original route through the affected city's CBD, even with the bypass open, will negatively impact eating and drinking places employment. For every turn added, eating and drinking places employment declines by almost 15 percent. It is logical to conclude that reduced mobility through a downtown would adversely impact sales (and consequently, employment) of eating and drinking establishments. The presence of basic industry positively impacts employment, as with the corresponding retail trade models, and the presence of nearby larger city also has positive impacts. The large magnitude of the bypass indicator elasticity reflects unobserved characteristics (such as traffic split) not captured in the model. 
4.11.12. Eating \& Drinking Places Payroll, County to State Ratio

\begin{tabular}{lrrr}
\hline Variable & Coefficient & \multicolumn{2}{c}{ t-statistic } \\
\hline LLPLD & $6.77 \mathrm{E}-08$ & 4.794 & $1.30 \%$ \\
POP_IN & $-2.38 \mathrm{E}-09$ & -3.260 & $-3.85 \%$ \\
BYPASS & $2.59 \mathrm{E}-03$ & 3.409 & $-56.18 \%$ \\
BNUM & $-4.67 \mathrm{E}-04$ & -3.746 & $-10.15 \%$ \\
BCBD & $-5.56 \mathrm{E}-04$ & -3.943 & $-0.45 \%$ \\
MFGEMP & $3.59 \mathrm{E}-07$ & 8.133 & $0.41 \%$ \\
Z1 & $-3.54 \mathrm{E}-04$ & -1.521 & $13.40 \%$ \\
Z2 & $-4.23 \mathrm{E}-04$ & -2.143 & $13.35 \%$ \\
Z56 & $4.36 \mathrm{E}-04$ & 2.585 & $-5.07 \%$ \\
Constant & $1.07 \mathrm{E}-02$ & 2.708 & \\
\hline Lagrange Multiplier Test & \multicolumn{4}{c}{$202.250(0.000)$} \\
Hausman Test & \multicolumn{4}{c}{$3.950(0.914)$} \\
\hline R-squared & 0.902 \\
\hline
\end{tabular}

This is the only model estimated in which all of the variables used in the corresponding employment model yielded statistically significant results, although the payroll model yields a larger p-value for the Hausman test than the employment model. Again, taking the bypass indicator and age indicators together, overall impacts of the bypass on eating and drinking places payroll (relative to the state) is positive, and the presence of a nearby larger city also has positive impacts. It should be noted, however, that the coefficients of the years 1-5 and 6-10 indicator are less negative for this model than for the corresponding employment model, though the corresponding elasticities show double-digit increases in payroll without a bypass present. 
4.11.13. Wholesale Trade Employment: County to State Ratio

\begin{tabular}{lrrr}
\hline Variable & \multicolumn{2}{c}{ Coefficient } & \multicolumn{2}{c}{ t-statistic } \\
\hline MFGPAYR & $-1.55 \mathrm{E}-01$ & -3.478 & $-0.28 \%$ \\
RETEMPR & $-1.40 \mathrm{E}+00$ & -3.110 & $-1.86 \%$ \\
RETPAYR & $2.35 \mathrm{E}+00$ & 5.446 & $2.84 \%$ \\
US30 & $2.25 \mathrm{E}-03$ & 2.474 & $-34.12 \%$ \\
Z123 & $9.83 \mathrm{E}-04$ & 3.095 & $-20.91 \%$ \\
Z4 & $1.03 \mathrm{E}-03$ & 2.321 & $-19.38 \%$ \\
Z9 & $-1.97 \mathrm{E}-03$ & -2.131 & $27.10 \%$ \\
Constant & $4.64 \mathrm{E}-04$ & 0.460 & \\
\hline Lagrange Multiplier Test & \multicolumn{4}{c}{$9.020(0.011)$} \\
Hausman Test & \multicolumn{4}{c}{$0.140(0.415)$} \\
\hline R-squared & \multicolumn{3}{c}{0.657} \\
\hline
\end{tabular}

The presence of the manufacturing sector negatively impacts wholesale trade employment (relative to the state), although while retail trade employment also has negative impacts, retail trade payroll has positive impacts. Wholesale trade employment (relative to the state) is also positively impacted if the affected city is located on a major route, as indicated by the positive coefficient of the US-30 indicator variable. Wholesale trade employment is positively impacted by the presence of a bypass for the first 20 years, though strangely, the impacts become negative for years $41-45$.

Note the magnitude of the elasticity of the US-30 indicator variable. This elasticity may reflect that the wholesale trade industry depends heavily on the local transportation system, and being located on a road that connects to other cities again serves as an important selling point in attracting development. 
4.11.14. Wholesale Trade Employment

\begin{tabular}{lccr}
\hline Variable & \multicolumn{2}{c}{ Coefficient } & \multicolumn{2}{c}{ tstatistic } & $-0.72 \%$ \\
\hline MTEMP & $-7.26 \mathrm{E}+02$ & -2.610 & $-0.17 \%$ \\
MFGPAYR & $-1.08 \mathrm{E}+04$ & -2.264 & $-2.18 \%$ \\
RETEMPR & $-1.77 \mathrm{E}+05$ & -3.799 & $2.23 \%$ \\
RETPAYR & $1.99 \mathrm{E}+05$ & 4.554 & $1.97 \%$ \\
LSPLD & $9.03 \mathrm{E}-02$ & 3.804 & $-22.16 \%$ \\
Z1234 & $1.13 \mathrm{E}+02$ & 3.775 & $23.16 \%$ \\
Z9 & $-2.25 \mathrm{E}+02$ & -2.395 & \\
Constant & $-1.12 \mathrm{E}+02$ & -0.520 & \\
Lagrange Multiplier Test & & $32.180(0.000)$ \\
Hausman Test & & $7.090(0.420)$ \\
\hline R-squared & \multicolumn{4}{c}{0.626} \\
\hline
\end{tabular}

Compared with the corresponding model normalizing employment against the state, the trends are similar. Higher employment and payroll in the manufacturing sector negatively impacts wholesale trade employment, whereas the retail trade sector has decidedly mixed effects. The bypass age indicators also have decidedly mixed impacts; while the year 1-20 indicator coefficient is positive, the year $41-45$ coefficient is negative. As expected, the larger the affected city and the closer the city to a larger city, the more positive the impacts. 
4.11.15. Wholesale Trade Payroll: County to State Ratio (Natural Logarithm)

\begin{tabular}{lccr}
\hline Variable & Coefficient & t-statistic & \multicolumn{2}{c}{ Elasticity } \\
\hline LMFGPAYR & $-1.61 \mathrm{E}-01$ & -1.629 & $-0.16 \%$ \\
RETEMPR & $-2.17 \mathrm{E}+02$ & -2.875 & $-1.50 \%$ \\
RETPAYR & $3.13 \mathrm{E}+02$ & 4.496 & $2.09 \%$ \\
LTRUCKR & $2.79 \mathrm{E}-01$ & 2.189 & $0.28 \%$ \\
HHIC & $-3.25 \mathrm{E}-01$ & -2.823 & $38.42 \%$ \\
US30 & $2.49 \mathrm{E}-01$ & 1.284 & $-22.03 \%$ \\
Z123 & $3.74 \mathrm{E}-01$ & 6.046 & $-31.22 \%$ \\
Z4 & $3.68 \mathrm{E}-01$ & 4.901 & $-30.80 \%$ \\
Constant & $-5.54 \mathrm{E}+00$ & -5.242 & \\
\hline Lagrange Multiplier Test & & & \\
Hausman Test & & $8.800(0.019)$ \\
R-squared & & \multicolumn{4}{c}{0.520} \\
\hline
\end{tabular}

As with the corresponding employment models, wholesale trade payroll is negatively impacted by the presence of manufacturing and increasing retail trade employment, although a larger magnitude of retail trade payroll (relative to the state) positively impacts wholesale trade payroll. The bypass age indicators are both positive, though strangely, the coefficient of the US-24 indicator is negative, a stark contrast from the positive coefficient of the US-30 indicator. Given that both variables reflect the bypassed city being located on the same route as other cities, this inconsistency may reflect unobserved characteristics of communities located along US-24, such as lower cost of living.

The lower R-squared value is indicative of unexplained heterogeneity of the error terms of the cross-sectional and time-series regressors. Taken together with the wholesale trade employment model, the presence of the bypass has overall positive impacts on the wholesale trade sector. 


\section{CHAPTER 5. CONCLUSIONS}

\section{$\underline{5.1 . ~ F i n d i n g s ~ o f ~ C a s e ~ S t u d i e s ~}$}

The findings of each affected city are discussed below. Communities with a bypass are labeled with (B), and communities with proposed bypasses are labeled with (NB).

Anderson (B): Anderson went into a long period of decline along with the American automotive industry in the 1970s and 1980s. The bypass, opened around this time, attracted retail shoppers who used to patronize neighborhood corner stores. Extensive retail development occurred along the relief route with little attention paid to mobility. As a result, the "relief route" now has 14-15 signals in a four-mile stretch, with travel times averaging 45 minutes during rush hour. As the Indianapolis metropolitan area expanded, Anderson residents began to patronize retail stores in nearby Fishers and Noblesville in Hamilton County. The city's Comprehensive Plan went 43 years without an update until 2005. The relief route is poorly designed and poorly maintained, according to local officials, and Anderson has become a suburban satellite of Indianapolis.

Angola (NB): The heavy volume of truck traffic using US-20 as a free alternative to the Indiana Toll Road has posed safety issues to local residents. Truck counts are over 1,400 trucks per day. Many of these trucks are laden with hazardous materials and have difficulty negotiating the downtown traffic circle 
and tear up local roads. The trucks hinder pedestrian traffic and downtownbound traffic, and visitors to downtown must use great caution when backing out of a parking spot. The bypass is currently on the Unfunded Long Range Plan Projects for the Fort Wayne District.

Boonville (NB): The city has been adversely impacted by the heavy coal truck traffic. Residents who live along the main roads have "given up" maintaining their houses dirtied by the dust from these trucks. The coal trucks often exceed the speed limit, creating hazardous conditions for drivers. Attempts were made to construct a bypass in the 1960s, but these efforts were hindered by local opposition. Because the construction date of the proposed state- and federally-funded northwestern bypass is uncertain, officials from the Warrick County Redevelopment Commission have proposed a reliever bypass that would be funded locally. This bypass would be shorter than the state- and federally-funded bypass.

Columbia City (B): Land values along the US-30 bypass rose as retail development began to occur. Unlike national chains that began to locate near the bypass, local businesses could not afford the land at these higher prices. The general state of the downtown building stock declined over time. The US-30 bypass bisects the city, and older residents do not like having to cross the busy road to run errands. Frontage roads have helped to divert retail-bound traffic, but the US-30 corridor remains congested. Overall, public perception of the bypass is positive. Residents value the convenience factor of having chain stores being located next to each other. The extensive retail development along the bypass has helped to create a new business district in the city. With the implementation of a TIF district near the bypass, the city has attracted new industry to the area, expanding the area's employment base.

Greencastle (NB): Heavy truck traffic through downtown Greencastle has decreased the downtown's attractiveness to residents. Concert performances on 
the north side of town can be hard to hear when trucks are passing through, and pedestrians often have difficulty crossing streets. These conditions have warranted the construction of a $\$ 100-\$ 120$ million bypass. The city's Comprehensive Plan, updated in 2001, addresses the issue of truck traffic and recommended the construction of the bypass. The routing of the bypass was chosen such that sprawl issues would be minimized. The bypass is expected to open up more land for industrial development, and the city will be able to use the bypass as a selling point in attracting such development. The bypass is expected to have parkway-like characteristics, according to local officials. Huntington (B): Huntington's economy was stagnant prior to the bypass's opening in 1964. Since it opened, extensive retail development has occurred along the corridor. Much of this development is served by frontage roads that help divert retail-bound traffic. The manufacturing employment base has grown somewhat, but this growth has been hindered in the past by local opposition and politics. Efforts to revive the downtown in the 1970s with the pedestrian mall concept proved ineffective. Parking remains an issue in the downtown. The bypass bisects the city, separating residences from schools, which has caused mobility and safety issues, forcing residents to travel by automobile. The city is currently exploring the feasibility of constructing a pedestrian bridge. The Jefferson Street corridor recently underwent a beautification project, and the results have made the street more attractive.

Logansport (B): Development along the bypass has been slow. It is expected that development will occur once the Hoosier Heartland Industrial Corridor (HHIC) is completed. Land use controls will be implemented to favor development downtown rather than along the bypass. Logansport has attracted industrial development south of the city, and an ethanol processing plant opened in 2007. Streetscaping and downtown development programs are being implemented to revive the downtown. Eastside businesses remain vibrant. 
Peru (B): The full benefits of the bypass will not be realized until the remainder of the HHIC is completed. Development has been limited due to environmental issues. Businesses previously located in downtown Peru have relocated to the bypass, although grocery stores remain near downtown. Local officials envision the bypass possibly becoming part of downtown later in the future. They view the proximity of the bypass to downtown Peru as "fortunate." Frontage roads have been built, and local officials expect significant retail development in the future.

Salem (NB): A combination of parking issues and heavy volumes of truck traffic passing through downtown has driven retail out of downtown. Residents often drive to nearby Scottsburg, Clarksville, and Louisville for their retail needs. The downtown remains busy with a variety of banks, specialty retailers, an art studio, and restaurants. The proposed bypass will be a limitedaccess truck route to be built as a Super-2. Listed under Major Moves Major New Highway Construction, construction of the bypass will begin in 2009. The bypass, in the planning stages since the 1960s, will help divert truck traffic that has difficulty navigating the unusual geometry of downtown.

Wabash (B): The bypass has become an important commercial corridor for the city of Wabash, but the full benefits will not be realized until the HHIC is completed. Frontage roads have been built to accommodate future development, and the County Zoning Ordinance has been updated to account for the presence of the bypass. The Honeywell Center has played an important role in reviving the downtown, and because of publicity efforts, the city's attractions have been featured on local cable channels. Economic development officials plan to shift to asset-based economic development that will focus on the area's strength in agriculture.

Warsaw (B): Orthopedic manufacturing companies expanded their presence in Warsaw following the bypass's opening, according to local officials. The 
city continues to have a large manufacturing employment base. Nearby lakes continue to attract tourists. Mobility along the US-30 corridor has become a problem, with the extensive retail and residential development that has occurred near the bypass. Frontage roads have been built to divert retail-bound traffic. Through semi truck traffic running red lights, however, poses a major safety issue. In addition to the US-30 bypass, a western IN-15 bypass has been proposed to accommodate the continued heavy truck traffic on the west side of town. The corridor remains in the planning stages. Property acquisition costs are expected to be high, but INDOT's traffic counts have shown that such a bypass is not warranted. Overall, the US-30 bypass has greatly benefited the city and has ensured its continued growth in the orthopedic manufacturing industry.

Washington (B): The US-50 bypass helped relieve congestion in downtown Washington caused by heavy semi and coal truck traffic. The diversion of trucks has made it easier to travel through downtown, allowing downtown businesses to grow. Local non-truck traffic along the original route has actually increased. Businesses both near the bypass and near the downtown have done well. Once the bypass opened, the city established a 2-mile zoning radius to limit development. However, fatalities have occurred at different intersections along the bypass, and INDOT is currently investigating potential safety issues. Within the downtown, upper floors of existing buildings are being converted to housing, similar to Lafayette. The combination of Amish tourism and the business travelers have kept hotels at 90 percent occupancy. The tax base would not be at the same level had the bypass not been built.

\subsection{Findings of Econometric Analysis}

Total Employment: Total employment of affected counties are positively im- 
pacted by the presence of a bypass. Over time, an affected county will contribute more to the state's economy in terms of employment. The presence of a nearby large city also positively impacts total employment.

Manufacturing: Even though the initial impacts on payroll are negative, there will be long-term benefits as the bypass ages. Employment will be positively impacted by the presence of a bypass. A bypass will provide a means of expanding the local manufacturing employment base over time.

Retail Trade: Although negative impacts were observed in the first ten years following the opening of a bypass, the overall impact of a bypass on both county employment and payroll was positive.

Eating \& Drinking Places: Both employment and payroll were negatively impacted by the presence of a bypass for the first ten years the bypass was opened. The large magnitudes of the elasticities of the bypass indicator for both models, however, showed that the presence of a bypass has benefits that overshadow these negative impacts.

Wholesale Trade: Overall impacts on both employment and payroll were positive. All bypass age indicators had double-digit elasticities. This shows that the wholesale trade industry is highly dependent on the presence of a bypass.

Healthcare: Negative impacts on annual earnings were observed for the first ten years the bypass was open. Impacts became positive starting with the $26^{\text {th }}$ year after the bypass was opened, with no statistically significant findings inbetween intervening years. This may be indicative of a lag between the opening of a bypass and the positive impacts shown in the model.

\subsection{Benefit-Cost Analysis of Impacts}

Numerous proposals for bypasses are received by state agencies every year. With rising construction costs, particularly material costs, it can be difficult for decision-makers to prioritize requested projects, particularly projects that can help 
achieve INDOT's mission of "enhancing...economic growth." Bypass projects should be selected based on which of the projects can provide the greatest benefits to both the state overall and the affected areas over the long term.

The statistical models have shown that in general, a bypass can provide the opportunity for economic growth, reflected in the models by positive increases in employment and payroll levels following the construction and opening of the bypass. Columbia City, the county seat of Whitley County, has experienced growth in the manufacturing sector since the US-30 bypass of the city opened in the late 1960s. Total payroll is used here as the key metric of benefit calculations.

The time-series plots below in Figure 5.1 show the first-quarter total payroll for Whitley County, for years 1970-1997. Both absolute values of payroll (adjusted for inflation in 2007 dollars) and the county-to-state ratios (i.e. payroll values for Whitley County divided by payroll for the entire state of Indiana) are shown.

Columbia City can be viewed as a "typical" city that was positively impacted, in the long term, by a bypass. Its trends will be used to approximate the potential benefits other communities could realize as a result of a bypass's construction and opening. 


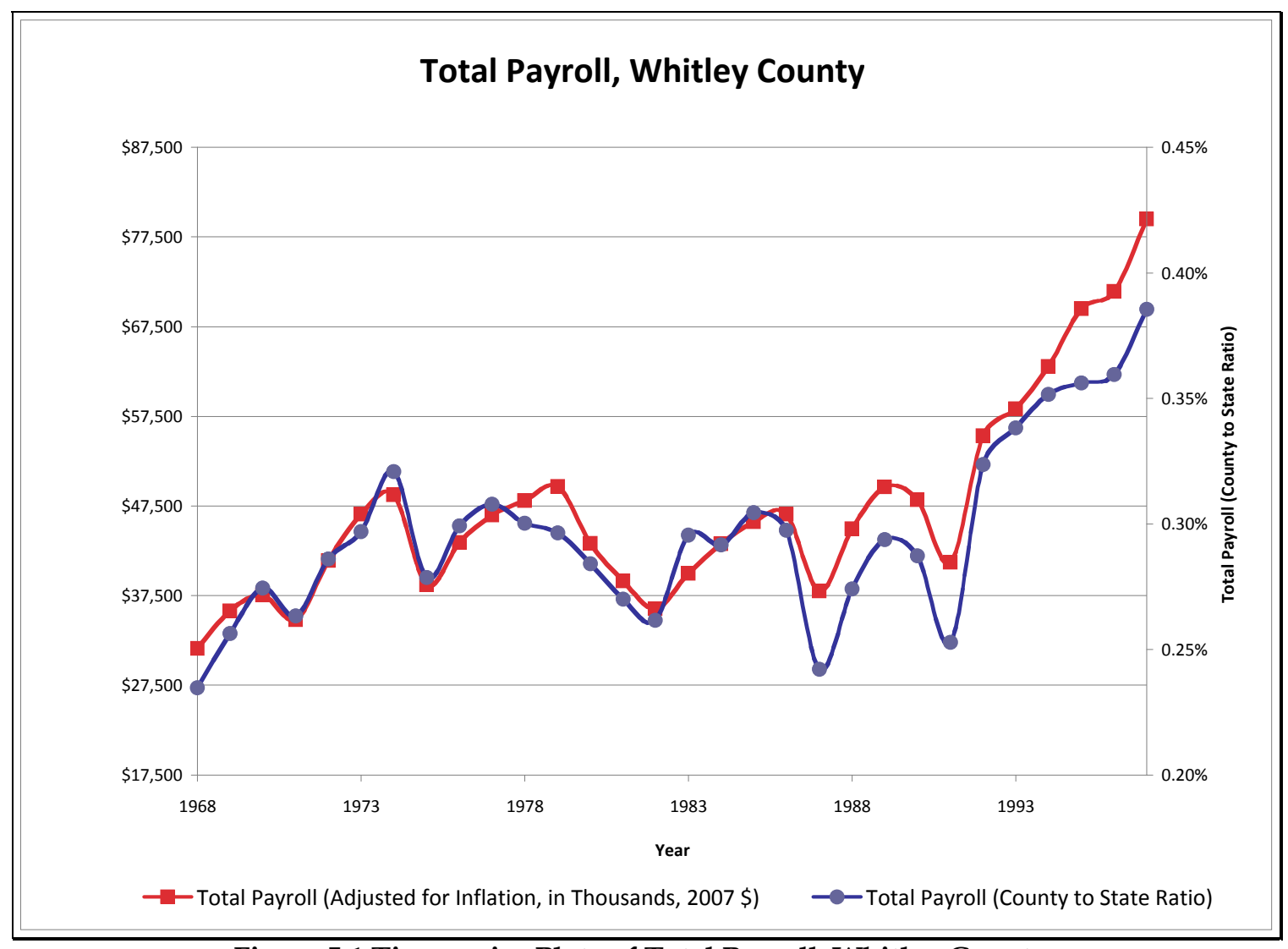

Figure 5.1 Time-series Plots of Total Payroll, Whitley County.

The "typical case" of Columbia City and its growth in total payroll over time will be applied to the city of Delphi, in Carroll County, to illustrate future potential benefits of a proposed bypass. Delphi will be bypassed to the south by the realignment of IN-25, the final component of the Hoosier Heartland Corridor (HHC) connecting Lafayette to Logansport. Construction of the bypass is slated to begin around 2012-14. Potential project costs were estimated from the Major Moves website (see Figure 5.2, below). 


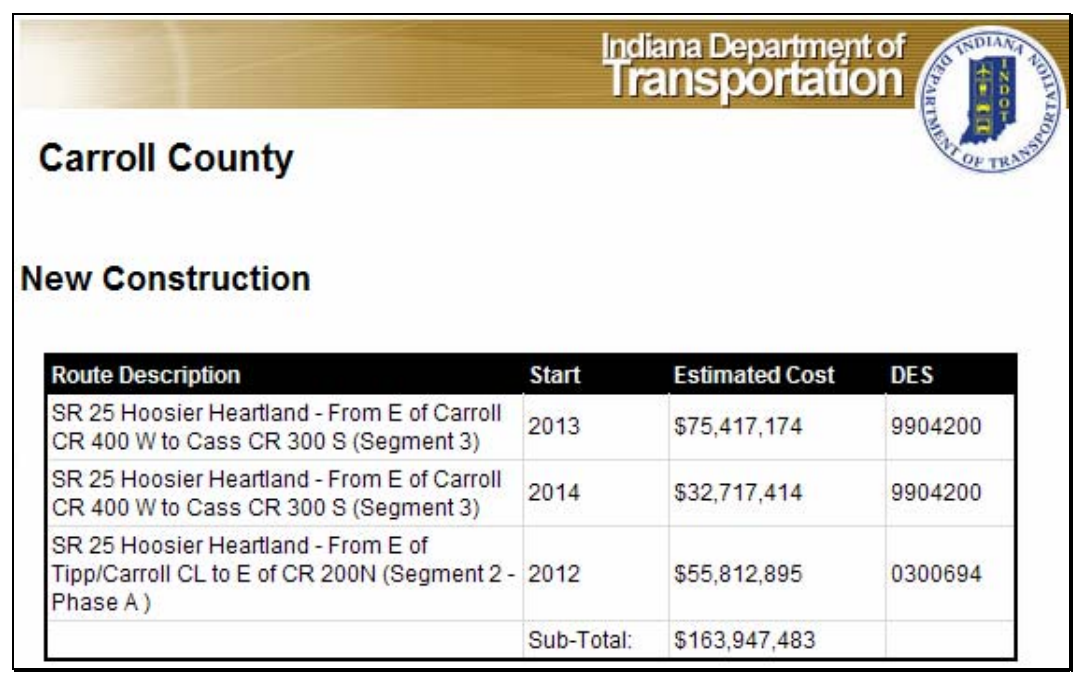

Figure 5.2 Estimated Project Costs for IN-25 (Hoosier Heartland Corridor), Carroll County. (Source: Indiana Department of Transportation).

For this hypothetical exercise, the combined costs for project with DES 9904200 (CR $400 \mathrm{~W}$ to Cass CR 300 S) in Figure 5.2 will be used, with total estimated cost $\$ 108,134,588$. It is assumed that this cost accounts for land acquisition, construction, and materials.

These calculations assume that the long-term benefits of the IN-25 bypass of Delphi will be roughly equivalent to the economic benefits realized by Columbia City. Calculations of benefits were based on Columbia City's economy at the time the bypass was opened, approximately 1968. Annual changes in total payroll (ACP), relative to the bypass opening year of 1968, were calculated using:

$$
A C P=\left(C S R_{\text {Current }}-C S R_{\substack{\text { Opening } \\ \text { Year }}}\right) \cdot S T O T P A Y_{\substack{\text { Current } \\ \text { Year }}}
$$

where the CSR terms represent county-to-state ratios for total payroll in the current year and the bypass opening year, respectively. In this case, the bypass 
opening year would be 1968. STOTPAY represents statewide total payroll in the year prior to the current year (adjusted for inflation). The county-to-state ratio for $1968 C S R_{\substack{\text { Opening } \\ \text { Year }}}$ is used as a baseline of evaluating benefits.

To illustrate, values for 1973 will be used (see Table 5.1). The annual change in first-quarter payroll (ACP) for 1973 is:

$$
\begin{aligned}
& A C P_{1973}=\left(C S R_{1973}-C S R_{1968}\right) \cdot \text { State }_{1973} \\
& A C P_{1973}=(0.297 \%-0.235 \%) \cdot(\$ 15,684,747.52)=\$ 9,766.07
\end{aligned}
$$

Table 5.1 Sample values for benefit-cost calculations

\begin{tabular}{ccccc}
\hline Year & $\begin{array}{c}\text { State First Quarter } \\
\text { Total Payroll, Thou- } \\
\text { sands 2007 \$ (STOT- } \\
\text { PAY) }\end{array}$ & $\begin{array}{c}\text { Total Payroll, } \\
\text { County-to-State } \\
\text { Ratio } \\
\text { (CSR) }\end{array}$ & $\begin{array}{c}\text { Change in Payroll } \\
\text { Relative to Bypass } \\
\text { Opening Year (ACP) }\end{array}$ & $\begin{array}{c}\text { Present Value of } \\
\text { Change in Payroll, } \\
\text { Base Year 1968 } \\
\text { (PACP) }\end{array}$ \\
\hline 1970 & $\$ 13,684,605.78$ & $0.274 \%$ & $\$ 5,451.48$ & $\$ 4,761.54$ \\
1971 & $\$ 13,211,502.33$ & $0.263 \%$ & $\$ 3,808.09$ & $\$ 3,108.53$ \\
1972 & $\$ 14,460,632.49$ & $0.286 \%$ & $\$ 7,448.98$ & $\$ 5,682.79$ \\
1973 & $\$ 15,684,747.54$ & $0.297 \%$ & $\$ 9,766.07$ & $\$ 6,963.07$ \\
1974 & $\$ 15,184,994.24$ & $0.321 \%$ & $\$ 13,095.82$ & $\$ 8,726.30$ \\
1975 & $\$ 13,883,841.93$ & $0.279 \%$ & $\$ 6,120.94$ & $\$ 3,811.81$ \\
1976 & $\$ 14,506,725.60$ & $0.299 \%$ & $\$ 9,381.59$ & $\$ 5,460.17$ \\
\hline$\ldots$ & $\ldots$ & $\ldots$ & $\ldots$ & $\ldots$ \\
1997 & $\$ 20,615,123.64$ & $0.386 \%$ & $\$ 31,116.62$ & $\$ 4,373.84$ \\
\hline \multicolumn{5}{c}{ Sum of Present Value of Change in Payroll (Thousands) } \\
\hline \multicolumn{5}{c}{} \\
\hline \multicolumn{5}{c}{}
\end{tabular}

For the original analysis timeframe of 30 years (1968-1997), each annual change was converted to its present value $(\mathrm{P})$ from future value $(\mathrm{F})$ at the beginning of the analysis time frame (that is, 1968) as follows:

$$
P=F(1+i)^{-N} \quad \text { (Eq. 5.2) }
$$


where $P$ represents the present (1968) value, $F$ represents the future value, $i$ represents the discount rate (assumed to be 7 percent), and $N$ represents the difference of the future and present years. Continuing with the example above, the present value of benefits (PACP in Table 5.1) for 1973 is:

$$
P A C P_{1973}=\$ 9,766.07 \cdot(1+0.07)^{-5}=\$ 6,963.07
$$

Annual payroll levels were estimated by multiplying the first-quarter payroll levels by four. The sum of the present values were used to calculate the equivalent uniform annual benefit (EUAB) was calculated using:

$$
E U A B=\underbrace{\left(4 \cdot 1000 \sum_{i=1968}^{1997} P A C P_{i}\right)}_{P} \frac{i \cdot(1+i)^{N}}{(1+i)^{N}-1}
$$

where $P$ represents the sum of present values of annual changes in payroll (equal to $4 \cdot 1000 \cdot \$ 105,527.27=\$ 422,109,070$ for total payroll),$i$ represents the discount rate (assumed to be 7 percent), and $N$ represents the analysis timeframe (30 years).

Using the above values, we have

$$
E U A B_{\text {Total }}=(\$ 422,109,070) \frac{0.07 \cdot(1+0.07)^{30}}{(1+0.07)^{30}-1}=\$ 34,106,252.08
$$

The equivalent uniform annual cost was estimated in a similar manner, with the same 7 percent discount rate but a more conventional 30 year timeframe. With $P$ $=\$ 108,134,588$, we have: 


$$
E U A C=(\$ 108,134,588) \frac{0.07 \cdot(1+0.07)^{30}}{(1+0.07)^{30}-1}=\$ 8,714,178
$$

The benefit-cost ratio is:

$$
B C R_{\text {Total }}=\frac{E U A B_{\text {Total }}}{E U A C}=\frac{\$ 34,106,252.08}{\$ 8,714,178}=3.98
$$

The same method as outlined above was used to calculate benefit-cost ratios for several other industry sectors: manufacturing, retail trade, eating \& drinking places, and wholesale trade. These benefit-cost ratios are summarized below in Table 5.2.

Table 5.2: Benefit-Cost ratios for various industry sectors

\begin{tabular}{cc}
\hline Industry Sector & BCR \\
\hline Total & 3.98 \\
Manufacturing & 2.51 \\
Retail Trade & 0.07 \\
Eating \& Drinking & -0.01 \\
Wholesale Trade & 0.98 \\
\hline
\end{tabular}

The calculated benefit-cost ratio for total payroll of 3.98 is a conservative estimate of the potential total benefits that a bypass can provide. While payroll levels can provide insight into a county's overall trends, payroll alone cannot capture the overall benefits and trends of a county's economy. Accounting for all possible benefits (such as reduction in fatalities, shorter traffic delays, and lower maintenance costs) would result in larger benefits, and consequently, a higher benefitcost ratio from a bypass project.

The benefit-cost ratios of specific industry sectors, however, present a more mixed picture. The manufacturing sector benefited from the bypass, as shown by 
the benefit-cost ratio of 2.51. This positive impact is also reflected in the statistical models developed in the previous chapter. While the wholesale trade sector "broke even", with a benefit-cost ration close to 1.00, the retail sector, particularly eating \& drinking places, were adversely impacted by the bypass, when construction costs are compared to benefits in payroll. These ratios agree with the statistical models produced in this study, which showed negative initial impacts and positive impacts later on. Annual change in payroll calculations mirror these trends, with large, negative initial impacts that could not be countered by positive impacts of lesser magnitude in later years, as shown by the time-series plots in Figure 5.3 (see below).

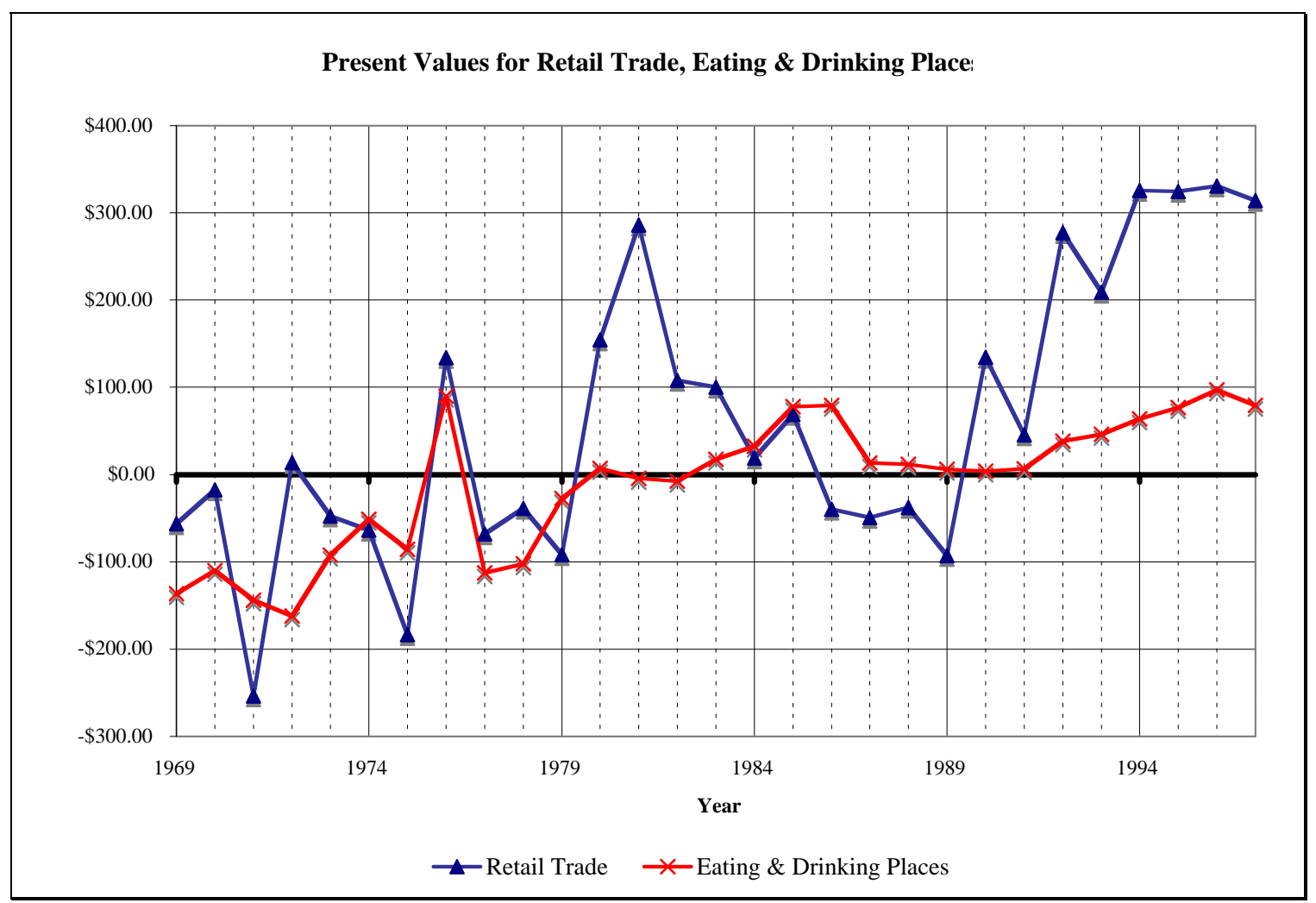

Figure 5.3 Present Values for Retail Trade, Eating \& Drinking Places sectors. Initial negative impacts on payroll, particularly Eating \& Drinking Places, negated later positive impacts.

Overall, the combination of statistical analysis and benefit-cost calculations show that the "basic" sectors and overall economy both were positively impacted by 
the bypass, while the "service" sectors experienced negative impacts in the shortterm, but more positive impacts in the long-term. The above calculations, while rough estimates, demonstrate how short-term construction costs of bypasses can have long-term, positive impacts on affected communities.

The benefits from the research study described in this report are more difficult to ascertain. Making more informed decisions about which proposed bypass projects to select or reject clearly has benefits, but the value of those benefits is difficult to quantify. The projected impacts of two cities with proposed bypasses, Mt. Vernon (in Posey County) and North Vernon (Jennings County), were compared, with the assumption that both bypasses would open in 2010 . Under a budget constraint, it was assumed that the county with the highest benefit-cost ratio would be a better candidate for a bypass. The benefit-cost analysis for both counties involved the following steps:

(1) Use the statistical model for total employment (see 4.11.1), which requires inputs for population of the affected county and the population of the county with the nearest large city, in conjunction with population projections provided by various state data centers to predict future employment. Because the statistical model for total employment models county employment relative to the state, the average projected statewide employment was used to calculate projected county employment for each horizon year.

(2) Rough estimates of total county payroll for each horizon year were calculated using the first-quarter average wage for each affected county in 2007. Similar to the Delphi benefit-cost analysis, these estimates were converted to equivalent uniform annual benefits and compared to the project cost. 
The horizon years, 2010 through 2030 in five-year increments, with 2010 serving as a baseline, were governed by the available population projection figures. Table 5.3 shows the nearest large cities and associated population projection sources.

Table 5.3 Nearest large cities and projection sources for Mt. Vernon and North Vernon

\begin{tabular}{cccccc}
\hline City & County & $\begin{array}{c}\text { City Projec- } \\
\text { tion Source }\end{array}$ & $\begin{array}{c}\text { Nearest } \\
\text { Large City }\end{array}$ & $\begin{array}{c}\text { Distance } \\
\text { (miles) }\end{array}$ & $\begin{array}{c}\text { Large City Projec- } \\
\text { tion Source }\end{array}$ \\
\hline Mt. Vernon & Posey & STATS Indiana & Evansville & 20.5 & STATS Indiana \\
North Vernon & Jennings & STATS Indiana & Louisville KY & 64.5 & KY State Data Center \\
\hline
\end{tabular}

Total employment, relative to the state, was projected for each horizon year $(2015,2020,2025$, and 2030) using the statistical model shown in 4.11.1. The baseline scenario, which represents the opening year of each bypass, was established in year 2010 by setting each bypass age indicator variable equal to zero. This baseline scenario served as the starting point in benefit-cost analysis.

To introduce uncertainty, the standard error of the regression was used to calculate "high" and "low" estimates $C S R_{\text {High-Low }}$ for each predicted value $C S R_{\text {Predicted }}$ using:

$$
C S R_{\text {High-Low }}=C S R_{\text {Predicted }} \pm-1.96(S E)
$$

where $S E$ represents the standard error of the regression. 
Rough estimates of actual total employment were calculated by multiplying each projected county-to-state ratio by the average projected statewide total employment StateTotEmp:

$$
\text { County Employment }=\text { CSR } \cdot \text { StateTotEmp }
$$

The statewide average projected total employment was calculated by taking the average of projected statewide total employment for years 2012 and 2014, the only available long-term projections provided by the Indiana Department of Workforce Development.

The rough estimates of county total payroll levels for each horizon year were calculated using:

$$
\text { Est. Annual Total Payroll }=\text { CSR } \cdot \text { Wage }_{{ }_{\text {Qst }}} \cdot 52 \text { weeks }
$$

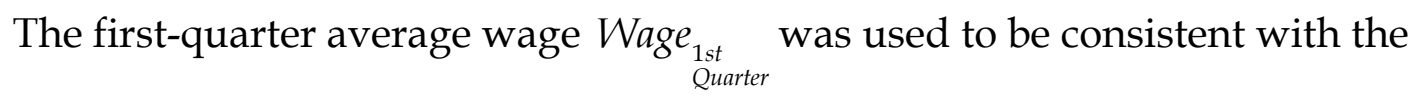
County Business Patterns data, which used only first-quarter payroll data. These average wages (\$853/week for Posey County, $\$ 608 /$ week for Jennings County) were gathered from Quarterly Covered Employment and Wages (QCEW) figures for year 2007, to remain in 2007 dollars.

A summary of the average weekly wages and estimated construction costs used in the benefit-cost calculations are summarized below in Table 5.4.

Table 5.4 Average weekly wages, statewide projected employment, and bypass construction costs used in benefit-cost calculations

\begin{tabular}{llc}
\hline Quantity & Amount & Source \\
\hline
\end{tabular}




\begin{tabular}{ccc}
$\begin{array}{c}\text { Average Weekly Wage, 1st Quarter, Po- } \\
\text { sey County, 2007 }\end{array}$ & $\$ 853$ & $\begin{array}{c}\text { STATS Indiana } \\
\text { (QCEW) }\end{array}$ \\
$\begin{array}{c}\text { Average Weekly Wage, 1st Quarter, Jen- } \\
\text { nings County, } 2007\end{array}$ & $\$ 608$ & $\begin{array}{c}\text { STATS Indiana } \\
\text { (QCEW) }\end{array}$ \\
$\begin{array}{c}\text { Statewide (IN) Average Projected Em- } \\
\text { ployment (Avg. of 2012 and 2014) }\end{array}$ & $3,313,800$ & $\begin{array}{c}\text { IN Department of } \\
\text { Workforce Devel- } \\
\text { ostimated Bypass Cost (Both) }\end{array}$ \\
EUAC (N = 30 yrs, $\mathrm{i}=7 \%)$ & $\$ 25,000,000$ & - \\
\hline
\end{tabular}

The total employment projections for Posey County (Mt. Vernon) and Jennings County (North Vernon) are shown below in Table 5.5.

Table 5.5 Predicted total employment for Posey County and Jennings County

\begin{tabular}{cccc|cccc}
\multicolumn{3}{c|}{ Posey County (Mt. Vernon) } & \multicolumn{3}{c}{ Jennings County (North Vernon) } \\
\hline \multirow{3}{*}{ Year Predicted Total Employment } & \multicolumn{3}{c}{ Year } & \multicolumn{3}{c}{ Predicted Total Employment } \\
& Mid & High & Low & & Mid & High & Low \\
\hline 2010 & 14,277 & 17,866 & 11,408 & 2010 & 26,788 & 33,522 & 21,406 \\
2015 & 16,641 & 20,824 & 13,298 & 2015 & 29,983 & 37,521 & 23,959 \\
2020 & 16,446 & 20,581 & 13,142 & 2020 & 31,858 & 39,868 & 25,458 \\
2025 & 16,204 & 20,277 & 12,948 & 2025 & 33,236 & 41,591 & 26,559 \\
2030 & 15,187 & 19,005 & 12,136 & 2030 & 34,579 & 43,272 & 27,632 \\
\hline
\end{tabular}

The future values $F$ of the increase in total payroll in each horizon year relative to the baseline year were calculated using:

$$
F=\text { Payroll }_{\text {Horizon }}-\text { Payroll }_{\text {Baseline }}
$$

where Payroll ${ }_{\text {Horizon }}$ represents the projected total payroll in the horizon year and Payroll $_{\text {Baseline }}$ represents the projected total payroll in the baseline year.

Future values were converted to present values for the baseline year in the same manner used for the Delphi benefit-cost analysis:

$$
P=F(1+i)^{-N}
$$


where $N$ represents the number of years past the baseline year. The sum of these values were used to calculate a rough EUAB value for a 30-year planning horizon and 7 percent discount rate:

$$
E U A B=\left(1000 \sum_{i=2015}^{2030} P_{i}\right) \frac{i \cdot(1+i)^{N}}{(1+i)^{N}-1}
$$

To simplify comparison, the same estimated project cost of $\$ 25,000,000$, converted to an EUAC value, was used for each project. The predicted annual payroll levels, present values of changes in payroll, EUAB values, and benefit-cost ratios for Mt. Vernon and North Vernon are shown below in Tables 5.6 and 5.7, respectively.

Table 5.6 Benefit-Cost calculations for Mt. Vernon

\begin{tabular}{rrrrrrr}
\hline \multirow{2}{*}{ Year } & \multicolumn{3}{c}{ Predicted Annual Total Payroll } & \multicolumn{3}{c}{ Present Value, Change in Payroll } \\
& Mid & High & Low & Mid & High & Low \\
\hline 2010 & $\$ 633,255$ & $\$ 792,459$ & $\$ 506,034$ & - & - & - \\
2015 & $\$ 738,113$ & $\$ 923,680$ & $\$ 589,827$ & $\$ 74,763$ & $\$ 93,559$ & $\$ 59,743$ \\
2020 & $\$ 729,492$ & $\$ 912,892$ & $\$ 582,938$ & $\$ 48,923$ & $\$ 61,222$ & $\$ 39,094$ \\
2025 & $\$ 718,725$ & $\$ 899,417$ & $\$ 574,333$ & $\$ 30,978$ & $\$ 38,767$ & $\$ 24,755$ \\
2030 & $\$ 673,630$ & $\$ 842,986$ & $\$ 538,298$ & $\$ 10,434$ & $\$ 13,057$ & $\$ 8,338$ \\
\hline & & Net & $\$ 165,097$ & $\$ 211,518$ & $\$ 135,067$ \\
& & & EUAB & $\$ 13,304,611$ & $\$ 17,045,456$ & $\$ 10,884,575$ \\
& & BCR & 6.60 & 8.46 & 5.40 \\
\hline
\end{tabular}

Table 5.7 Benefit-Cost Calculations for North Vernon

\begin{tabular}{ccccccc}
\hline \multirow{2}{*}{ Year } & \multicolumn{2}{c}{ Predicted Annual Total Payroll } & \multicolumn{3}{c}{ Present Value, Change in Payroll } \\
& Mid & High & Low & Mid & High & Low \\
\hline 2010 & $\$ 846,920$ & $\$ 1,059,841$ & $\$ 676,774$ & - & - & - \\
2015 & $\$ 947,935$ & $\$ 1,186,252$ & $\$ 757,495$ & $\$ 72,022$ & $\$ 90,129$ & $\$ 57,553$ \\
2020 & $\$ 1,007,238$ & $\$ 1,260,464$ & $\$ 804,884$ & $\$ 81,497$ & $\$ 101,987$ & $\$ 65,125$ \\
2025 & $\$ 1,050,777$ & $\$ 1,314,950$ & $\$ 839,677$ & $\$ 73,887$ & $\$ 92,463$ & $\$ 59,043$ \\
2030 & $\$ 1,093,239$ & $\$ 1,368,087$ & $\$ 873,608$ & $\$ 63,654$ & $\$ 79,656$ & $\$ 50,866$ \\
\hline & & & Net & $\$ 291,060$ & $\$ 364,235$ & $\$ 232,587$ \\
& & & EUAB & $\$ 23,455,516$ & $\$ 29,352,397$ & $\$ 18,743,315$
\end{tabular}


With construction costs of each bypass assumed to be equal, it is evident that constructing a bypass in North Vernon would have more benefits than building a bypass in Mt. Vernon. Three key factors affect the benefit-cost ratios: (a) Projected population levels, which were higher for Jennings County than Posey County, (b) the average weekly wage; while Jennings County had a significantly lower average weekly wage, the lower wage was canceled out by higher projected employment, and (c) the estimated construction costs, assumed to be equal for both counties. If the proposed Mt. Vernon bypass had a construction cost of $\$ 12,500,000$, half the initial cost, its benefit-cost ratios would double, making construction of a bypass Mt. Vernon more beneficial. If both counties had equivalent weekly wages and projected population levels, only construction costs would affect the benefit-cost ratios.

Using the statistical model for total employment in conjunction with projected population and employment levels can provide a means for decision-makers to evaluate whether construction of a bypass in place A vs. place B would be more beneficial to the state economy and would represent the best use of limited state funds. However, when evaluating bypass project proposals, decision-makers should also consider the "readiness" of each community to adapting to the presence of a bypass, be it through planning policies, establishing new economic development initiatives, or other means of maintaining economic vitality. The communities profiled in this report should provide decision-makers with a variety of examples of which planning policies and economic development initiatives have been most effective. The combination of the set of statistical models, the community case studies, and the benefit-cost analyses should aid decisionmakers in planning bypasses that will benefit local and state interests. 


\subsection{Implications of Impacts}

Previous studies of bypasses have focused primarily on the impact of bypasses on traffic-dependent businesses, with an emphasis on how sales are impacted, particularly in the retail sector. This project aimed to build on previous findings and focus on how other parts of an affected community's economy were affected, particularly employment and payroll. In economic analysis, external economic factors such as recessions often overshadow local impacts. This study accounted for these impacts by normalizing employment and payroll figures against the state, allowing for a clearer picture of the impacts of a bypass on affected communities to emerge. The econometric models developed have shown statistically significant impacts.

Throughout the interviews conducted for this study, the growth of the manufacturing sector in communities with bypasses has frequently been a talking point. This is the case from the continued expansion of the orthopedic manufacturing industry in Warsaw to the new industrial park recently opened near the bypass in Logansport. The statistical models show that, in the long term, the presence of a bypass will increase manufacturing employment and payroll.

The random-effects specification of the model has important implications. Because these models fit the random-effects specification as shown by the statistical tests, they can be used to predict potential economic impacts of other counties with bypasses.

Even with the bypass open, if it is difficult it is to follow the original route through a downtown (represented in the models as the number of turns), the statistical models show that employment and payroll for all industries are nega- 
tively impacted. Although a bypass may be present, truck traffic and through traffic coming from origins not served by the bypass will still need to pass through a city's downtown, as is the case with Logansport. Many of these streets were not designed with wide trucks in mind. Even with a bypass, mobility through a community is still important. Principal routes through a community should require as few turns as possible.

Many of the bypasses in Indiana are 30 years or older, and three bypasses are more than 50 years old (Lebanon, Kokomo, and Lafayette). Many of the lessons learned from these bypasses have come well after development has taken place along the bypasses. As learned from the interviews, many of the traffic calming measures put in place, such as frontage roads, have been reactive (rather than proactive) measures. Some of these reactive measures have had detrimental effects, such as the implementation of the pedestrian mall in Huntington after the US-24 bypass was opened in 1964. However, other measures implemented have begun to draw visitors into bypassed communities' business districts. For example, Huntington has implemented streetscaping and the placement of signage along main roads, particularly Jefferson Street, improving the attractiveness of the downtown. Logansport has plans to implement similar policies. Washington capitalizes on the Amish tourism industry, and its downtown remains vibrant. Wabash draws in tourists with the popular Honeywell Center.

The statistical models have shown that employment will largely be positively impacted by the presence of a bypass. Counties with bypasses, over time, will contribute more to the state's economy. Bypasses, in short, will provide the public with an opportunity to expand the local employment base. 


\subsection{Implementation}

INDOT has already implemented measures to limit access to future bypasses. Current planned bypasses, such as the remainder of the US-231 bypass around West Lafayette and the US-31 "bypass of the bypass" in Kokomo will have specific restrictions on development and access control. These restrictions will enhance mobility along future bypasses and address the issue of uncontrolled development around bypasses, but the issue of economic impacts must still be addressed.

At present, a number of communities have approached INDOT requesting a bypass, such as Angola, Greencastle, Huntingburg, and Warsaw. In the case of Huntingburg, increasing volumes of truck traffic carrying hazardous materials from the Crane Naval Weapons Support Center through downtown have raised concerns about public safety. Similar to Angola and Boonville, the large volume of these trucks is beginning to affect quality of life. To direct both INDOT and these communities through the decision making process, a clear, concise guide should be prepared. The guide will cover the lessons learned from the case studies (see 5.1) and the implications of the statistical models developed for this study (see 5.2).

\subsection{Future Work}

Future work could expand the guide mentioned in the previous section. The findings of previous studies, particularly the Handy et al. Texas study and the Washington State study, should be included in this guide, as these findings emphasize proactive planning. To answer the question, "What will be the long-term effects on employment in my county?", the findings of the statistical models de- 
veloped in this report should be expanded and refined. These models can provide a clear, objective picture of what could happen to an area's economy if a bypass is built.

While the models illustrate what could happen to an affected area if a bypass were built, the models do not explicitly address what could happen to an affected community's downtown, an important issue for community members and officials alike. Brief synopses of the history of previous bypassed communities should be provided in the guide. The histories of these communities will help lead officials and community members into a discussion of which city they are most similar to or which impacts could likely happen to them.

The findings from the present study should be incorporated into the IPOC Bypass Selection Criteria described in Chapter 2. Additional criteria to be added could include predicted employment with and without the bypass, the presence of land use controls, and the opinions of public officials.

To expand on the findings of this study, a more disaggregate approach (below the county level) should be taken. The use of geographic information systems (GIS) has become commonplace in the planning process. Given the increasing amount of publicly available data, the impacts of bypasses at the city, street, and parcel level could be determined using GIS software packages. Traffic volumes and other data from INDOT's Road Inventory Database (RID) could be incorporated into the study. The statistical models developed in this study could be expanded to accommodate this more disaggregate approach. 


\section{LIST OF REFERENCES}




\section{LIST OF REFERENCES}

Babcock, M.W., and Davalos, J.A. (2004). “Case Studies of the Economic Impact of Highway Bypasses in Kansas." Kansas State University. Journal of the Transportation Research Forum, Vol. 43, No. 1, Spring 2004.

Brail, R.K. (1987). “Microcomputers in Urban Planning and Management." Center for Urban Policy Research, New Brunswick, NJ.

Branham, A.K., A.D. May, Jr., and Michael, H.L. (1953). “Economic Evaluation of Two Indiana Bypasses." Highway Research Board Bulletin, 1953, No. 67. Joint Highway Research Project, Purdue University, West Lafayette, IN.

Burress, D. (1996). "Impacts of Highway Bypasses on Kansas Towns." As prepared for the Kansas Department of Transportation, October 1996, Report No. 226. Retrieved 9/4/06 from www.ipsr.ku.edu/resrep/bypass.htm.

City of Warsaw. Website. Retrieved November 12, 2007, from http://www.warsawcity.net/index.cfm

Corradino Group/Indiana, The (2003). Environmental Assessment/Corridor Study: U.S. 231 From I-70 to I-65, Final Report. Prepared for Indiana Department of Transportation. Retrieved August 27, 2007, from http://www.in.gov/dot/projects/us231/.

Corradino Group/Indiana, The (1995). State Road 25: Hoosier Heartland Corridor Illustrative Alternatives. Prepared for Indiana Department of Transportation. 
Gillis, W.R, Ph.D (1994). “Lessons from Eastern Washington: State Route Mainstreets, Bypass Routes, and Economic Development in Small Towns." EWITS Research Report No. 2, Washington State University, Pullman, WA. Greene, W.H. (2003). “Econometric Analysis.” Fifth Edition. Pearson Education, Inc., Upper Saddle River, NJ.

Greene, W.H. (1995). “LIMDEP Version 7.0 User's Manual.” Econometric Software, Inc., Bellport, NY.

Handy, S., S. Kubly, D. Larsen, J. Sralla, S. Vanka, Oden, M. (2001). “Economic Impacts of Highway Relief Routes on Small- and Medium-Size Communities: Case Studies." Center for Transportation Research, The University of Texas at Austin, Austin, TX.

HyettPalma, City of Angola, and Indiana Downtown (2006). Angola Downtown Action Agenda 2006. Retrieved August 13, 2007, from http://www.angolain.org/Planning/Angola_Downtown_Action_Agend a.htm.

Indiana Department of Transportation (2005). Draft Environmental Impact Statement, US 31 Kokomo Corridor Project.

Indiana Department of Transportation (2007). Final Environmental Impact Statement, US 31 Kokomo Corridor Project.

Indiana Department of Transportation (2006a). INDOT 2016 Long Range Project Review and 2017-2030 Long Range Project Meeting Notes. Retrieved August 13, 2007, from

http://www.in.gov/dot/div/planning/lrp/earlyconsultation/ftwayne20 06.pdf

Indiana Department of Transportation (2006b). Major Moves: Major New Highway Construction (2006-2015). Retrieved August 28, 2007, from http://www.in.gov/dot/majormoves/pdfs/New_Construction_20062015.pdf 
Indiana Department of Transportation, Fort Wayne District (2007). Unfunded Long Range Plan Projects. Retrieved August 13, 2007, from http://www.in.gov/dot/div/planning/lrp/2007update/Listings/Distric t/Fort\%20Wayne.pdf.

INDOT Planning Oversight Committee (2005). Protocols \& Policies, Edition 1.1. Indiana Department of Transportation.

Jarrett, J., Handy, S.L., and Vanka, S. (2001). "Planning for the Impacts of Highway Relief Routes on Small- and Medium-Size Communities." Center for Transportation Research, The University of Texas at Austin, Austin, TX.

Kleymeyer, J.E. (2001). “Impact of By-Passes to Ohio Communities Under 35,000 Population." Prepared for the Ohio Department of Transportation by John E. Kleymeyer and Associates. Retrieved April 17, 2007, from http://www.dot.state.oh.us/research/2001/Planning/14724-FR.pdf. Kosciusko County Convention and Visitors Bureau website. "County History." Retrieved November 12, 2007, from http://www.koscrb.org/kchistory.html

Leong, D., and Weisbrod, G (1999). "Summary of Highway Bypass Studies." Excerpted from Economic Impact Analysis: St. Croix River Crossing - Minnesota TH 36/Wisconsin STH 64, prepared by Economic Development Research Group for Minnesota DOT, WisDOT.

McNeil, A (1971). Travel Time and Accident Benefits Due to Reconstruction of U.S. 52 Bypass at Lafayette, Indiana. Joint Highway Research Project, Purdue University, West Lafayette, IN, No. 9 - July 1971.

Ohio Department of Transportation (1999). ODOT Process for Evaluating Requests for Bypasses. Draft.

Priser, M (2004). Timeline from the Past to the Present. Retrieved November 12, 2007, from http://yesteryear.clunette.com/150yearspart2.html 
Ratio Architects, Inc. (2001). City of Greencastle, Indiana, Comprehensive Plan. Retrieved August 27, 2007, from http://www.cityofgreencastle.com/2_Building/comp\%20plan/compdir. aspx. 
Region III-A. (2005). Semi Tractor Traffic Binder. Prepared by Region III-A, June 13, 2005. City of Angola, Steuben County, IN. Retrieved August 13, 2007, from

http://regioniiia.org/documents/City \%20of\%20Angola\%20Semi\%20Traf fic\%20Binder\%20Binder.pdf.

Schneider, K., and K. Thayer (2003). “No, No, No, No, No Again: Fifth bridge rejection should redirect funding to better traffic solutions." Great Lakes Bulletin News Service. Retrieved September 12, 2007, from http:// www.mlui.org/transportation/fullarticle.asp?fileid=16598

Srinivasan, S., and K. Kockelman (2000). “The Impacts of Bypasses on SmallAnd Medium-Sized Communities: An Econometric Analysis." University of Texas at Austin. Journal of Transportation and Statistics, Vol. 5, No. 1. Retrieved October 20, 2006, from www.bts.gov/publications/journal_of_transportation_and_statistics/vol ume_05_number_01/html/paper_04/index.html.

Thompson, E., Miller, J., and J. Roenker (2001). “The Impact of a New Bypass Route on the Local Economy and Quality of Life." Center for Business and Economic Research, Kentucky Transportation Center, College of Engineering University of Kentucky. Retrieved 9/10/06 from ntl.bts.gov/lib/23000/23700/23788/KTC_01_10_SPR_219_00_2I.pdf.

U.S. Census Bureau. County Business Patterns. Retrieved April 17, 2007, from http://www.census.gov/epcd/cbp/view/cbpview.html. Washington County Chamber of Commerce (2007). "Tourism." Retrieved November 12, 2007, from http://www.washingtoncountychamber.org/html/tourism.htm Washington County Economic Growth Partnership, Inc (2007). “Major Employers in Washington County." Retrieved November 12, 2007, from http://www.wcegp.org/jobs/employers.html 
Washington, S.P., Karlaftis, M.G., and Mannering, F.L. (2003). “Statistical and Econometric Methods for Transportation Data Analysis." Chapman \& Hall/CRC, Boca Raton, FL.

Weiss, M (2004). Hoosier Heartland Industrial Corridor. Federal Highway Administration. Retrieved 9/23/06 from www.fhwa.dot.gov/Planning/econdev/hoosier.htm.

Whitley County Economic Development Corporation (2007). "Directory of Whitley County Industries." Retrieved November 12, 2007, from http://www.whitleybiz.com/main-industries.htm

Yeh, D., Gannon, M., and D. Leong (1998). “The Economic Impacts of Highway Bypasses on Communities." Wisconsin Department of Transportation, Madison, WI. 
APPENDICES 


\section{Appendix}

\section{APPENDIX: SIMULATANEOUS EQUATION MODELING OF ECONOMIC IM- PACTS OF THE US-24 BYPASS IN HUNTINGTON, IN}

\section{A.1. Motivation and Theory}

Recent studies of the impacts of bypasses on small- and medium-sized communities have attempted to quantify the extent of long-term economic impacts. The task of establishing a statistical link between the presence of a bypass and a corresponding change in economic indicators, such as employment, payroll, and sales can be complicated. External economic factors, such as inflation, recessions, and layoffs must be accounted for. In addition, industry sectors are not independent of one another. Retail trade, for example, is dependent on basic industry, such as manufacturing.

Simultaneous equation models can capture these relationships. Estimation of systems of equations by Ordinary Least Squares (OLS) violates will yield inaccurate results due to correlation between regressors and disturbances. Systems of equations are generally favored over single-equation models as they account for cross-equation disturbance term correlation (Washington et al., 2003). Seemingly unrelated regression equations (SURE) can be used to capture correlations of these disturbance terms. In other words, SURE models can account for the unobserved relationships between industry sectors. 
To illustrate, economic data for Huntington County were considered. The US-24 bypass has been open since 1964, allowing for observation of long-term impacts. The SURE model will take the form:

$$
\begin{gathered}
Y_{1}=\alpha_{1}+\beta_{1} X_{1}+\varepsilon_{1} \\
Y_{2}=\alpha_{2}+\beta_{2} X_{2}+\varepsilon_{2} \\
M \\
Y_{N}=\alpha_{N}+\beta_{N} X_{N}+\varepsilon_{N}
\end{gathered}
$$

where

$Y$ is the dependent variable,

$\alpha$ is a constant,

$\beta$ is a vector of coefficients,

$X$ is a vector of independent variables, and

$\varepsilon$ is the disturbance term.

The SURE command in LIMDEP also accounts for first-order serial correlation (autocorrelation), or correlation of disturbances over time. The disturbance term for each equation takes the form:

$$
\varepsilon_{i, t}=\rho_{i} \varepsilon_{i, t-1}+u_{i, t}
$$

where

$\varepsilon_{i, t}$ is the disturbance term for equation $i$ at time interval $t$, $\rho$ is the autocorrelation coefficient for equation $i$, $\varepsilon_{i, t-1}$ is the disturbance term for equation $i$ at previous time interval $t-1$, and $u_{i, t}$ is the random disturbance term. 
The SURE models are estimated by LIMDEP via feasible generalized least squares (FGLS). The autocorrelation coefficients are determined using OLS estimates, whereas the similar three-stage least squares procedure (3SLS) uses the estimates of two-stage least squares (2SLS) (Washington et al., 2003). The error structure in Equation A.2 is the same error structure as the one-way random effects specification for panel data estimation (Greene, 1995).

\section{A.2. Results}

The estimated model consists of five equations modeled simultaneously for Huntington County from 1970-1997. The dependent variables are:

(1) Manufacturing employment (County-to-state ratio) (Natural logarithm)

(2) Manufacturing payroll (County-to-state ratio) (Natural logarithm)

(3) Wholesale trade payroll (County-to-state ratio) (Natural logarithm)

(4) Retail trade payroll (County-to-state ratio) (Natural logarithm)

(5) Health services annual earnings (County-to-state ratio)

The GLS autocorrelation coefficient $\rho_{i}$ is also listed for each equation.

For the 28 observations (1970-1997) and six parameters per model, there are 22 degrees of freedom. The critical $\mathrm{t}$-statistics for statistical significance are:

Confidence Level

90 percent

95 percent

99 percent

\section{Critical t-statistic}

1.321

1.717

2.508 
A.2.1. Manufacturing employment (County-to-state ratio) (Natural logarithm)

\begin{tabular}{lrrr}
\hline Variable & Coefficient & t-statistic & Mean of X \\
\hline Constant & $-3.54 \mathrm{E}+01$ & -6.618 & \\
POPSL & $1.24 \mathrm{E}+02$ & 5.417 & $1.20 \mathrm{E}-01$ \\
LLPLD & $1.30 \mathrm{E}-04$ & 4.660 & $9.17 \mathrm{E}+04$ \\
POP_IN & $-1.51 \mathrm{E}-06$ & -3.240 & $5.50 \mathrm{E}+06$ \\
LRETPAYR & $-2.20 \mathrm{E}+00$ & -5.122 & $-5.35 \mathrm{E}+00$ \\
SYRSOPEN & $6.97 \mathrm{E}-04$ & 3.146 & $4.86 \mathrm{E}+02$ \\
\hline R-squared & & & 0.769 \\
Adjusted R-squared & & 0.717 \\
\hline GLS Autocorrelation Coefficient & & 0.105 \\
\hline
\end{tabular}

A continuous variable representing the number of years the bypass was open was used in place of the age indicator variables specified in Chapter 4 . When the age indicator variables were used, coefficients were not significantly different from one another. A continuous variable was deemed appropriate for this reason.

The estimated model for Huntington County is consistent with the corresponding two-way random effects model developed in 4.11.4 in that the coefficient of the square of the years open variable is positive, which is similar to the positive coefficients of the majority of the age indicator variables in 4.11.4. The coefficient of the large city distance ratio variable is positive, which indicates that the presence of a nearby larger city, in this case Fort Wayne (in Allen County), benefits Huntington County with respect to manufacturing employment. Strangely, the coefficient of the retail trade payroll variable is negative. This may be indicative of unobserved characteristics of the relationship between basic (manufacturing) and service (retail) industries that are unique to Huntington County. 
A.2.2. Manufacturing payroll (County-to-state ratio) (Natural logarithm)

\begin{tabular}{lrrr}
\hline Variable & Coefficient & t-statistic & Mean of X \\
\hline Constant & $-4.84 \mathrm{E}+01$ & -5.256 & \\
POPSL & $1.93 \mathrm{E}+02$ & 4.902 & $1.20 \mathrm{E}-01$ \\
LLPLD & $1.83 \mathrm{E}-04$ & 3.855 & $9.17 \mathrm{E}+04$ \\
POP_IN & $-2.51 \mathrm{E}-06$ & -3.257 & $5.50 \mathrm{E}+06$ \\
LRETPAYR & $-3.11 \mathrm{E}+00$ & -4.189 & $-5.35 \mathrm{E}+00$ \\
SYRSOPEN & $1.25 \mathrm{E}-03$ & 3.378 & $4.86 \mathrm{E}+02$ \\
\hline R-squared & & & 0.651 \\
Adjusted R-squared & & 0.571 \\
\hline \multicolumn{2}{l}{ GLS Autocorrelation Coefficient } & & 0.035 \\
\hline
\end{tabular}

The signs and magnitudes of the coefficients for the model are similar to the corresponding variables in A.2.1. The positive coefficient of the square of the years open variable for both models indicates that the US-24 bypass has largely benefited Huntington County with respect to manufacturing payroll and employment. The R-squared values, however, are lower than that of the corresponding two-way random-effects models, which indicates that unobserved characteristics of Huntington County have not been captured in the model.

A.2.3. Wholesale trade payroll (County-to-state ratio) (Natural logarithm)

\begin{tabular}{lrrr}
\hline Variable & Coefficient & t-statistic & Mean of X \\
\hline Constant & $-6.82 \mathrm{E}+01$ & -7.993 & \\
POPSL & $1.89 \mathrm{E}+02$ & 6.039 & $1.20 \mathrm{E}-01$ \\
LLPLD & $2.55 \mathrm{E}-04$ & 6.418 & $9.17 \mathrm{E}+04$ \\
LRETPAYR & $-3.40 \mathrm{E}+00$ & -5.737 & $-5.35 \mathrm{E}+00$ \\
EATESTR & $-1.77 \mathrm{E}+02$ & -2.702 & $6.60 \mathrm{E}-03$ \\
SYRSOPEN & $-1.19 \mathrm{E}-03$ & -3.914 & $4.86 \mathrm{E}+02$ \\
\hline R-squared & & & 0.804 \\
Adjusted R-squared & & 0.760 \\
\hline \multicolumn{2}{l}{ GLS Autocorrelation Coefficient } & & 0.421 \\
\hline
\end{tabular}


The coefficients of the retail trade payroll variable and variable for number of eating $\mathcal{E}$ drinking places establishments are both negative. This indicates that serviceoriented industries in Huntington County have negatively impacted wholesale trade payroll (relative to the state). The magnitude of the GLS autocorrelation coefficient is greater than that of either manufacturing model, which indicates strong positive correlation of the disturbance terms. The coefficient of the square of the years open variable is negative, which is in contrast to the positive coefficients of the age indicator variables of the corresponding seven-county model developed in 4.11.15. In other words, the US-24 bypass has negatively impacted Huntington County's wholesale trade industry. This is also implied by the negative coefficient of the US-24 indicator variable in 4.11.15. The adjusted R-squared for this model is higher than the model developed in 4.11.15, indicating a better fit.

A.2.4. Retail trade payroll (County-to-state ratio) (Natural logarithm)

\begin{tabular}{lrrr}
\hline Variable & Coefficient & t-statistic & Mean of X \\
\hline Constant & $-1.05 \mathrm{E}+01$ & -9.669 & \\
POPSL & $3.58 \mathrm{E}+01$ & 7.009 & $1.20 \mathrm{E}-01$ \\
LLPLD & $4.65 \mathrm{E}-05$ & 9.329 & $9.17 \mathrm{E}+04$ \\
POP_IN & $-5.75 \mathrm{E}-07$ & -5.977 & $5.50 \mathrm{E}+06$ \\
WHOESTR & $-4.04 \mathrm{E}+01$ & -3.743 & $6.65 \mathrm{E}-03$ \\
EYRSOPEN & $5.06 \mathrm{E}-17$ & 2.198 & $2.67 \mathrm{E}+14$ \\
\hline R-squared & & & 0.875 \\
Adjusted R-squared & & 0.846 \\
\hline GLS Autocorrelation Coefficient & & -0.027 \\
\hline
\end{tabular}

The EYRSOPEN variable represents the number of years the bypass has been open raised to the tenth power. The coefficient of this variable is positive, which indicates that retail trade payroll in Huntington County has benefited from the US-24 bypass. The coefficients of both population variables are positive, which shows that both the increasing population of Huntington County and nearby 
Fort Wayne positively impact retail trade payroll. This is logical in that a larger population provides a larger customer base. Interestingly, the coefficient of the number of wholesale trade establishments variable is negative. When considered together with the wholesale trade model in A.2.3, the retail trade and wholesale trade sectors in Huntington County appear to negatively impact each other. The GLS autocorrelation coefficient is close to zero, indicating that the disturbance terms are not strongly correlated.

A.2.5. Health services annual earnings (County-to-state ratio)

\begin{tabular}{lrrr}
\hline Variable & Coefficient & t-statistic & Mean of X \\
\hline Constant & $-1.25 \mathrm{E}-02$ & -5.114 & \\
POPSL & $1.52 \mathrm{E}-01$ & 8.209 & $1.20 \mathrm{E}-01$ \\
LLPLD & $1.42 \mathrm{E}-07$ & 6.182 & $9.17 \mathrm{E}+04$ \\
POP_IN & $-3.14 \mathrm{E}-09$ & -6.414 & $5.50 \mathrm{E}+06$ \\
EATESTR & $8.10 \mathrm{E}-02$ & 1.720 & $6.60 \mathrm{E}-03$ \\
SYRSOPEN & $4.12 \mathrm{E}-07$ & 1.455 & $4.86 \mathrm{E}+02$ \\
\hline R-squared & & & 0.938 \\
Adjusted R-squared & & 0.924 \\
\hline GLS Autocorrelation Coefficient & & 0.089 \\
\hline
\end{tabular}

The coefficient of the square of the years open variable is positive but not statistically significant above the 90 percent confidence level. This indicates that the US24 bypass has not impacted annual health services earnings to the extent it has affected the other industries. As with the other models, the coefficients of the population variables are positive. The adjusted R-squared value is the highest of the five equations simultaneously estimated, indicating a good statistical fit. 


\section{A.3. Findings}

The signs of the coefficients of the estimated models for Huntington County largely follow the corresponding seven-county models developed in Chapter 4, with the exception of the model for wholesale trade payroll. The US-24 bypass has negatively impacted wholesale trade in Huntington County. The retail trade sector also appears to negatively impact wholesale trade, and vice versa.

In general, Huntington County has benefited from the US-24 bypass, particularly the manufacturing sector. However, the R-squared values for both manufacturing models were considerably lower than the corresponding seven-county models, which is indicative of unobserved heterogeneity not captured in the models. Corrections for autocorrelation were necessary, particularly for the wholesale trade model. Simultaneously estimating these equations has accounted for unobserved relationships between the industry sectors in Huntington County. Like the seven-county two-way random-effects models, these equations account for external economic factors (through the use of county-to-state ratios) and regional effects (by including the population of nearby Allen County).

Future work should involve the full seven-county set of data. Each industry sector should be modeled simultaneously under the two-way random-effects error specification to fully capture the relationships between industry sectors and account for correlation across counties and over time. 


\section{Users Guide for Bypass Impact Estimations}

Prepared for Indiana Department of Transportation

by Joshua B. Mills and Jon D. Fricker, August 2009

\section{Motivation}

This guide is intended to provide a standard set of criteria for helping decision-makers to determine whether construction of a bypass is advisable. State agencies, public officials, and citizens can use the contents of this guide throughout the decision-making process. The first section discusses overall impacts on an affected community and what factors can affect a bypass's impact on a community's economy. The second section outlines case studies of recently completed and proposed bypasses of various communities in Indiana, along with historical cases.

\section{Overall Impacts}

The statistical models developed for this project have shown that a number of factors affect a bypassed community's economy in terms of employment and payroll in various industry sectors. These models can be found in the draft JTRP report (Mills and Fricker 2008). The key factors are as follows:

Age of the bypass: For certain industry sectors, employment and payroll in a county tended to be adversely impacted for the first 15 years a bypass was open, but recovered and grew in the years thereafter. Other industry sectors did not show a significant change in employment or payroll until the bypass had been open for 20-25 years. For example, while total employment in a county was positively impacted, manufacturing payroll was adversely affected for the first 15 years a bypass was open but then recovered and grew in later years, indicating the presence of a time lag. In short, immediate impacts should generally not be expected once a bypass is open; there will likely be a lag of at least 15 years before any significant change in employment or payroll takes place.

Difficulty of navigating a community's downtown: The difficulty of navigating through the affected community's central business district (CBD) was measured by the number of turns required to follow the bypassed route's original alignment. The models showed that, even with the bypass open, a hard-to-navigate downtown was associated with lower total employment and payroll of retail stores and restaurants, although these impacts were mitigated by the bypass.

Population of affected community and presence of nearby large city: Most industries in bypassed communities were, in general, positively impacted by the presence of a larger city. These impacts were more positive for larger bypassed cities. Similar positive impacts from nearby larger cities have been observed in previous studies (Rephann and Isserman 1994; Srinivasan and Kockelman 2001). Bypassed communities with higher populations 
were more positively impacted by a bypass. Other studies have found that smaller communities (under 2000 population) were more likely to be adversely impacted by a bypass (Wells and Farnworth 2001; Yeh et al. 1998).

Time-series plots of manufacturing payroll (normalized against the state) for selected counties are shown below in Figure 1. Warsaw (Kosciusko County) experienced large growth in manufacturing payroll since the US-30 bypass opened in 1972, whereas Wabash (Wabash County) has seen a decline in manufacturing payroll. These different trends are evidence that a bypass will not always have the expected impact.

Normalizing county-level figures against the state was found to be essential in controlling for external economic factors. These county-to-state ratios also provided insight into how each affected county's contribution to the state's economy was affected by a bypass (see Figure 1).

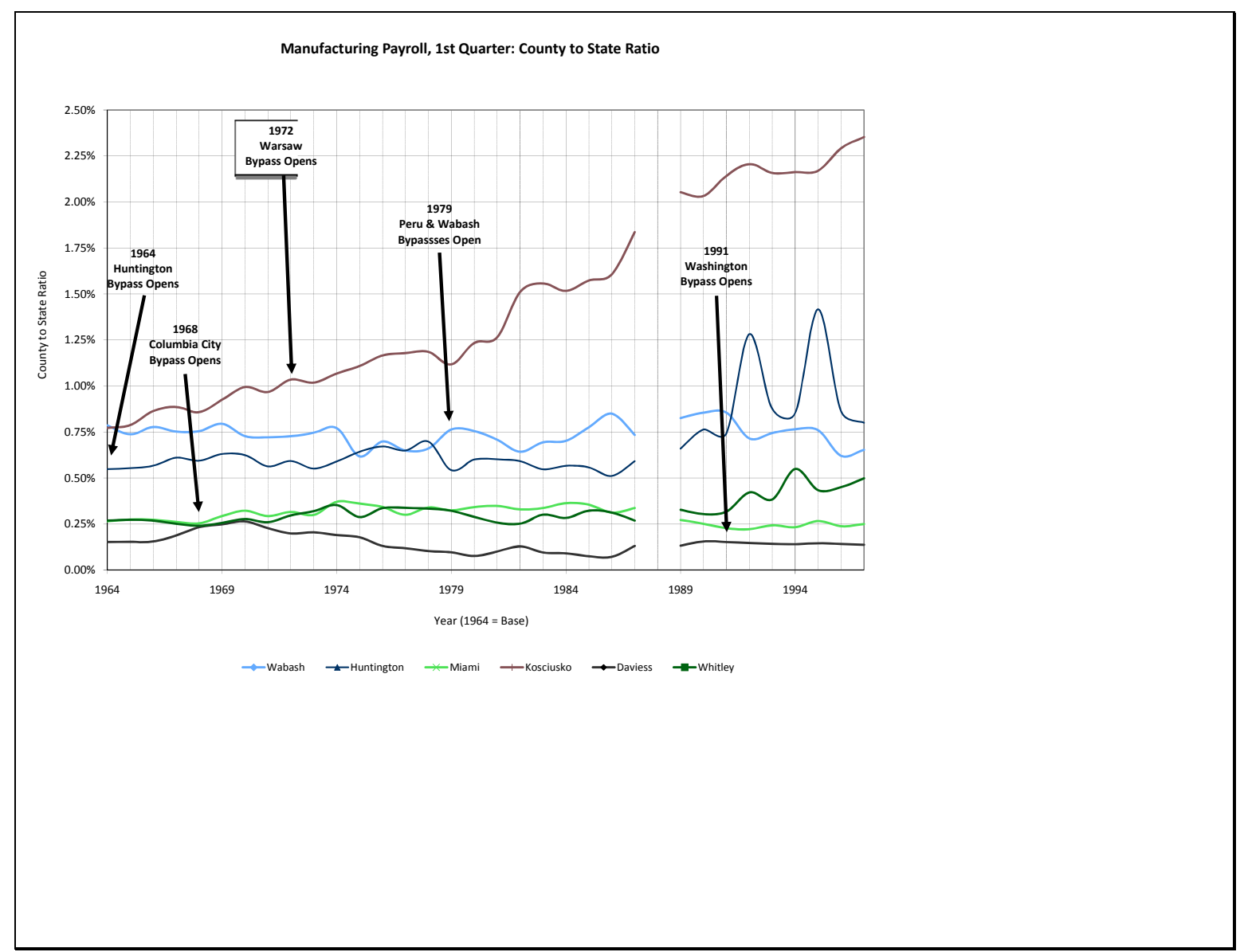

Figure 1: Time-series Plots of Manufacturing Payroll for Selected Counties

The impacts of bypasses on selected industries' employment and payroll levels are summarized below in Table 1, with + denoting generally positive impacts and - denoting generally negative impacts. For most industry sectors, impacts differed in the early and later years a bypass was open. 
Table 1: Summary of Bypass Impacts on Various Industry Sectors

\begin{tabular}{lcc}
\hline Industry & $\begin{array}{c}\text { Initial } \\
(\mathbf{1 - 1 5} \text { years) }\end{array}$ & $\begin{array}{c}\text { Later } \\
\text { (16+ Years) }\end{array}$ \\
\hline Total Employment (County to State Ratio) & + & + \\
Proprietors Employment (County to State Ratio) & - & - \\
Manufacturing Payroll (County to State Ratio) & - & + \\
Manufacturing Employment (County to State Ratio) & + & + \\
Manufacturing Employment & + & + \\
Health Services Annual Earnings (County to State Ratio) & - & + \\
Retail Trade Employment (County to State Ratio) & 0 & + \\
Retail Trade Employment & + & - \\
Retail Trade Payroll (County to State Ratio) & - & + \\
Retail Trade No. Establishments (County to State Ratio) & + & + \\
Eating \& Drinking Places Employment (County to State & - & + \\
Ratio) & - & + \\
Eating \& Drinking Places Payroll (County to State Ratio) & + & - \\
Wholesale Trade Employment (County to State Ratio) & + \\
Wholesale Trade Employment & + & + \\
Wholesale Trade Payroll (County to State Ratio) & + \\
\hline
\end{tabular}

The findings for major industry sectors are outlined below.

Total Employment: Total employment in an affected county is positively impacted by the presence of a bypass. Over time, an affected county will contribute more to the state's economy in terms of employment. The presence of a nearby large city also positively impacts total employment.

Manufacturing: Even though the initial impacts on payroll are negative, there will be longterm benefits as the bypass ages. Employment will be positively impacted by the presence of a bypass. A bypass will provide a means of expanding the local manufacturing employment base over time. Growth in "basic" industry can bring about "second-round effects" of growth in retail and service industries as discussed by Burress (1996). Basic workers are workers who "are employed in industry, commercial, and office facilities whose location selections are based on considerations other than locally required access" (Brail 1987). Basic industries, when deciding where to locate, are sensitive to a number of factors outlined by officials interviewed for this study, such as market and labor access, transportation costs, and the availability of "shovel-ready" sites.

Retail Trade: Employment (relative to the state) benefited from the presence of a bypass, although these benefits were not realized until after the bypass had been open for at least 25 years on average. The presence of a nearby large city also positively impacted retail trade employment (relative to the state). Retail trade payroll (relative to the state), however, is negatively impacted in the short term, though these negative impacts lessen 
over time. Total and per capita sales in affected communities can be adversely impacted by the presence of a bypass (Srinivasan and Kockelman 2000; Thompson et al. 2001).

Eating \& Drinking Places: Both employment and payroll in a county were negatively impacted by the presence of a bypass for the first ten years the bypass was opened. The presence of a bypass, as shown by the models, has long-term, positive benefits and impacts that overshadow these negative impacts.

Negative short-term impacts were also observed by Srinivasan and Kockelman (2000), though the negative impacts were most pronounced for smaller communities (population less than 5000). Their study, which focused primarily on sales, found that total sales for eating \& drinking places were most adversely impacted in smaller communities, but showed little to no change in larger communities (population greater than 10,000 ).

Sole Proprietors and Partnerships: Proprietors' employment reflects the number of sole proprietorships and partnerships in a given county or city. Such establishments are often family businesses and other smaller business operations. Over time, the impact of a bypass on proprietors' employment becomes more negative. A study in Kentucky showed that 90 percent of businesses located at or near a bypass were new to the bypassed area (Thompson et al. 2001). Smaller stores on the original route, such as mom-and-pop stores, often have difficulty competing with their larger counterparts and end up closing down.

\section{Case Studies}

Communities with Recently Constructed and Proposed Bypasses

The following case studies describe recently constructed and proposed bypasses of various communities in Indiana, along with issues that should be addressed for each community.

Logansport: Little development has occurred along the US-24 bypass since its completion in 1999, though this is likely due to the Hoosier Heartland Highway (HHH) not being completed. The lag in retail development along the bypass, however, is consistent with the lag of positive impacts in eating \& drinking places shown in Table 1. It is likely that retail and other development will locate to the bypass once the HHH is completed. While US-24 now bypasses the city to the south, several state routes (IN-17, IN-25, IN-29) continue to run through the downtown, with many twists and turns.

Truck traffic running through downtown continues to exert wear-and-tear on local roads. Possible reroutings (not necessarily new alignments) of any or all of these routes to minimize the number of turns through downtown should be considered. Wayfinding signage on the bypass should also be provided to direct travelers to local attractions such as the Dentzel Carousel or local restaurants such as Hap's. If local businesses are not allowed to advertise along the bypass, some acceptable signage to notify travelers on the bypass of the best routes to city retail areas would help both travelers and retailers.

Mt. Vernon: This community is geographically similar to Boonville in that IN-62 is a fourlane highway connecting each community to Evansville. Both communities also have large 
volumes of truck traffic. The high volumes of coal truck traffic in downtown Boonville left soot deposits on downtown buildings and houses. Quality-of-life issues should be investigated in the case of Mt. Vernon. Local officials and residents should be interviewed to determine whether the large truck volumes passing through town are having any adverse impacts on the local economy.

Delphi: The proposed alignment of the HHH connecting Lafayette to Logansport will bypass the city of Delphi to the south. The city, however, has taken a recent hit to its economy with the loss of several manufacturers. The models have shown a bypass can provide an opportunity for growth in the manufacturing sector, but external economic factors still play a large role. While the loss of jobs in Delphi may not have been preventable, the future IN-25 bypass will open up land with improved accessibility for economic development and industrial parks.

Angola: Similar to Boonville, a large number of trucks are traveling along the main route (US-20) through the city, in this case to avoid the toll road to the north. The type of commercial traffic traveling through the city should be investigated. The need for a bypass of Angola may be lessened should the trucks passing through downtown not be coal trucks or similar soot-depositing vehicles. In addition to considering commercial traffic composition, safety issues caused by the trucks, particularly in school zones, should be addressed, as well as the difficulty of driving through downtown Angola.

Rushville: In anticipation of the opening of the Honda plant in Greensburg, local economic development officials stepped up efforts to attract additional industry. The city is likely to have spillover effects from the Honda plant, but there may be a lag in development, although the models show that manufacturing employment would aid this increase should the IN-44 bypass be constructed.

Communities with "Mature" Bypasses (Historical Cases)

These communities have had a bypass for at least a decade. The lessons learned from these communities should be considered during the decision-making process of planning a bypass.

Columbia City: Land values along the US-30 bypass rose as retail development began to occur. Unlike national chains that began to locate near the bypass, local businesses could not afford the land at these higher prices. The general state of the downtown building stock declined over time. The US-30 bypass bisects the city, and older residents do not like having to cross the busy road to run errands. Frontage roads have helped to divert retailbound traffic, but the US-30 corridor remains congested. Overall, public perception of the bypass is positive. Residents value the convenience factor of having chain stores being located next to each other. The extensive retail development along the bypass has helped to create a new business district in the city. With the implementation of a Tax Increment Finance (TIF) district near the bypass, the city has attracted new industry to the area, expanding the area's employment base. The influx of chain stores following the construction of the bypass has also been documented in Kentucky (Thompson et al. 2001). 
The Kentucky study found that just under 15 percent of downtown retail businesses relocated to the bypass, likely a result of higher land prices along the bypass.

Wabash: The bypass has become an important commercial corridor for the city of Wabash. Frontage roads have been built to accommodate future development, and the County Zoning Ordinance has been updated to account for the presence of the bypass. The Honeywell Center has played an important role in reviving the downtown, and because of publicity efforts, the city's attractions have been featured on local cable channels. Economic development officials plan to shift to asset-based economic development that will focus on the area's strength in agriculture.

Washington: The diversion of trucks has made it easier to travel through downtown, allowing downtown businesses to grow. Once the bypass opened, the city established a 2mile zoning radius to limit development. The combination of Amish tourism and the business travelers have kept hotels at 90 percent occupancy. The tax base would not be at the same level had the bypass not been built, according to local officials.

\section{Other Issues}

A common issue raised by local residents with a bypass in general is whether retail and other businesses will leave the downtown. The circumstances of downtown businesses should be investigated to identify these and any other issues regarding the downtown's continued vitality. The downtown revitalization efforts of other Indiana communities such as Washington and Wabash (as described in the previous section) should be pointed out to local officials as examples of what could be done to maintain a downtown's economic vitality.

Other general issues should be considered for communities with proposed bypasses. Local officials should be consulted to determine the status of the city or county Comprehensive Plan and the plans for downtown and outlying areas once the bypass is constructed. If a bypass is not warranted, local officials should have a "backup plan" for dealing with increased downtown traffic volumes, particularly if safety is an issue. Local land use and zoning policies should ensure development does not impede mobility. The views of local businesses and residents should also be considered.

Gillis (1994) evaluated how bypasses had impacted small communities in Washington State. His findings and their relevance to Indiana communities are discussed below.

(1) Central business districts in communities with a developed local customer base are less likely to be adversely impacted by a bypass than business districts dependent on through traffic. Will the economic vitality of Delphi remain strong once the IN-25 bypass is constructed? Does this finding hold true in the case of Washington, whose downtown has not declined since the opening of the US-50 bypass in 1991, or with Huntington, whose citizens shop locally but prefer to shop at chain stores not located downtown? 
(2) Bypasses that improve market access to major trading centers, such as metropolitan areas, open up new opportunities for small towns for economic development. Community officials from Logansport, Peru, and Wabash believe that the completion of the Hoosier Heartland Highway $(\mathrm{HHH})$ will induce higher levels of economic development due to lower transportation costs.

(3) Systematic development of highway-related businesses and other retail services along bypass interchanges can help mitigate possible economic losses that occur from the diversion of traffic from the central business district. This has yet to occur around Logansport, although such development has been proposed for the areas surrounding the future portion of the HHH. A number of "big-box" stores have opened around Huntington and Wabash along US-24. Was this development "systematic?"

(4) Annexing property associated with new interchange developments is an important tool that can be utilized by cities to mitigate tax base losses associated with possible business closing and land use changes in the central business district. Several cities have taken steps to ensure areas surrounding the bypass contribute to the tax base. For example, the US-30 corridor through Columbia City has attracted significant retail development. Community officials believe the west side of the city may become a part of the downtown. The establishment of a Tax Increment Finance (TIF) district has solidified the employment base in the city according to local officials interviewed for this study.

(5) Land use plans should be flexible enough to accommodate new types of downtown uses in communities that are impacted by a bypass. Numerous economic development corporations and community officials in Indiana have taken steps to ensure their respective downtown areas will thrive, such as the development of an entertainment district in downtown Wabash, anchored by the Honeywell Center. Wabash has also recently updated its County Zoning Ordinance to account for the bypass.

(6) Enticing tourists and shoppers to travel into the central business district is important to the economic and overall quality of life in bypasses communities. With improvement to the riverfront area, an aggressive PR program, and wayfinding signage, downtown Logansport could attract considerably more visitors and tourists to the CBD. Logan's Landing is currently taking such steps to revitalize the downtown.

\section{Conclusion}

This guide gives examples of how bypasses can impact affected communities. Construction of a bypass will not guarantee economic improvements in a community; rather, a bypass will provide an opportunity for economic growth. "Success" of a bypass depends on a number of factors, such as the presence of a nearby large city, the overall economy, and particularly the actions of affected stakeholders. Each stakeholder should contribute to the planning process in order to strike a balance between development along the bypass and maintenance of the economic vitality of the affected community's downtown. Land use controls should be implemented to ensure mobility along the bypass is not impeded. Local 
officials should promote the unique assets of the community and the community's strengths and distinctive characteristics. With all affected stakeholders, from the state level to the community level, working together, the benefits a bypass can provide can be maximized and the adverse impacts minimized.

\section{References}

Brail, R.K. (1987). "Microcomputers in Urban Planning and Management." Center for Urban Policy Research, New Brunswick, NJ.

Burress, D. (1996). "Impacts of Highway Bypasses on Kansas Towns.” As prepared for the Kansas Department of Transportation, October 1996, Report No. 226. Retrieved 9/4/06 from www.ipsr.ku.edu/resrep/bypass.htm.

Gillis, W.R, Ph.D. (1994). "Lessons from Eastern Washington: State Route Mainstreets, Bypass Routes, and Economic Development in Small Towns." EWITS Research Report No. 2, Washington State University, Pullman, WA.

Mills, J.B., and J.D. Fricker (2008). “Effects of Bypasses.” Draft Final Report, Joint Transportation Research Program, Purdue University, West Lafayette, IN.

Rephann, T., and A. Isserman (1994). "New Highways as Economic Development Tools: An Evaluation Using Quasi-Experimental Matching Methods." Regional Research Institute, West Virginia University.

Srinivasan, S., and K. Kockelman (2000). "The Impacts of Bypasses on Small- And MediumSized Communities: An Econometric Analysis." University of Texas at Austin. Journal of Transportation and Statistics, Vol. 5, No. 1.

Thompson, E., Miller, J., and J. Roenker (2001). "The Impact of a New Bypass Route on the Local Economy and Quality of Life." Center for Business and Economic Research, Kentucky Transportation Center, College of Engineering, University of Kentucky.

Wells, S., and T. Farnworth (2001). "Economic Impacts of Highway Bypasses on Small Communities - A Review." Wilbur Smith Associates, November 2001.

Yeh, D., Gannon, M., and D. Leong (1998). "The Economic Impacts of Highway Bypasses on Communities." Wisconsin Department of Transportation, Madison, WI. 